\title{
Machining of biocompatible materials - Recent advances
}

\author{
Dragos Axinte1,2, ${ }^{1,}$ Yuebin Guo ${ }^{3}$, Zhirong Liao' ${ }^{1}$, Albert J. Shih", Rachid M'Saoubi5, Naohiko Sugita 6
}

${ }^{1}$ Machining and Condition Monitoring Group, Faculty of Engineering, University of Nottingham, UK

${ }^{2}$ Faculty of Engineering, University of Nottingham, Ningbo, China

${ }^{3}$ Department of Mechanical and Aerospace Engineering, Rutgers University, Piscataway, NJ 08854, USA

${ }^{4}$ Department of Mechanical Engineering, University of Michigan, Ann Arbor, MI 48105, USA

${ }^{5} R \& D$ Materials and Technology Development, Seco Tools AB, Fagersta SE-73782, Sweden

${ }^{6}$ Department of Mechanical Engineering, The University of Tokyo, Tokyo, Japan

Machining of biocompatible materials is facing the fundamental challenges due to the specific material properties as well as the application requirements. Firstly, this paper presents a review of various materials which the medical industry needs to machine, then comments on the advances in the understanding of their specific cutting mechanisms. Finally it reviews the machining processes that the industry employs for different applications. This highlights the specific functional requirements that need to be considered when machining biocompatible materials and the associated machines and tooling. An analysis of the scientific and engineering challenges and opportunities related to this topic are presented.

Cutting, biomedical, biocompatible materials

\section{Introduction}

For centuries surgery was mainly limited to direct interventions to the human body with no extras, i.e. implants, involved in this process. Nevertheless, with deeper understanding of the human anatomy and the development of materials that can be compatible with human body, advancements in the designing and testing of implants and surgical devices have been rapidly made. Starting only about 100 years ago [141], the industries related to the making of implants, tooling and instrumentation for surgery have seen high-growth rates (i.e. around $7-12 \%$ per annum [150]). Of course, with such a demand from industry and, especially, with the pressure from healthcare organisations for fast and reliable surgical interventions this cascades down to the need of development, adaptation and use of appropriate enabling manufacturing technologies among which the cutting of biocompatible material is of key importance.

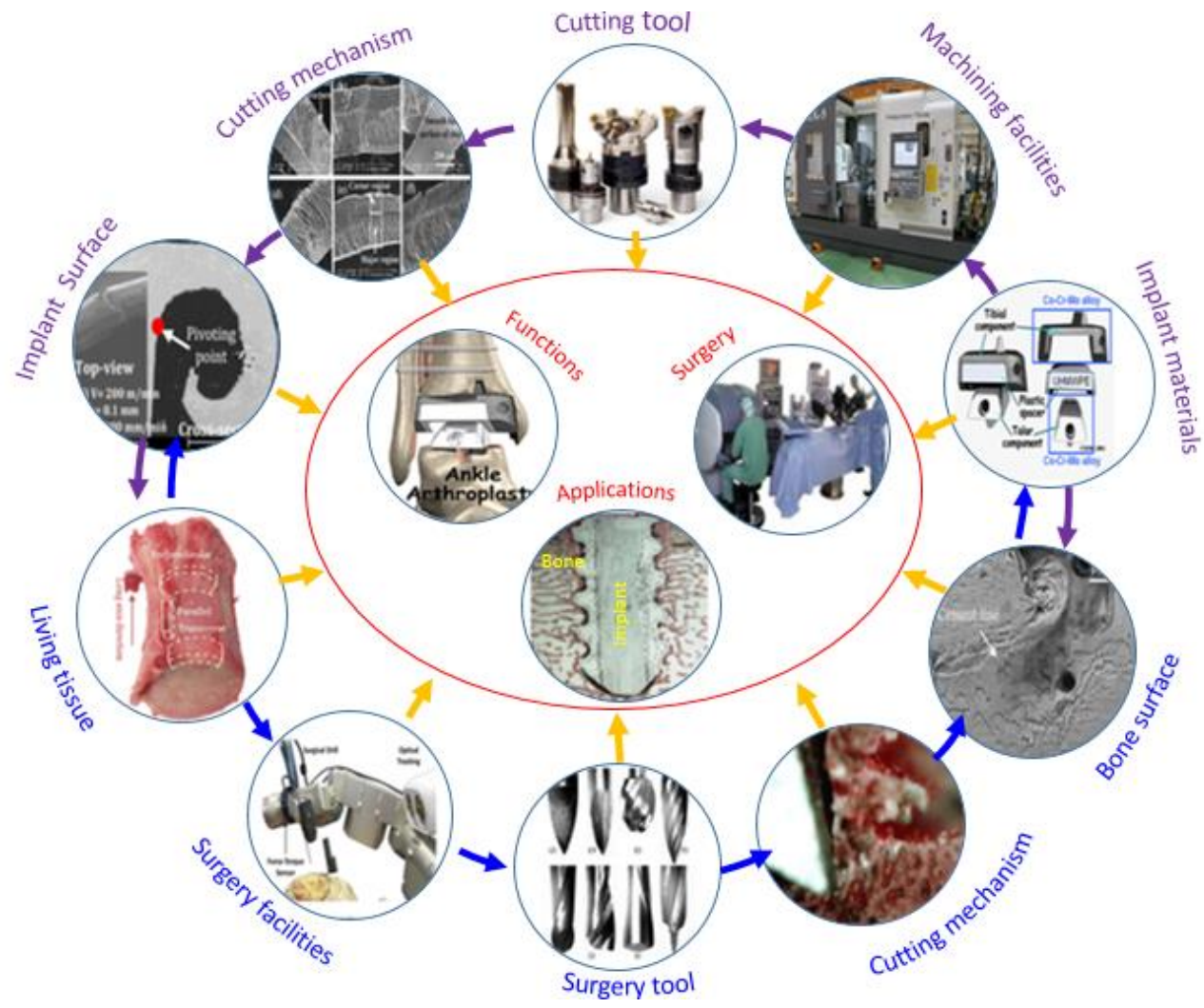

Fig. 1 An overview cutting procedures for both implants and surgery processes (example for an ankle arthroplasty surgery)

Biocompatible materials, here, mostly refer to those materials that interact with human tissues or organs in a manner that enable their total or partial functionality which relate to their surface, and structural compatibility. The surface compatibility of the machined surfaces mainly refers to their degree of adaption to the host tissues, in respect to biological, chemical and surface characteristics, while the structural compatibility refers to the mechanical behaviour acceptance, such as stiffness, elastic modulus and strength, which would affect the genuine integration between implant and tissue interface [150]. Thus, there is a wide use of biocompatible materials for implants which need to be machined with high geometrical and surface quality standards.

Cutting is the most common process for both manufacturing of the medical implants and performing surgical interventions. It is precise and provides high material removal rates [165]. Nevertheless, cutting operations in this set of applications can encounter very diverse materials when considering the target applications which could be both implants and human tissues; this is not to mention the very different requirements on the quality of the surface generated by cutting that are highly dependent on 
applications. Here, manufacturing implants by cutting refers to metallic biomaterials (e.g. stainless steels, $\mathrm{Ti} / \mathrm{Mg}, \mathrm{Ni} / \mathrm{Ti}$ alloys), inorganic and non-metallic biomaterials (e.g. ceramics) as well as organic materials (e.g. polymer and polymer composites) while, cutting for surgical operations refers to both soft and hard tissues. The cutting of soft tissues refers to skin, fat, muscle, and soft organs and it is commonly performed using scalpel blades and scissors. The cutting of hard tissues refers to bone structures (of different densities) for which a variety of, somehow, conventional tools (e.g. drills, taps, saws, milling cutters) are used. Thus, to support a wide variety of surgical procedures and individualised patient needs, a large number cutting tools of different shapes, sizes, and cutting edge geometries are required for fulfilling the specific implants' functionalities and medical procedures. Fig. 1 shows an example for medical implant with an overview of the cutting processes of both living tissues and engineered biocompatible materials that contribute to the implant manufacture and surgical procedures.

\section{Biomaterials}

\subsection{Metallic biomaterials}

\subsubsection{Stainless steels}

Stainless steels have been widely used as biomaterials because of their low cost, good mechanical and corrosion resistant properties, and adequate biocompatibility (Fig. 2).

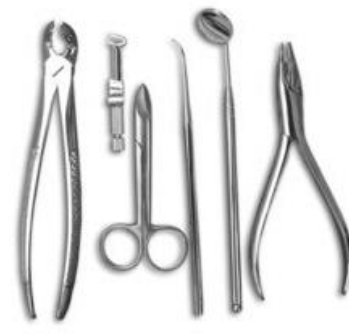

(a)

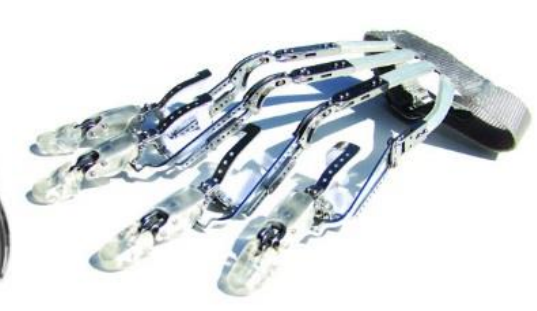

(b)
Fig. 2. Biomedical applications of stainless steel [188] (a) surgical instruments, and (b) finger prostheses [181].

Stainless steels can be classified into austenitic, martensitic, ferritic, duplex and precipitation-hardening martensitic [9, 213]. Austenitic stainless steels, especially AISI 316L, are most widely used for biomedical applications, since they are nonferromagnetic, which is essential for biomedical applications where the high (17-20\%) Cr content contributes to its high passivation ability. 316L stainless steel possesses acceptable biocompatibility and suitable density for load-bearing purposes thus making this a desirable surgical-implant material. However, the adverse effects of $\mathrm{Ni}$ ions being released into the human body have promoted the development of "nickel-free nitrogen containing austenitic stainless steels". By combining the benefits of stable austenitic structure, high strength, better corrosion and wear resistance and superior biocompatibility in comparison to the currently used austenitic stainless steels, these newly developed nickel-free high nitrogen austenitic stainless steels are becoming more popular [181].

\subsubsection{Titanium based alloys}

Titanium alloys exhibit an excellent combination of properties, including higher strength, lower modulus of elasticity and excellent biocompatibility compared with stainless steels [101, 214]. Thus, Ti alloys are widely used as dental implants, orthopaedic prostheses and fixtures (Fig. 3). Titanium alloys can be categorized into $\alpha$-type, $(\alpha+\beta)$-, and $\beta$-type Ti alloys according to their primary constitutional phase(s) [113]. The $\alpha$-type Ti alloys are composed of the single $\alpha$-phase (hexagonal closed-packed (HCP) structure), while the $\beta$-type group is composed of singlephase $\beta$-microstructures (body-centered (BCC) structure). The $(\alpha+\beta)$-type Ti alloys are composed of two-phase $\alpha+\beta$ microstructures.



(a)

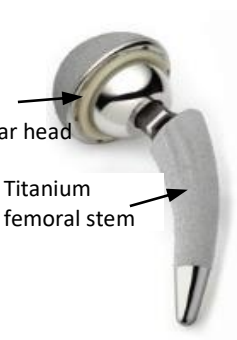

(b)

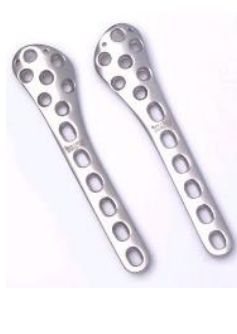

(c)
Fig. 3. Applications of titanium implants (a) dental implant [8], (b) hip implant [110], and (c) orthopaedic fixture plate [198].

The Ti6Al4V alloy is the most commonly employed $\alpha+\beta$ titanium biomedical alloy and is normally used in annealed condition. The metastable biomedical alloys are preferred in solution treated (ST) as well as aged conditions. The $\alpha+\beta$ treated structures have higher strength, higher ductility, and higher low cycle fatigue while the $\beta$ treated structures have higher fracture toughness. In general, the strength of an alloy increases with increasing $\beta$ stabiliser content. Ti6Al4V extra low interstitials (ELI) grade alloy contains small amounts of interstitial impurities, oxygen $(0)$, carbon $(C)$, nitrogen $(\mathrm{N})$ and hydrogen $(\mathrm{H})$; this alloy shows great toughness because the impurities decrease the fatigue strength and, consequently, is used for bone fixation plates and the stems of artificial hip joints.

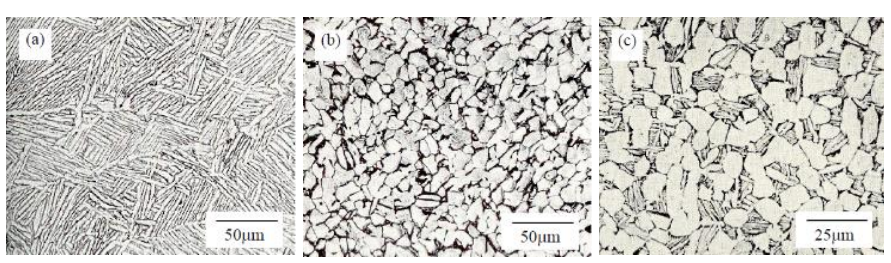

Fig. 4. Different microstructures that can be produced in Ti6Al4V; (a) lamellar, (b) equiaxed and (c) bimodal [21].

\subsubsection{Magnesium alloys}

Magnesium alloys are biodegradable and the dissolved $\mathrm{Mg}^{2+}$ would be easily absorbed or consumed by the human body, which is useful for the healing process of the human body after surgical interventions. Comparing to permanent implants, the applications of biodegradable implants avoid the second surgery and reduce patient pain. The Young's modulus of Mg alloys is similar to human bones which is helpful to minimize "stress shielding" [201]. Magnesium alloys have also been considered as cardiovascular stents, orthopaedic implants such as screws, plates, or other fixture devices, etc (Fig. 5) [33]. 


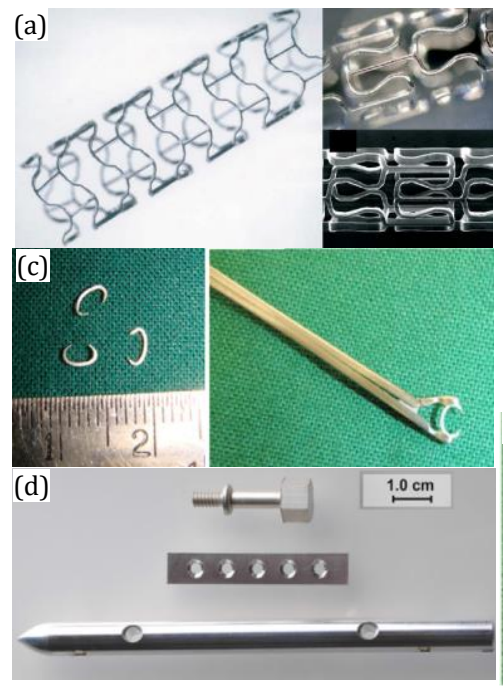

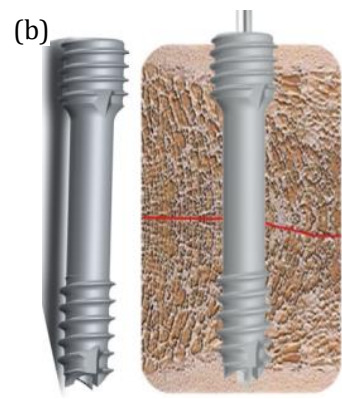

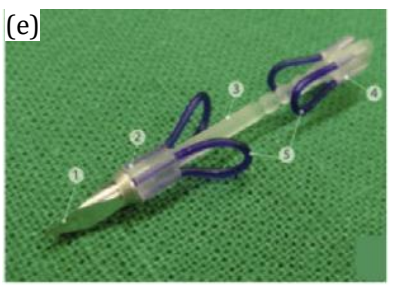

Fig. 5. Real/possible applications of biodegradable magnesium implants: (a) cardiovascular stents [53], (b) MAGNEZIX screw [200], (c) microclip for laryngeal microsurgery [37], (d) biodegradable orthopaedic implants [191] and (e) wound-closing devices [71].

Alloying is one of the possible solutions to reduce the corrosion rate of $\mathrm{Mg}$ in the human body. Elements like $\mathrm{Mn}, \mathrm{Cu}, \mathrm{Al}, \mathrm{Ca}, \mathrm{Zr}, \mathrm{Gd}$ and $\mathrm{Zn}$ have all been explored. A concern with alloying approach is biocompatibility of the alloying elements. The binary alloy system of Mg-Ca has attracted a considerable attention in recent years to be used as implant material [153]. On the Mg-rich side of this system, the maximum solubility of calcium in the magnesium lattice at room temperature amounts to $0.8 \mathrm{wt} \%$. Low alloyed $\mathrm{Mg}$ Ca systems consist of an $\alpha$-phase solid solution (magnesium with interstitial calcium) and a eutectic structure ( $\alpha$ phase $\left.+\mathrm{Mg}_{2} \mathrm{Ca}\right)$. The addition of a small amount of $\mathrm{Ca}$ increases the corrosion resistance and minimizes the grain growth and leads to smaller grains in casts [148] (Fig. 6).
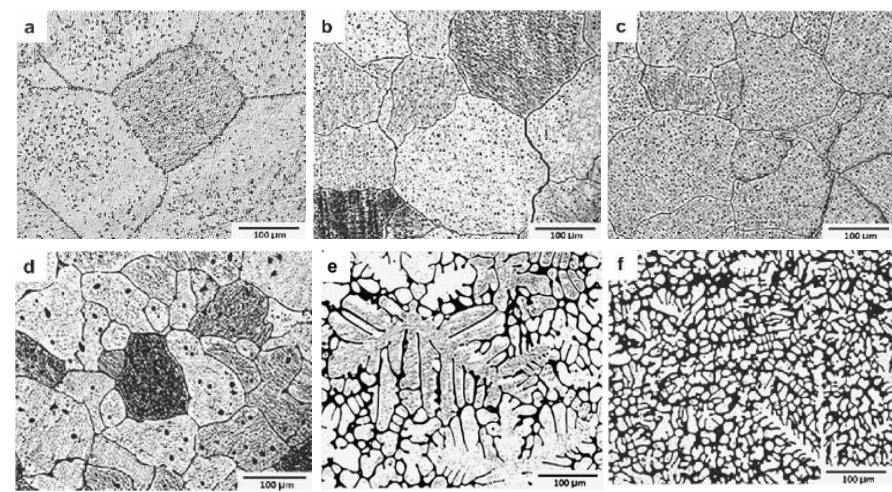

Fig. 6. Optical micrographs of (a) pure Mg, (b) Mg-Ca0.5, (c) Mg-Ca1.25, (d) Mg-Ca2.5, (e) Mg-Ca5.0 and (f) Mg-Ca10.0 [148].

\subsubsection{Cobalt based alloys}

Due to their excellent mechanical properties, high corrosion and wear resistance as well as low friction coefficient, $\mathrm{CoCr}$ alloys are widely used for artificial joint prosthesis as bearing surfaces. Their wear resistance is particularly excellent as compared other metallic biomaterials such as stainless steels and titanium alloys. For instance, Co-28Cr-6Mo alloys have been used for ball and cup of artificial hip joints including both metal-on-UHMWPE (Ultra High Molecular Weight Polyethylene) and metal-on-metal joints as well as in the sliding components of artificial knee joints (Fig. 7).

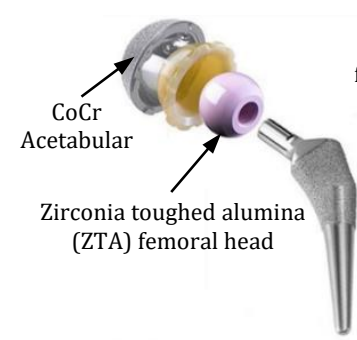

(a)

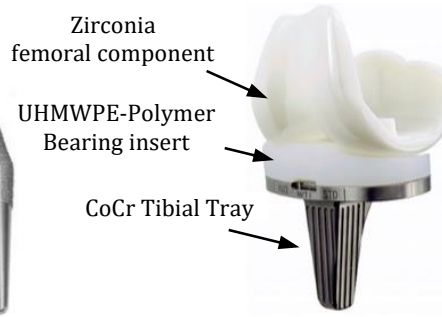

(b)
Fig. 7. Applications of different biomaterials in (a) hip and (b) knee implants $[27,184]$.

The microstructure $\mathrm{CoCr}$ has two phases, i.e., $\varepsilon$-type Co (HCP) and $\gamma$-type Co (FCC). The $\varepsilon$-phase has higher strength, due to the limited number of slip systems. The precipitates in CoCr alloys are classified into intermetallic compounds and carbonitrides. The phase and morphology of the precipitates are significantly affected by the carbon and nitrogen contents. Fig. 8 shows the microstructures of as-cast Co-28Cr-6Mo alloys with carbon contents of 0 to 0.41 mass $\%$ and nitrogen contents of 0 to 0.24 mass $\%$. A dendrite matrix and interdendritic and grain boundary precipitates were observed in the alloys, except in Fig. 8(e).

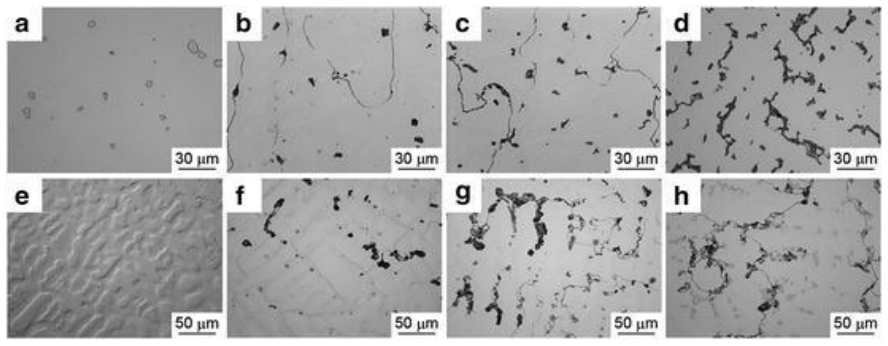

Fig. 8 Microstructures of as-cast Co-28Cr-6Mo alloys with various carbon and nitrogen contents: (a) $0 \mathrm{C}-0 \mathrm{~N}$, (b) $0.16 \mathrm{C}-0 \mathrm{~N}$, (c) $0.24 \mathrm{C}-0 \mathrm{~N}$, (d) $0.41 \mathrm{C}-0 \mathrm{~N}$ [32], (e) $0 \mathrm{C}-0.2 \mathrm{~N}$, (f) $0.16 \mathrm{C}-0.2 \mathrm{~N}$, (g) $0.27 \mathrm{C}-0.24 \mathrm{~N}$ and (h) $0.34 \mathrm{C}-0.21 \mathrm{~N} 186$ ].

\subsubsection{Shape-memory alloys}

Nitinol, a nearly equiatomic nickel-titanium shape memory alloy (SMA), has wide range of applications in cardiovascular stents, micro-actuators, and high damping devices (Fig. 9) [52]. Nitinol exhibits two unique mechanical behaviours: thermal shape memory and superelasticity. The phase transformation that occurs in Nitinol is dependent on the start and finish thermal transitions of the austenite and martensite crystalline phases. Fig. 10 shows the path that thermal shape memory takes place. Assuming nitinol initially is in austenitic state (0), with no applied stress, and is cooled along path $\mathrm{O} \rightarrow \mathrm{A}$ to below the martensite finish temperature $\left(M_{f}\right)$. A complete transformation from austenite to martensite (twinned) occurs. The material is deformed through reorientation and detwinning of martensite along path $\mathrm{A} \rightarrow \mathrm{B}$. Then, the load $\mathrm{B}$ releases on path $\mathrm{B} \rightarrow \mathrm{C}$ causing elastic unloading of the reoriented detwinned martensite and the material stays deformed. On heating above the austenite finish temperature $\left(A_{f}\right)$, the material transforms from martensite to austenite and recovers the pseudoplastic deformation "remembering" its former shape. The austenitic nitinol can be loaded along the path $\mathrm{O} \rightarrow \mathrm{E}$ above the austenite finish temperature $\left(A_{f}\right)$ through a stress-induced transformation to the martensitic state. A large elastic strain up to $11 \%$ can be achieved. Upon unloading along the path $\mathrm{E} \rightarrow 0$, the material will transform back to austenitic state and the superelastic deformation will be recovered, demonstrating a hysteresis loop in the stress-strain diagram. These properties are 
exploited in implants that change their shapes when activated by the change in temperature when embedded in the human body.

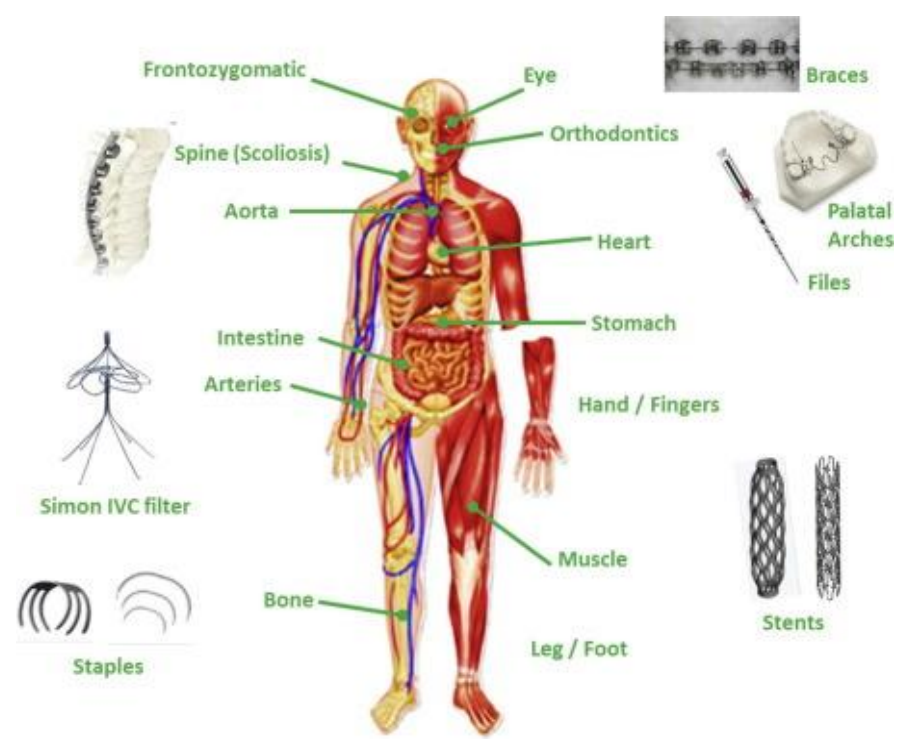

Fig. 9 SMA applications in the biomedical domain [131].

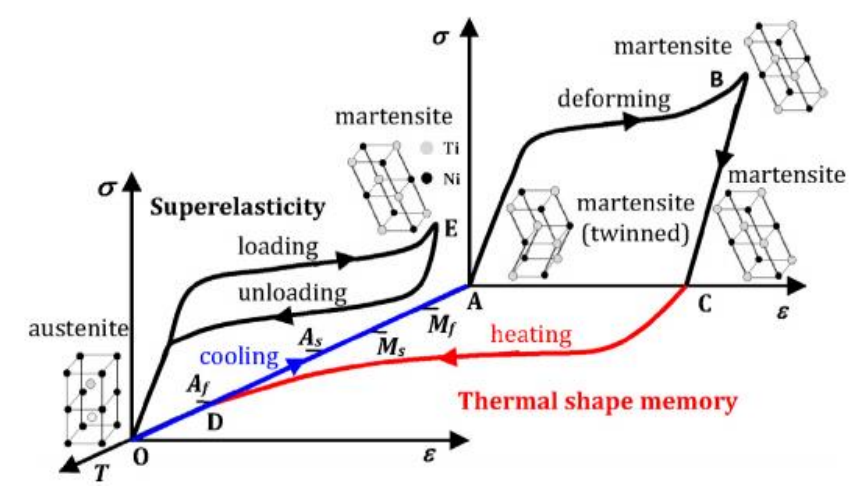

Fig.10 Stress-train-temperature diagram of Nitinol [67] to enable the understanding of their use in biomedical implants

\subsection{Inorganic and non-metallic biomaterials}

Comparing to metals like $\mathrm{Co}, \mathrm{Cr}$ and $\mathrm{Ni}$ which are usually employed as implants, ceramics like alumina and zirconia have several excellent properties: wettability, low friction, high wear resistance and biocompatibility, which make them suitable to use as implants such as hip and knee implants (Fig. 7).

\subsubsection{Alumina}

Alumina has been used since the 1970s as an implant material for artificial joint prostheses. The type used is a polycrystalline $\alpha-\mathrm{Al}_{2} \mathrm{O}_{3}$, often referred to simply as $\mathrm{Al}_{2} \mathrm{O}_{3}$. The crystallinity of $\alpha$ $\mathrm{Al}_{2} \mathrm{O}_{3}$ is rhombohedral which can be described as a compact hexagonal stacking of $\mathrm{O}^{2-}$ anions, while the two-thirds of the octahedral interstices are occupied by $\mathrm{Al}^{3+}$ cations. The strong ionic-covalent bonds and the rhombohedral structure combine to restrict dislocation movement, which makes plastic deformation impossible except at very high temperatures [149]. Implants usually employ polycrystalline structures, which consists of a crystalline phase (the $\alpha$-phase), made up of a large number of small grains, typically with a size less than a few micrometres.

\subsubsection{Zirconia}

Zirconia-based femoral heads were introduced in the 1980s in response to concerns about $\mathrm{Al}_{2} \mathrm{O}_{3}$ femoral head fractures in total hip arthroplasty (THA). Pure $\mathrm{ZrO}_{2}$ exists in three polymorphic (crystalline) forms: cubic $(c)$, tetragonal $(t)$ and monoclinic $(m)$ phases. Transformation of $\mathrm{ZrO}_{2}$ from one phase to the next is dependent on temperature, and is depicted by the following equilibrium: The $t$ to $m$ transformation is martensitic in nature. It occurs at $\sim 950{ }^{\circ} \mathrm{C}\left(M_{s}\right)$ on cooling and is accompanied by a shear strain of $\sim 16 \%$ and a volume expansion of $\sim 5 \%$. The transformation is reversible and occurs at $\sim 1165^{\circ} \mathrm{C}\left(A_{s}\right)$ on heating. In pure (unstabilised) $\mathrm{ZrO}_{2}$, the shape change and volumetric expansion associated with the $t$ to $m$ transformation invariably results in cracking and loss of structural integrity if the material is cycled through the transformation temperature, or if simply cooled from the fabrication temperature, typically $\sim 1400^{\circ} \mathrm{C}-1600^{\circ} \mathrm{C}$. As a result, destabilised $\mathrm{ZrO} 2$ is not used as an engineering material [35]. Oxides such as $\mathrm{MgO}, \mathrm{CaO}$ or $\mathrm{Y}_{2} \mathrm{O}_{3}$ can be added to $\mathrm{ZrO}_{2}$ to control the phase stability of $\mathrm{ZrO}_{2}$, and accordingly, several types of tough $\mathrm{ZrO}_{2}$-containing ceramics have been developed, referred to as partially stabilized $\mathrm{ZrO}_{2}$ (abbreviated PSZ) or tetragonal zirconia polycrystals (TZP).

\subsubsection{Zirconia toughened alumina (ZTA)}

ZTA is a composite consisting of fine $\mathrm{ZrO}_{2}$ particles dispersed in a dense, fine-grained $\mathrm{Al}_{2} \mathrm{O}_{3}$ matrix. Typically, the $\mathrm{ZrO}_{2}$ particles (often stabilised with small amounts of $\mathrm{Y}_{2} \mathrm{O}_{3}$ ) have sizes of 0.5-1.0 $\mu \mathrm{m}$ or smaller and make up $\sim 20 \mathrm{vol} \%$ of the solid. The $\mathrm{ZrO}_{2}$ particles can have an $m$-phase or $t$-phase structure (or a mixture of both), but the largest improvements in strength and fracture toughness have been observed when the particles have a $t$-phase structure. A critical factor is a $t-\mathrm{ZrO}_{2}$ particle. Based on the ZTA composition, but also including small amounts of additives such as $\mathrm{SrO}$ and $\mathrm{Cr}_{2} \mathrm{O}_{3}$, by the optimisation of sintering conditions, a composite (also called AMC) can be made with a flexural strength greater than $1200 \mathrm{MPa}$, a fracture toughness of $6.5 \mathrm{MPa} \cdot \mathrm{m}^{1 / 2}$ and a Vickers hardness number of 1975 HV.



Fig. 11. The microstructure of AMC by BIOLOX® delta [27].

\subsubsection{Mechanical properties}

An insightful understanding of mechanical behavior of ceramics is essential to the machining of ceramic implants. As an example, the mechanical properties that could affect the machinability of ceramics for $\mathrm{Al}_{2} \mathrm{O}_{3}$ and $\mathrm{ZrO}_{2}$ is presented in Table 1 .

Currently grinding is the most common process for shaping this group ceramic implants $[15,208]$. Although conventional cutting processes could be of interest on these applications, further research is needed to explore this is an avenue.

Table 1. Selected properties of $\mathrm{Al}_{2} \mathrm{O}_{3}$ and $\mathrm{ZrO}_{2}$-based ceramics [149].

\begin{tabular}{lllll}
\hline Property & $\mathrm{Al}_{2} \mathrm{O}_{3}$ & MgO-PSZ & Y-TZP & ZTA \\
\hline
\end{tabular}




\begin{tabular}{|c|c|c|c|c|}
\hline Young's modulus (GPa) & $400-450$ & $200-250$ & $\begin{array}{l}200- \\
250\end{array}$ & $\begin{array}{l}300- \\
350\end{array}$ \\
\hline Tensile strength (MPa) & $250-300$ & $300-400$ & -- & -- \\
\hline $\begin{array}{l}\text { Compressive } \\
\text { strength (MPa) }\end{array}$ & $\begin{array}{l}2000- \\
3000\end{array}$ & $\begin{array}{l}2000- \\
3000\end{array}$ & $\begin{array}{l}3000- \\
4000\end{array}$ & -- \\
\hline Flexural strength & $300-500$ & $600-700$ & $\begin{array}{l}1000- \\
1500\end{array}$ & $\begin{array}{l}700- \\
1000\end{array}$ \\
\hline $\begin{array}{l}\text { Fracture toughness } \\
\left(\mathrm{MPa} \cdot \mathrm{m}^{1 / 2}\right)\end{array}$ & $4-5$ & $6-10$ & $6-12$ & $6-10$ \\
\hline Hardness (GPa) & $14-16$ & $10-12$ & $12-14$ & $12-15$ \\
\hline
\end{tabular}

\subsection{Organic materials}

\subsubsection{Soft and hard tissues}

Cutting of soft and hard tissues is done widely in healthcare and has critical implications for the quality of surgical interventions. The hard or calcified tissue includes bone and tooth enamel, dentin and cementum. The soft tissue includes muscles, fascia, nerves, blood vessels, tendons, ligaments, skin, fat, synovium and various organ tissues.

Bone, a living "workpiece" structure to be cut during the orthopaedic surgery, is composed of two main tissues with different mechanical properties: the cortical bone in outer layer and the cancellous bone filling the inner region of cortical layer [156, 175] (Fig. 12 a). Cortical bone with higher density, sustaining elevated mechanical loads, represents the majority of the materials to be cut in any surgery operations. Similar to fibre reinforced composites, this anisotropic part mainly consists of osteons (fibre) and interstitial lamellae (matrix) [106]. Between the interstitial lamellae matrixes and osteons there is a thin layer (1-5 $\mu \mathrm{m}$ ) called cement line which is a weak zone (interface) that is prone to crack initiation and propagation around the osteons [63].



(a)

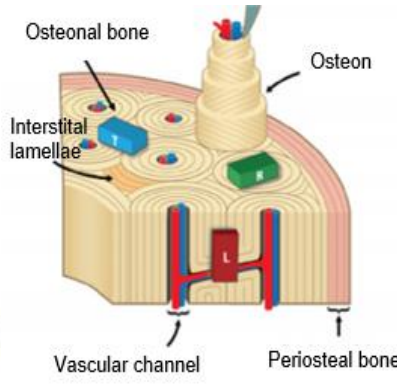

(b)



(c)
Fig. 12. Bone structure: (a) bone main components [175], (b) cortical bone [135] and (c) cancellous bone [189]

As shown in Table 2, the particular structure of the bone results in anisotropic properties which would yield different cutting mechanism when compared to isotropic materials. In recent years, research interest has been paid on bone cutting related to the surgery application, especially on the hard part of cortical layer, as shown in Fig. 12 [161].

Table 2 Mechanical property of cortical bone

\begin{tabular}{lcc}
\hline Cortical bone property & $\begin{array}{c}\text { Longitudinal } \\
\text { direction }\end{array}$ & $\begin{array}{c}\text { Transverse } \\
\text { direction }\end{array}$ \\
\hline Mode I fracture toughness $\mathrm{G}_{\mathrm{c}}(\mathrm{N} / \mathrm{m})[56]$ & $644 \pm 102$ & $1374 \pm 183$ \\
Mode II fracture toughness $\mathrm{G}_{\mathrm{c}}(\mathrm{N} / \mathrm{m})[56]$ & $2430 \pm 836$ & $4710 \pm 1284$ \\
Young's modulus $\mathrm{E}(\mathrm{GPa})[156]$ & 17.90 & 10.1 \\
Poisson's ratio $v[156]$ & 0.4 & 0.4 \\
Tensile stress $(\mathrm{MPa})[156]$ & 135 & 53 \\
\hline
\end{tabular}

\subsubsection{Polymers and polymer-composites}

Polymers and fibre reinforced polymer composites are widely used as biomaterials as they can be customised for biocompatiblity and mechanical performance. Compared with metallic materials, the polymers-based implants display superior corrosion and fatigue properties while offering the advantage of not releasing metal ions into the body.

\subsubsection{Polymers}

A variety of polymers, e.g. polyethylene (PE), polyethylene terephthalate (PET), polymethylmethacrylate (PMMA), polytetrafluoroethylene (PTFE) and polyetheretherketone (PEEK), for bioengineering applications have been developed with their mechanical properties similar to bone material (Table 3). These materials are mainly used for applications where high surface finish and dimensional accuracy is required (e.g. total knee joint replacement-Fig. 7). Uniquely, when cutting processes are applied to polymers, the workpiece surface quality is dependent on the specific material properties such as the glass transition temperature $(\mathrm{Tg})$, the melt temperature $(\mathrm{Tm})$, the molecular weight (MW), the viscosity, and the relaxation rate [27]. Thus, the polymers present special characteristics when machining when compared with metals $[5,151]$ :

- Exhibit viscoelastic behaviour, which means strain response to an applied load has both instantaneous, or elastic, and transient, or viscous components.

- Below $\mathrm{T}_{\mathrm{g}}$, the polymer changes its behaviour from a soft and rubbery to a hard and glassy state, and its stiffness increases remarkably.

- Rupture and extreme fracture process always occurs in chip formation.

- Low thermal conductivity leads to a rapid heat built-up and increased temperature in the workpiece material.

Table 3. Mechanical properties of typical polymeric biomaterials [19]

\begin{tabular}{lcc}
\hline \multicolumn{1}{c}{ Material } & $\begin{array}{c}\text { Modulus } \\
(\mathrm{GPa})\end{array}$ & $\begin{array}{c}\text { Tensile strength } \\
(\mathrm{MPa})\end{array}$ \\
\hline $\begin{array}{l}\text { Polyethylene (PE) } \\
\text { Polyethylene terephthalate (PET) }\end{array}$ & 0.88 & 35 \\
Polymethylmethacrylate (PMMA) & 2.55 & 61 \\
polytetrafluoroethylene (PTFE) & 0.5 & 59 \\
Polyetheretherkctone (PEEK) & 8.3 & 27.5 \\
\hline
\end{tabular}

\subsubsection{Fibre reinforced composites}

For hard tissue (e.g. cortical bone) repairs, metals and ceramic are widely applied while, however, these could result in "stressshielding" [150] due to the mismatch of stiffness between hard tissue and metallic/ceramic implants (see Table 1 and 2). This mismatch can affect bone remodelling and the healing process which would lead to bone atrophy. The fibre reinforced polymer 
(FRP) composites offer low modulus and high strength while allowing the possibility to control the reinforcement phase and the volume fraction for implant properties customisation to match those of the host tissue for improving structural biocompatibility [61, 199]. The FRP composites consist of fibres (e.g. silica, glass, hydroxyapatite, and carbon), that provide the high strength, and matrix (polymer, e.g. PEEK, PE), that mainly enable the biocompatibility of polymers matrix [205, 210]. Fig. 13 and 14 show various applications of different polymer composite and a glass fibre-reinforced composite application as a threaded implant $[13,150]$.

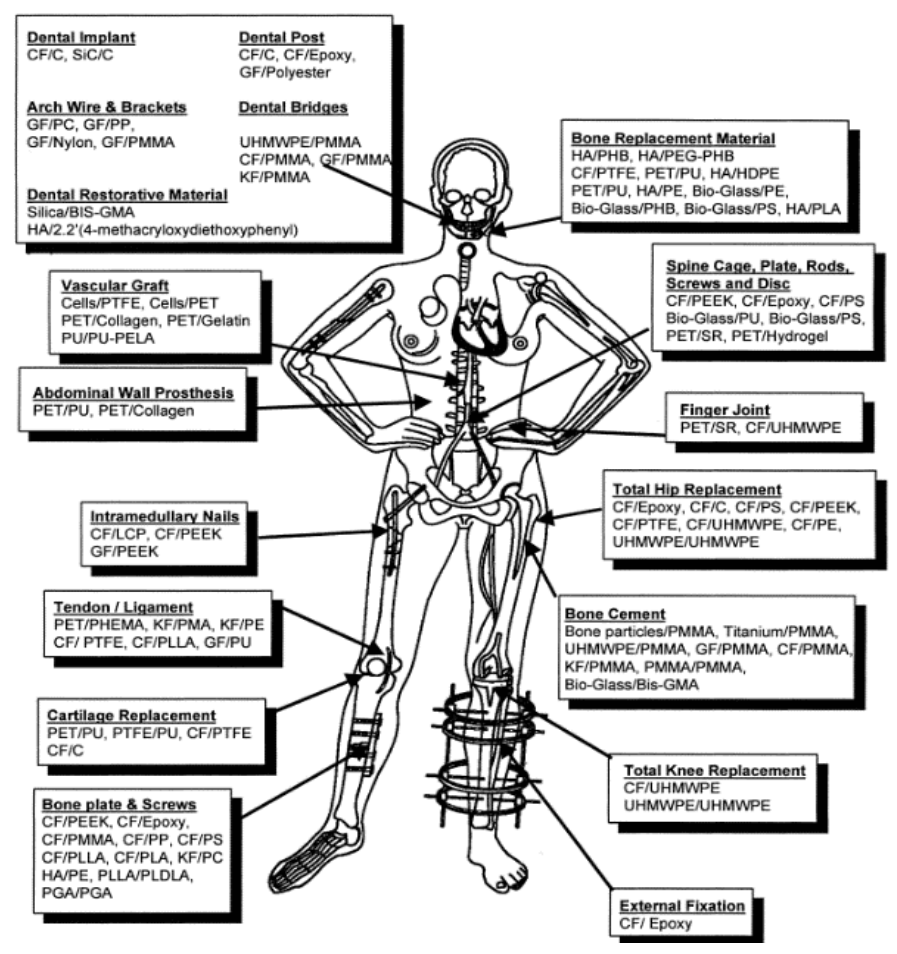

Fig.13 Various application of different polymer composite [150]
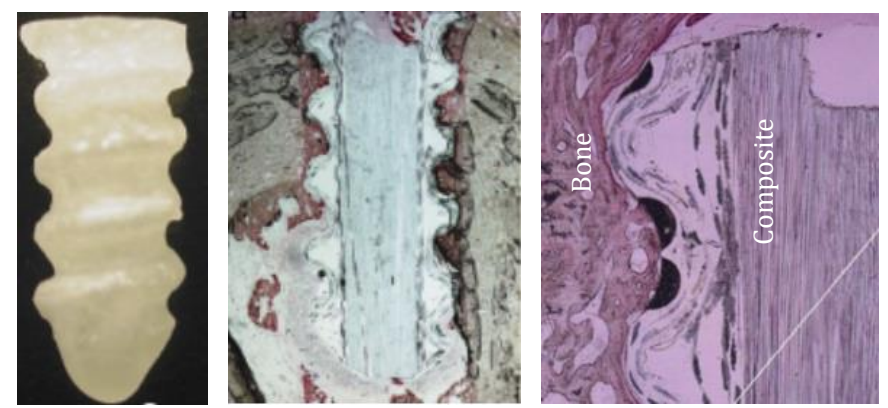

Fig.14 Glass fibre-reinforced composite in implant application [13]

\section{Cutting mechanisms specific to biocompatible materials}

\subsection{Cutting of metallic biomaterials}

\subsubsection{Stainless steels}

The austenitic stainless steels have high work hardening tendency even at low deformation rates making them difficult to machine. Furthermore, their high toughness and ductility lead to formation of long continuous chips and intense adhesion of the workpiece material to the cutting tool which results in significant adhesive wear. High temperatures at the tool-chip interface result in an increase of diffusion and chemical wear. In addition, the builtup edge formation and tearing off during cutting can also lead to machining instability, which would result in cutting edge chipping [137].

Material removal mechanisms: The examination of coated cutting tools using a scanning electron microscope (SEM) in the backscattered electron imaging mode (BSE) showed that three distinct regions could be identified on the rake surface in Fig. 15: (a) close to tool tip where a zone with little adhesion where only small asperities of work material are present; (b) mid-contact length: region of tool-chip interfacial sliding and (c) second half of toolchip contact: a thick adhering layer of work material appearing in white [118]. The investigation into the tool/chip/workpiece contact showed that the friction coefficient is very sensitive to the sliding velocity [20] when machining austenitic stainless steels.

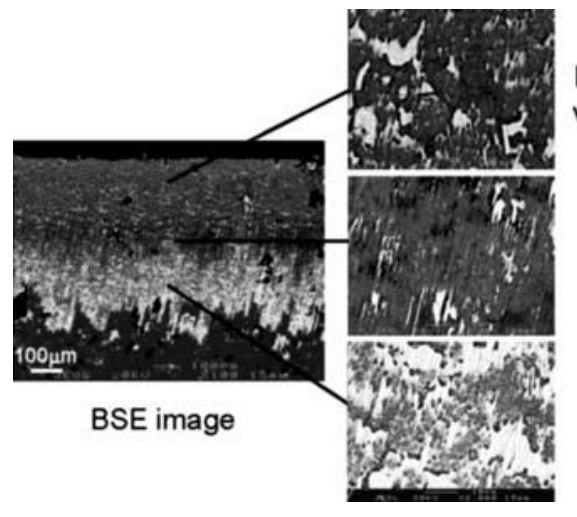

(a)

Intimate contact with little material transfer

(b)

Interfacial sliding

Material deposit and sticking

Fig. 15. Micrograph observations of tool rake surface in turning of $316 \mathrm{~L}$ (vc $=160 \mathrm{~m} / \mathrm{min}, \mathrm{L}=330 \mathrm{~m}$ ) [118].

Finite element analysis (FEA) was used to simulate the material removal and surface formation in cutting austenitic stainless steel 316L $[134,138]$. This enabled the study of the effect of cutting parameters and cutting tool geometry on cutting forces, chip morphology, temperature distributions and residual stresses versus experimental results [187].

Surface integrity: The significant heat generation during cutting stainless steels leads to high temperatures in the tool/workpiece contact zone and high tensile residual stress is introduced (Fig. 16) [119]; this could be detrimental when machining medical implants where long service life is expected.



Fig. 16 Residual stresses profiles in dry turning 316L stainless steel [119].

\subsubsection{Titanium-based alloys}

Widely employed in the aerospace industry, Ti-based alloys (e.g. Ti6Al4V) find extensive use in biomedical applications (e.g. orthopaedic implants - Fig. 17). Since the workpiece material and machining techniques overlap for these group of applications, similarities in research methods and goals exist [190, 117]; hence, 
references to material removal mechanisms and workpiece surface integrity are briefly discussed.

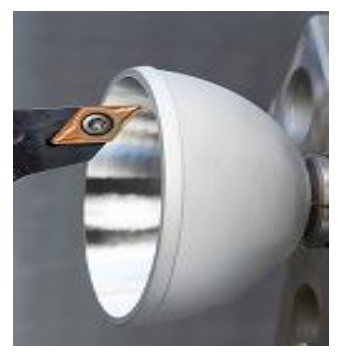

(a)

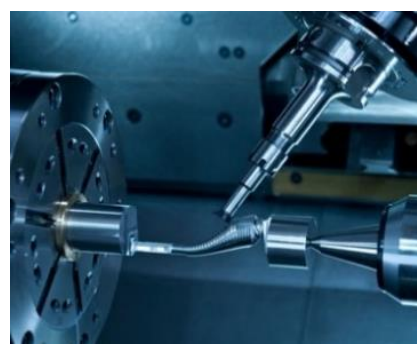

(b)
Fig. 17 Examples of machining of titanium hip implants: (a) turning of acetabular head and (b) milling of femur component.

Material removal mechanisms: As a representative example, chip formation in Ti6Al4V cutting is strongly influenced by adiabatic shearing which results in serrated chip morphology (Fig. 18) [42, 73]. When cutting Ti6Al4V at low cutting speed, the chip obtained is discontinuous, while with the increase of cutting speed the chip serration effect becomes greater [79] (Fig 19); not surprising, the chip segmentation frequency could be captured in the dynamic component of the cutting force (Fig. 20) [179].

Surface integrity: The surface roughness of Ti alloys orthopaedic implants influences the bone response significantly. Smooth surfaces $\left(S_{a}<1 \mu \mathrm{m}\right)$ have less strong bone responses than rougher surfaces [179]. However, there is little study in the cutting literature to investigate how to achieve the favourable surface roughness for better bone osteosis. The corrosion resistance of $\mathrm{Ti}$ implants is influenced significantly by the surface oxidation layer. Surface spectroscopic analysis of machined Ti implants show that the surface oxide generated during machining consists mainly of $\mathrm{TiO}_{2}$ and small amounts of other oxidation states such as $\mathrm{Ti}_{2} \mathrm{O}_{3}$ and TiO with a typical thickness of 3-6 nm [114].

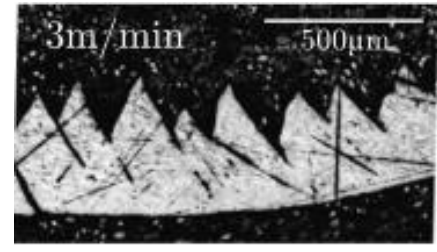

(a)

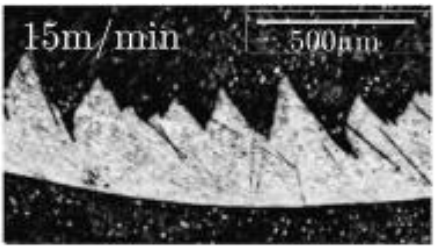

(b)
Fig. 18 Micrograph photos of cross-sections of chips [73].

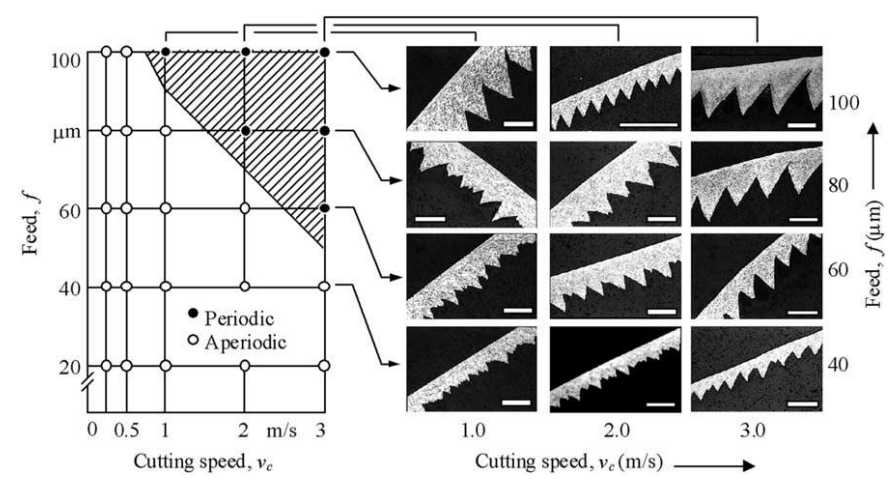

(a)

(b)

Fig. 19 Chip morphology as a function of cutting speed and feed in the orthogonal cutting of Ti6Al4V. All scale bars in (b) are $100 \mu \mathrm{m}$ [14].
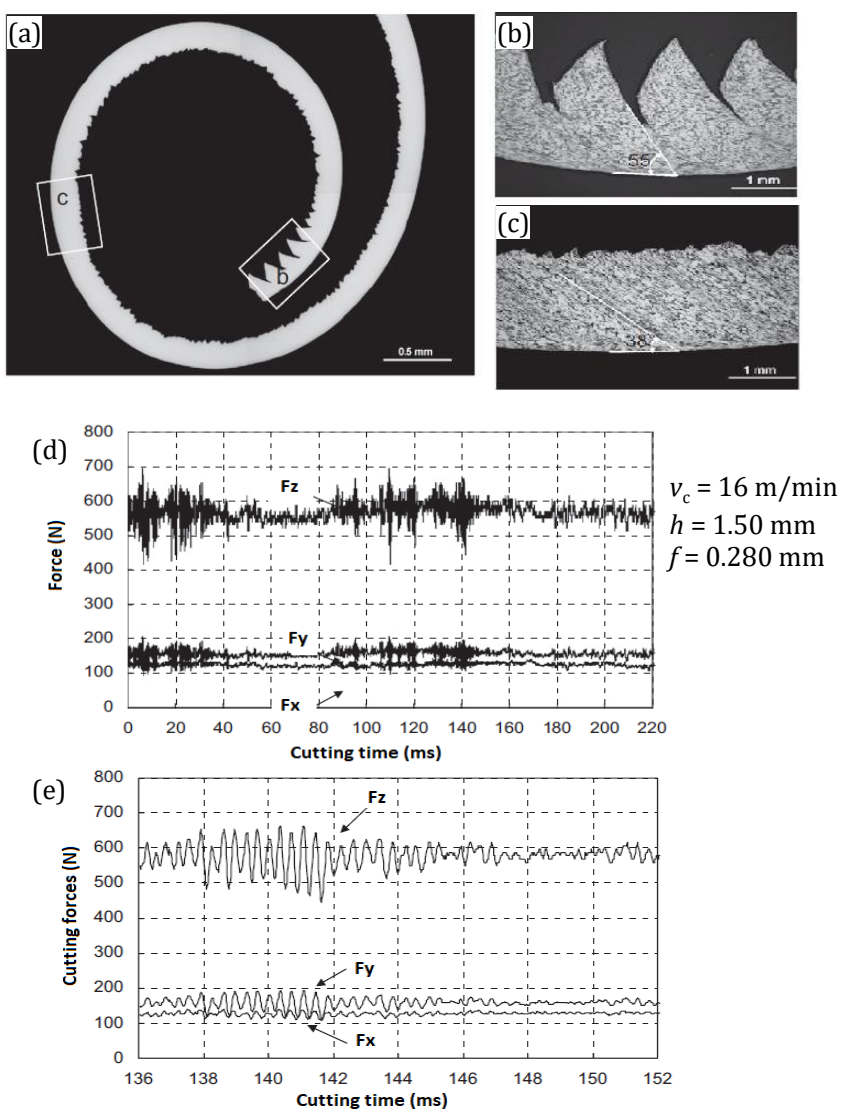

Fig. 20 Segmented chips induce variation in cutting forces with time: (a) chip cross-section with (b) mixed segment and (c) continuous shape; (d) variation in cutting force, (e) showing more details [179].

Another key aspect is residual stresses distribution as it has (d) nsiderable influence on fatigue and corrosion resistance of the implant. The nature (compressive/tensile) and magnitudes of residual stress profiles are determined by the highly nonlinear coupling of mechanical and thermal loading occurring during machining [109]. Compressive residual stresses in the cutting and feed directions were observed. With abundant cutting fluid supply (to reduce the thermal effect), worn tools tend to produce more (e) mpressive residual stress due to the due to a reduction in the tool's clearance angle and subsequent increase in the toolworkpiece contact area (Fig. 21) [81]. Not surprising, under dry cutting conditions, the residual stress is more tensile with increasing tool wear due to the increased thermal loads [33]. The $\beta$ phase seems to experience more deformation and volume shrinkage in the near surface with the increased cutting speed; however, phase transformation was not observed.



Fig. 21 Residual stress profile for turning Ti-6Al-4V at $120 \mathrm{~m} / \mathrm{min}, 0.25$ $\mathrm{mm} / \mathrm{rev}, 0.25 \mathrm{~mm}$ depth of cut (DOC) with cutting fluid supply [81]. 
The microhardness at the machined surface can significantly (e.g. 70-90\%) increase when compared with that of the bulk material $[54,77]$. This aspect is of high relevance when considering the contact conditions between the different components of the implants as well as with the host organs (Fig. 22) [178].

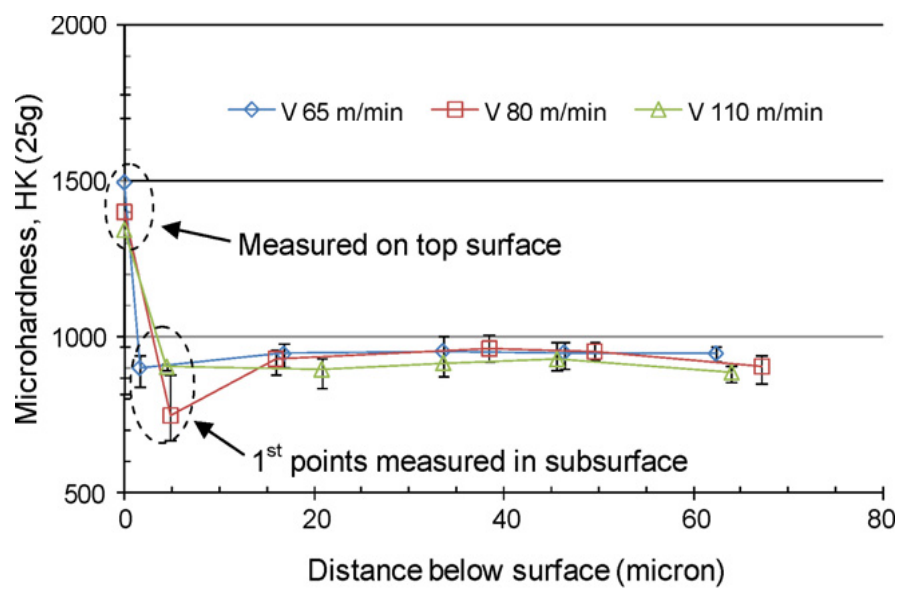

Fig. 22 Microhardness distribution under an end milled Ti-6Al-4V workpiece surface $\left(f=0.08 \mathrm{~mm} /\right.$ tooth, $a_{e}=4 \mathrm{~mm}, a_{p}=1.5 \mathrm{~mm}$ ) [178].

\subsubsection{Magnesium alloys}

Material removal mechanisms: Dry machining of magnesium alloys is preferred to avoid the pollution from the cutting fluid. Although Mg is highly flammable, chip ignition and sparks did not happen in high speed dry cutting of MgCa alloy [152], a common implant material. Examples of common lamellar chip structures are presented in Fig. 23 for MgCa where it can be observed that the lamellae in the major section (e.g. top region - Fig. 23e) incline due to the shearing by the side cutting edge, while the lamellae in the corner section (e.g. bottom region - Fig. 23e) are vertical due to the influence of corner radius of the cutting edge [68].
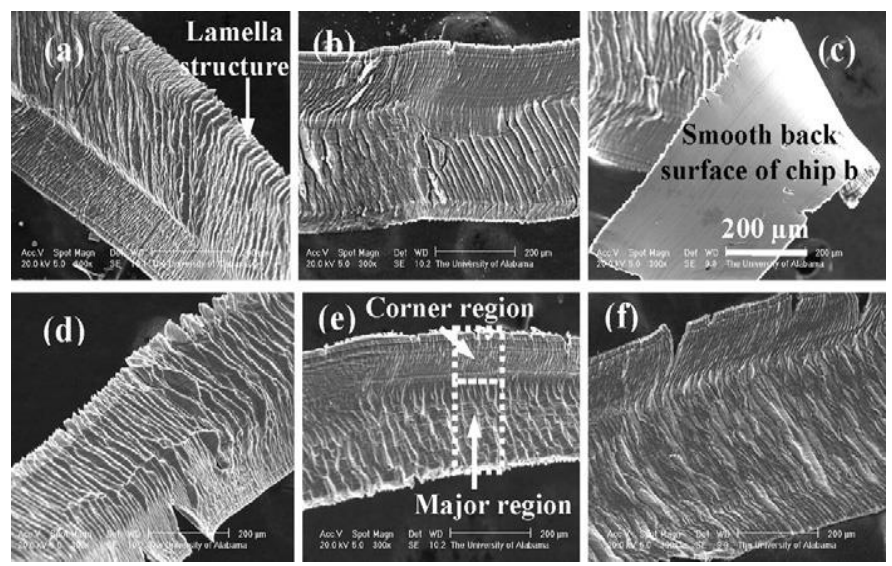

Fig. 23 Examples of lamellar structures of chips when dry milling of MgCa0.8: (a) $1200 \mathrm{~m} / \mathrm{min}$, (b) $1600 \mathrm{~m} / \mathrm{min}$, (c) $1600 \mathrm{~m} / \mathrm{min}$, (d) 2000 $\mathrm{m} / \mathrm{min}$, (e) $2400 \mathrm{~m} / \mathrm{min}$ and (f): $2800 \mathrm{~m} / \mathrm{min}$ [68].

Surface integrity: The residual stress distribution shows a minor influence on the subsurface with little penetration depth (< $200 \mu \mathrm{m})$ [47]. The highest compressive residual stress ( $\sim 30 \mathrm{MPa})$ is found in the machined MgCa3.0 subsurface in a depth of $160 \mu \mathrm{m}$ [47]. The microhardness profiles in Fig. 24 clearly show that surface materials experience strain hardening [68], a situation that is likely to influence the working behaviour of the implant once embedded in the human body.

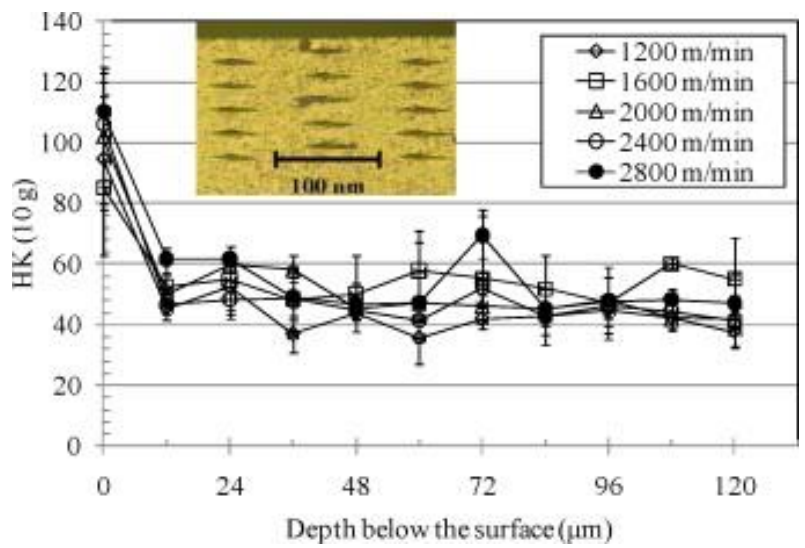

Fig. 24 Microhardness profiles under dry milled surface of Mg-Ca0.8 alloy [68].

\subsubsection{Cobalt-based alloys}

The surface roughness of biological load bearing surfaces, e.g. hip and knee implants, can significantly affect the wear and friction phenomena. It is recommended by ISO that the surface roughness for the load bearing surfaces should be below $20 \mathrm{~nm}$. Furthermore, controlled dimensional/geometrical accuracies could enable suitable amount of lubrication to fill the surface gaps and reduce wear debris medical implant applications. However, this is not achieved by only one process: Fig. 25 shows an example of millinggrinding-polishing a knee implant. To achieve a fine surface roughness needed for such applications, after cutting (e.g. milling, drilling) operations, specialised finishing processes need to be employed such as automated bonnet polishing [34, 211], simultaneous 5-axis polishing with resilient tools [46, 185], drag finishing, magnetic abrasive finishing (MAF) [207], or magnetorheological fluid polishing [168].

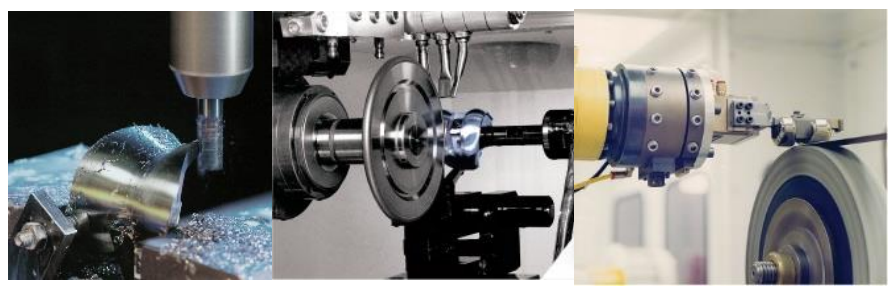

Fig. 25 Milling-grinding-polishing process chain of Co-Cr-Mo knee implants

\subsubsection{Shape-memory alloys}

Material removal mechanisms: Due to the shape memory and superelasticity effects, high ductility, and strong work hardening, short tool life, poor chip breaking, and burr formation are critical issues when cutting this group of alloys [194-196]. Furthermore, the cutting forces for nitinol are extremely high (e.g. up to $5000 \mathrm{~N}$ when drilling nitinol) and this could be due to the high toughness and viscosity, and the unique superelasticity [111]. To address this, cryogenic machining of nitinol yields lower cutting forces compared to dry machining (up to $50 \%$ ) due to its phase transformation. While nitinol transforms to austenite in dry cutting process due to the increased temperature, the material is in the martensite state during cryogenic machining (Fig. 10) [93, 94]. Because of these limitations, cutting is rarely used in the manufacturing of nitinol medical devices. Laser cutting is more popular, for example in the manufacturing of stents.

Surface integrity: One characteristic of the machined nitinol surfaces is large exit burrs (Fig. 26) which, in general terms, present two distinct areas: a white layer in the rim zone and bulk in the subsurface. White layers caused by large deformations in 
cutting are of austenitic structure and harder than the bulk, which comes from the effects of strain and cyclic hardening $[67,203]$.
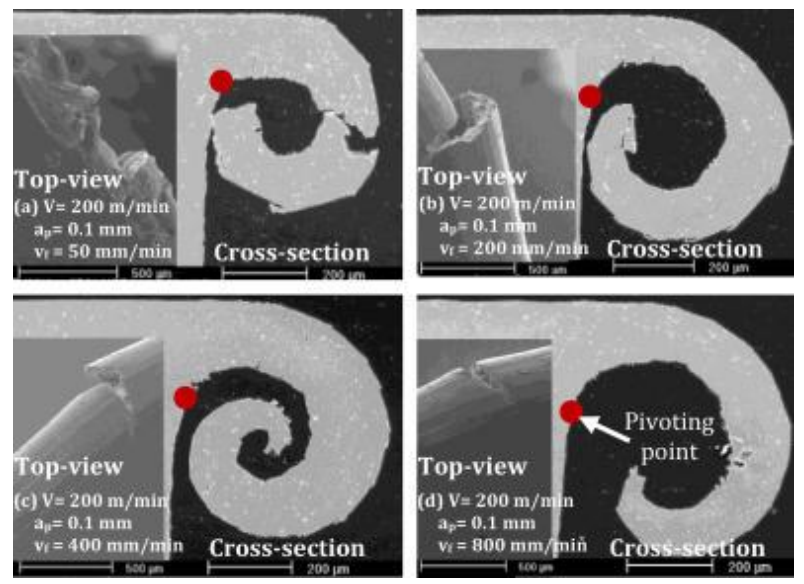

Fig. 26 Cross-sections and top-views (see inserts) of burrs generated in milling of nitinol [67].

\subsection{Polymers and polymer-composite cutting}

\subsubsection{Polymer cutting}

Different from metallic materials, the polymer is difficult to cut mainly due to its viscoelastic properties which affect the chip formation and workpiece deformation and could result in inadequate surface finish. That is, the low elastic modulus leads to high elastic deformations during chip formation while the rheological behaviour make the cutting process more complex by generating flow, shear and crack chips $[5,193]$. Thus, based on the viscoelastic property, the polymer cutting methods can be divided into two different regions: cutting in conditions which result in temperatures above or under $\mathrm{T}_{\mathrm{g}}$ when material removal is dominated by ductile or brittle modes respectively.

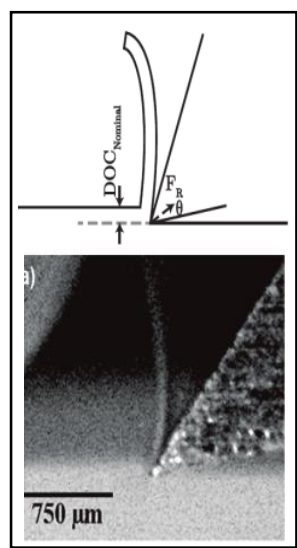

(a) r/DOC $\approx 0$

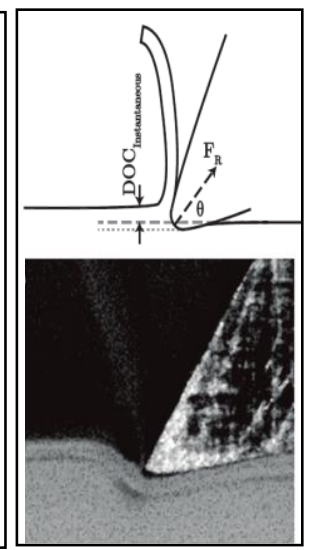

(b) $\mathrm{r} / \mathrm{DOC}<1$

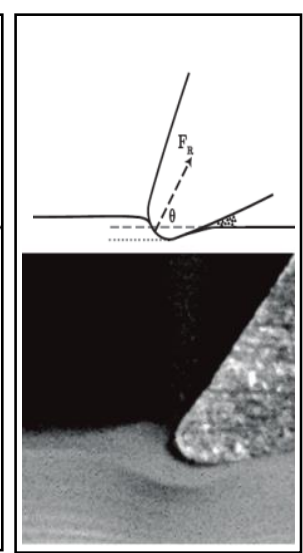

(c) $\mathrm{r} / \mathrm{DOC}>1$
Fig. 27. High-speed camera images of UHMWPE machining with varying tool sharpness at low DOC: (a) sharp, (b) worn, (c) highly worn tools [5].

When the temperature is above $T_{g}$, the cutting process is affected mainly by the cutting parameters, tool geometry and sharpness. According to Aldwell et al. [5], due to polymers' viscoelastic behaviour, the effective DOC is always smaller than nominal value because of instantaneous elastic recovers and over time expansion from viscous relaxation (see Fig. 27). This leads to a different extent of workpiece deformations which affect the chip formation mechanism such as compression cracking of the material when the radius of curvature ( $\mathrm{r}$ ) of the cutting edge exceeds the DOC (Fig. 27c). Additionally, low DOC also makes the cutting conditions to occur under negative rake angle, which yield high forces, temperature and surface damage (Fig. 28).
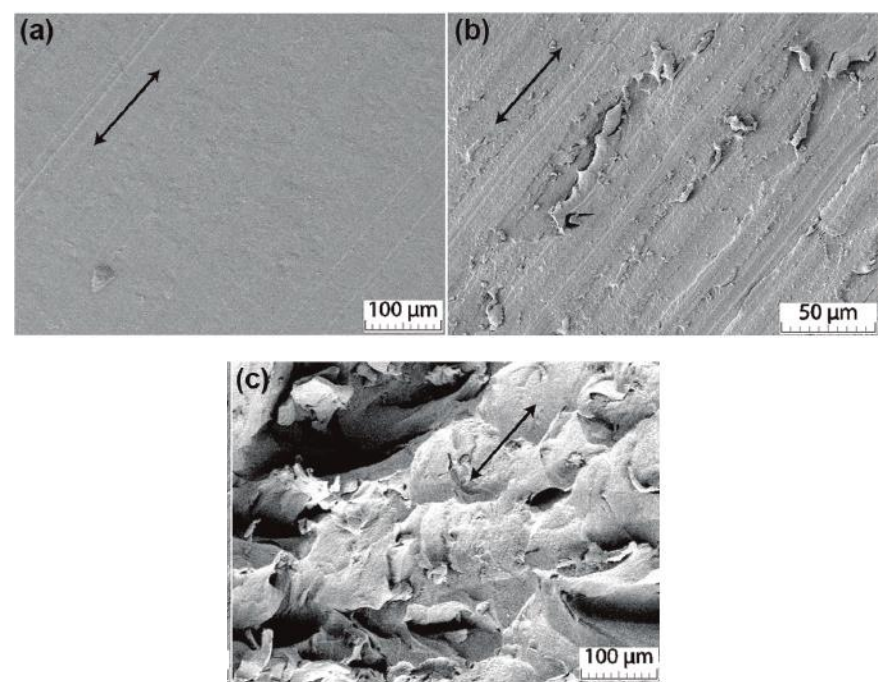

Fig. 28. Surface damage of machined UHMWPE under varying tool conditions: (a) sharp, (b) worn and (c) highly worn cutting edge [5].

The chip morphology mainly manifests as continuous and discontinuous types and transitions from flow, shear to crack type due to the viscoelastic behaviour of the polymer (see in Table 4) $[5,99]$. Chip management when machining of polymers is also a challenge, as the continuous chips tend to wrap around workpieces and tools, and sometimes interfere with the cutting operation itself.

Table 4 Types of chips formed in polymer machining [5].

\begin{tabular}{|c|c|c|}
\hline Type of chip & Cause & formation \\
\hline $\begin{array}{l}\text { Continuous- } \\
\text { flow }\end{array}$ & Produced by high elastic deformations & piece \\
\hline $\begin{array}{l}\text { Continuous- } \\
\text { shear }\end{array}$ & $\begin{array}{l}\text { Shearing occurs along the shear plane } \\
\text { upwards from the point of the cutting tool. } \\
\text { Continuous chip because of small shear } \\
\text { intervals }\end{array}$ & \\
\hline $\begin{array}{l}\text { Discontinuous } \\
\text {-simple shear }\end{array}$ & $\begin{array}{l}\text { Shearing occurs along the shear plane. } \\
\text { Discontinuous chips because of larger } \\
\text { shear intervals. }\end{array}$ & \\
\hline $\begin{array}{l}\text { Discontinuous } \\
\text { - complex }\end{array}$ & $\begin{array}{l}\text { Chips are produced by complex stress } \\
\text { resulting from the action of a large } \\
\text { compressive stresses in combination with } \\
\text { shear stresses }\end{array}$ & \\
\hline $\begin{array}{l}\text { Discontinuous } \\
\text { - crack }\end{array}$ & $\begin{array}{l}\text { Chips formation dominated by brittle } \\
\text { fracture Cracking around the cutting edge }\end{array}$ & \\
\hline $\begin{array}{l}\text { Discontinuous } \\
\text { - complex } \\
\text { (shear with } \\
\text { crack) }\end{array}$ & $\begin{array}{l}\text { Cracks occur at a downward angle from } \\
\text { the cutting point as well as separation of } \\
\text { material along usual shear plane. }\end{array}$ & \\
\hline
\end{tabular}

Also, the workpiece deformation, favoured by low thermal conductivity of the polymer which increases the temperature in the cutting zone, leads to the generation of burrs [5]. Thus, to overcome the problem of viscoelasticity, the polymer is always being cut either with high cutting speed or low temperature to increase the apparent stiffness $[58,90]$. Machining at or around the glass transition temperature can greatly improve surface quality in polymer machining (Fig. 29) [90]. Immediately below $\mathrm{T}_{\mathrm{g}}$, the polymer changes from a rubbery to a glassy state, and its stiffness increases remarkably. In addition, its adhesion decreases because 
the motion of molecules is suppressed. Aldwell et al. (2015) showed that workpiece pre-cooling to cryogenic temperatures $(100-150 \mathrm{~K})$ increases workpiece stiffness and improves surface quality in the machining of UHMWPE [6].

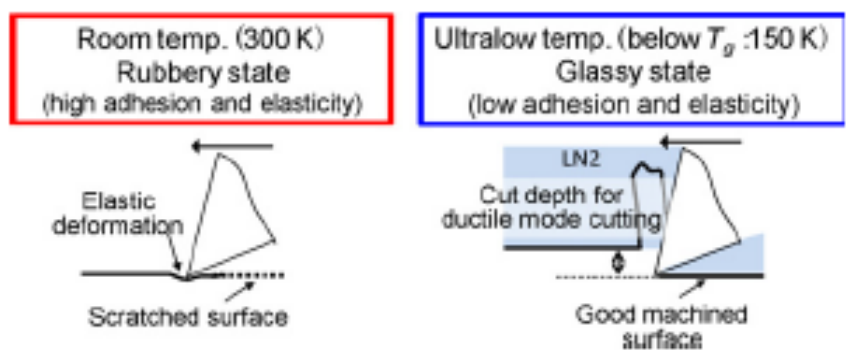

Fig. 29. Concept of cryogenic micromachining of polymers [90].

The cutting mechanism of polymers below the glass transition temperature is different from cutting at room temperature, which is mainly dependent on the cutting depth. As shown in Fig. 30 [90], at small cutting depth $(\sim 1 \mu \mathrm{m})$ the cutting process is ductile. An increase of cutting depth results in the elevation of the cutting temperature and the material locally changes from the glassy to the rubbery state which inhibits the polymer from being machined in the ductile mode. The elasticity and adhesion of polymer that has partially transitioned to the rubbery state induce "tear"-type cutting. At larger cut depth, the cutting process transits from tear type cutting to brittle mode cutting completely.

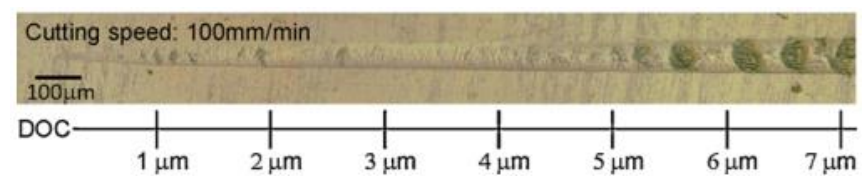

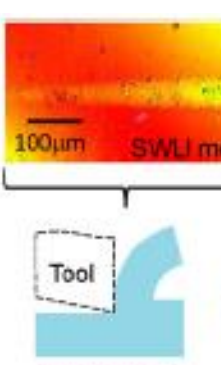

Ductile mode

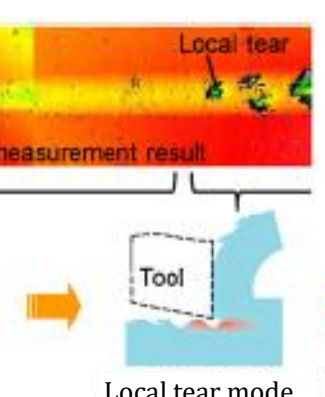

Local tear mode
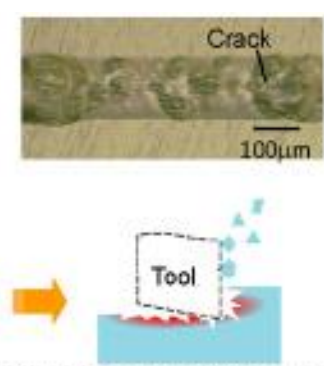

General tear and Brittle mode

Fig. 30. Transition of cutting mode during cryogenic cutting of viscoelastic polymers with an increasing depth of cut [90].

\subsubsection{Polymer composite cutting}

The fibre reinforced polymer composites (FRP), which consist of glass or carbon fibre and polymer matrix, present an obvious anisotropy of mechanical properties which is reflected in significant differences in cutting mechanism depending of fibre 3D orientation $[40,65]$. The effects on the fibre deformation, fibre fragmentation and fibre-matrix debonding have been reported as the major material removal mechanisms $[49,206]$. Specifically, during the cutting process part of the fibre-matrix interface can suffer from debonding while the rest of the fibre-matrix interface has a bonding force to constrain the deflection of the fibre caused by the cutting force (as shown in Fig. 31). Nevertheless, randomness of the fibre (as constituent with higher mechanical properties) distribution within the matrix is reflected in the variance of the cutting forces [125].



Fig. 31. Deformation of a fibre during cutting of FRP [206].

With respect to the cutting mechanism of FRP composites, delamination is one of the main modes of failure, especially in drilling. Delamination is a separating phenomenon of adjacent laminates or layers along their interfaces (Fig. 32) [112], and mainly caused by tensile and bending loads during machining [84, 145]; increasing in feed rate, thrust force and drill diameter caused an increase in delamination and surface roughness [84].
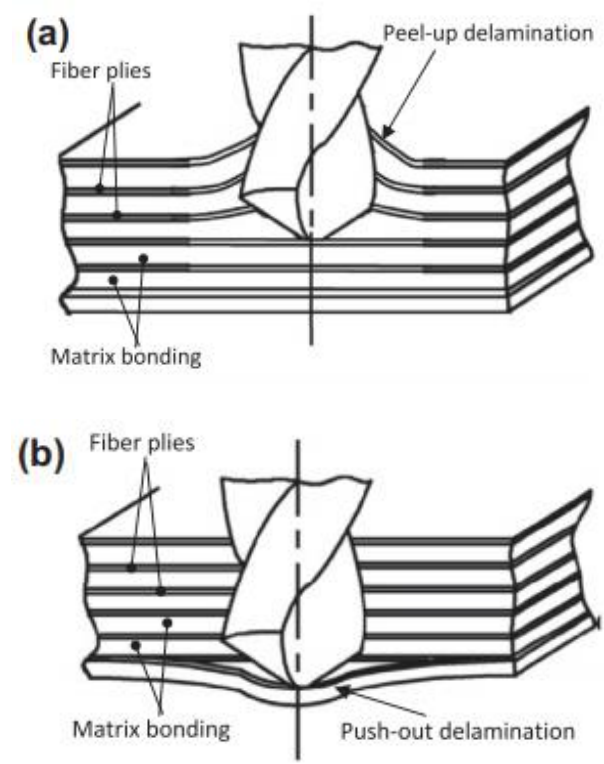

Fig. 32. Mechanism of drilling-induced delamination in FRP composite laminates: Peel-up (a) and push-out and (b) delamination [112]

The damage mechanism in FRP machining includes fibre fracture and pull-out, fibre/matrix debonding, crack and delamination, as shown in Fig. 33 [12, 59]. For surface generation, conventional milling and drilling are commonly used in the production lines for polymer-composite machining $[91,120]$, which, however, could introduce severe subsurface damage and high cutting forces [16, $92,120]$. An effective way to minimise these effects is to employ abrasive machining, e.g. grinding [78], abrasive drilling [43], abrasive waterjet cutting $[158,159]$ and special tool design $[25$, 88]. Nevertheless, when machining of polymer-composites for biomedical applications, care needs to be taken that delaminations and fibre pull-outs do not occur not only because it could affect the structural integrity of the parts but also it can also damage the tissues that could be in contact with them. 




(a)

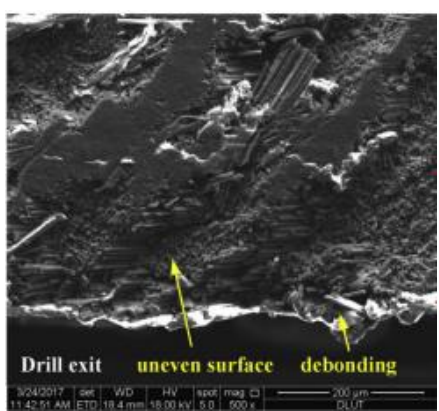

(b)
Fig. 33. Surface damage under: (a) milling [12] and (b) drilling [59].

\subsection{Bone cutting}

Since cortical bone is the first and most difficult layer to be cut in any bone surgical intervention, strict procedures are in place to avoid cutting malfunctions which could affect the bone cell from physical or histology point of view.
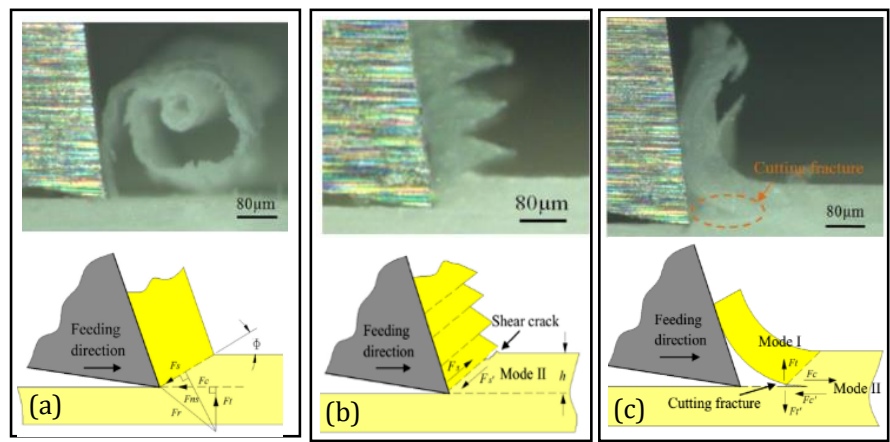

Fig. 34. Chip formation in cortical bone cutting showing different cutting modes (a) shear cutting, (b) shear-crack cutting and (c) fracture cutting with varying cutting depths [106]
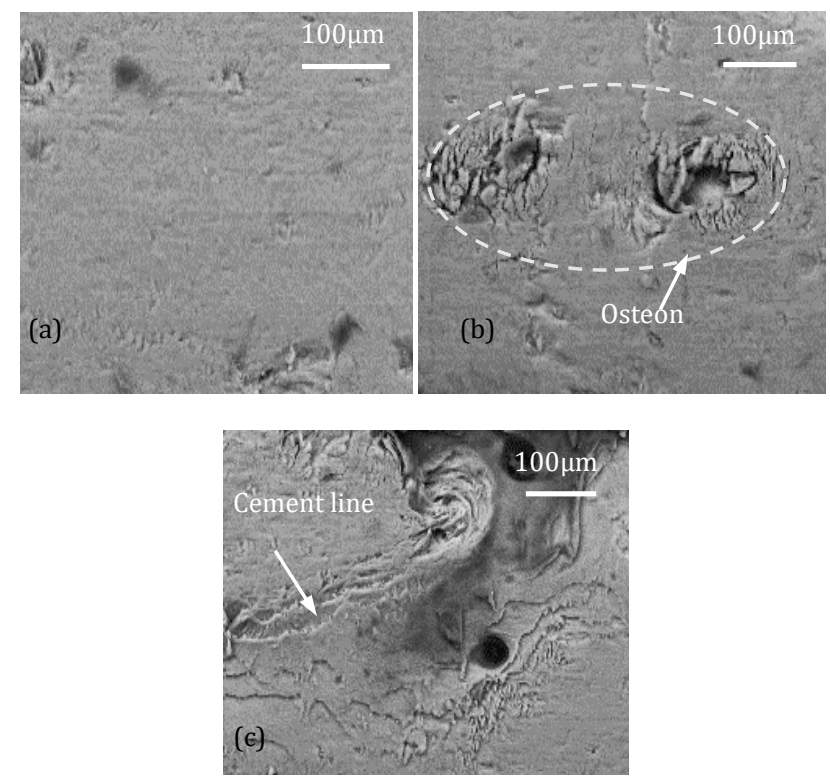

Fig. 35. Surface damage of bone for different cutting modes: (a) shear cutting, (b) shear-crack cutting and (c) fracture cutting [106].

As a semi-brittle material, the bone cutting process is always accompanied with crack or fracture chip formation [174] governed by a special cutting mechanism. It has been [106] found that the chip formation of bone orthogonal cutting transits from shear cutting, shear-crack to fracture cutting modes with the increase of uncut chip thickness; for this Liao [106] proposed a fracture mechanics based cutting model to explain the chip formation and cutting process (Figs. 34 and 35), with which a threshold of depth of cut could be estimated to predict the cutting modes. It is also found that the specific cutting force is reduced when the fracture cutting mode is dominant $[106,175]$.

When placing implants in contact with bone tissues, the machined cancellous bone is found to be the primary cause of osteoarthritis; thus, the particularities of cancellous bone machining also need to be considered with great care [85]. However, very limited studies on the cancellous bone cutting exist (Jackson et al. [85], Mitsuishi et al. [127] and Malak et al. [121]). It was found that the chip formation transits from fragmented to continuous and discontinuous type with the increase of cutting depth and tool rake angle. Bone marrow is extruded out of the free surfaces when the cutting depth is greater than $1.0 \mathrm{~mm}$ (Fig. 36).
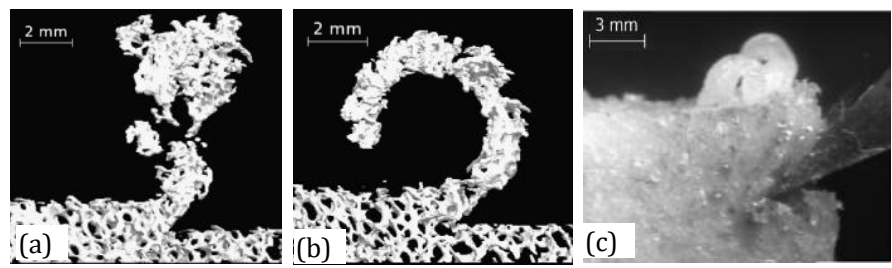

Fig. 36. Chip formation in cancellous bone cutting showing: chip morphology with rake angle (a) $23^{\circ}$ and (b) $45^{\circ}$ and (c) marrow extrusion with high depth of cut [121]

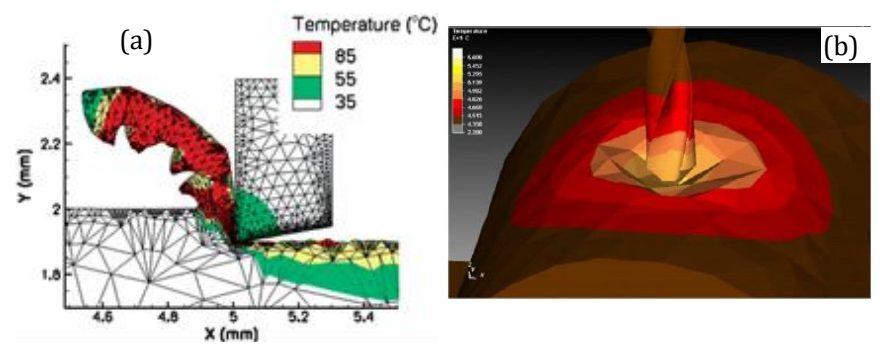

Fig. 37. FE simulations on bone cutting in (a) orthogonal cutting [36] and (b) drilling [161].

To enable further analysis on the influence of cutting parameters upon the outcomes of machining of bone structures, finite element (FE) modelling has been used. Orthogonal (Fig. 37a) [36] and 3D, (i.e. drilling Fig. 37b - [161]) cutting of bone have been simulated by FE to provide a possible substitute for experimental work for predicting cutting forces and temperatures so that damage of bone can be minimised.

\subsection{Cutting Mechanics of Soft Tissue}

Cutting of soft tissue is often technically challenging due to the deformation resulted under the cutting forces. Lacking adequate structural support, soft tissue has large deformations before the initiation of separation and continues to deform during cutting, and limits the application of higher cutting forces. If the tissue is soft, ductile, and tough-to-cut, such as the intestines and blood vessels, the cutting blade or needle will be difficult to effectively cut or penetrate the soft tissue, respectively. The oblique cutting mechanics of soft tissue has been summarised in [104]. The rake angle and inclination angle at the cutting point are two key parameters to determine the force in cutting soft tissue. The high inclination angle is particularly critical to reduce the cutting force. Under high inclination angle, the effect of rake angle, unlike in metal cutting, was found to be not as important [132]. 


\section{Machining processes and tooling solutions}

\subsection{Parameters and tooling for machining of metallic parts}

For implant manufacturing, due to specific surface requirements and the use of various materials, the cutting tools and solutions are very diverse. Table 5 lists three application examples (i.e. hip and knee replacements and dental implants) of tooling and machining solutions for the implant manufacturing for three representative classes of materials, i.e. metallic, polymer and ceramic materials.

Table 5 Tooling solutions for implants machining [160]

\begin{tabular}{|c|c|c|c|}
\hline \multirow[b]{2}{*}{ 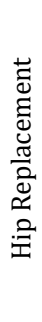 } & Acetabular Cup & Femoral Cap & STEM \\
\hline & $\begin{array}{l}\mathrm{CoCr} \\
\text {-turn spherical } \\
\text { e diameter } \\
\text { tream tooling; } \\
\text { h pressure oil } \\
\text { lant }\end{array}$ & $\begin{array}{l}\text { CoCr } \\
\text { Turn spherical } \\
\text { outside diameter } \\
\text { Jetstream tooling } \\
\text { High pressure oil } \\
\text { coolant }\end{array}$ & $\begin{array}{l}\text { Ti-6Al-4V } \\
\text { Drill \& counterbore } \\
\text { Custom drill \& } \\
\text { chamfer; } \\
\text { Water soluble, } \\
\text { through coolant }\end{array}$ \\
\hline \multirow[b]{2}{*}{ 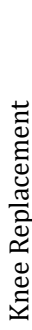 } & Femoral Part & Bearing Insert & Tibial Tray \\
\hline & $\begin{array}{l}\text { Finish outside } \\
\text { profiles } \\
\text { Solid carbide ball } \\
\text { nose cutters; Water } \\
\text { soluble flood coolant }\end{array}$ & $\begin{array}{l}\text { UHMWPE- } \\
\text { Polymer } \\
\text { Produce condyle surface } \\
\text { Jabro carbide } \\
\text { Air cooling }\end{array}$ & $\begin{array}{l}\text { Finish base of tibial } \\
\text { tray } \\
\text { Jabro solid carbide } \\
\text { end mill; Water } \\
\text { soluble flood coolant }\end{array}$ \\
\hline \multirow[b]{2}{*}{ 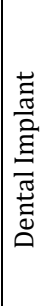 } & Abutment & Bridge \& Bar & Crown \\
\hline & $\begin{array}{l}\text { Ri } 6 \mathrm{AI}-4 \mathrm{~V} \\
\text { Jabro HFM cutter; } \\
\text { Emulsion cooling }\end{array}$ & $\begin{array}{l}\text { Roughing } \\
\text { Jabro HFM cutter; } \\
\text { Emulsion cooling }\end{array}$ & $\begin{array}{l}\text { Zirconia } \\
\text { Roughing } \\
\text { 650L020-diamond } \\
\text { tool; Emulsion } \\
\text { cooling }\end{array}$ \\
\hline
\end{tabular}

Metallic implants are commonly machined using solid-carbide cutting edges, usually with engineered coatings (e.g. TiAlSiN) to provide high metal removal rates and fine surface roughness for minimising subsequent polishing times. Due to the low thermal conductivity of Ti-based alloys used for medical implants, the majority of the heat generated is not carried by chips but transferred to cutting edge, thus, increasing tool temperature [72]. High tool temperature softens the material, damages coatings, accelerates edge chipping, promotes rapid chemical reaction and diffusion wear which limits the cutting speed, material removal rate (MRR) and productivity $[60,163]$. The integration of advanced tool material, coating, and cutting edge geometry [44] to overcome barriers in high MRR cutting of Ti-based alloys is an ongoing research and development in the tool industry. The general guidelines for drilling, milling and turning of Ti-based alloys are using a large rake angle and sharp edges (honing for light cutting edge preparation) to reduce the work-hardening, and large relief angle to reduce friction caused by spring-back of machined surface; also, PVD coatings of 3 to $5 \mu \mathrm{m}$ TiAlN or TiAlSiN, providing good hot-hardness are used. Built-up edge is a common issue in cutting Ti-based alloys and needs post-coating polishing on tool rake faces or drill flutes. For rotating tools, such as drills or solid endmills, the tool substrates with 1 to $2 \mu \mathrm{m}$ WC grain size with $10 \%$ cobalt is a compromise of hardness and toughness. For the indexable milling insert, additional heat inert elements can be used to improve thermal stability due to hot-cold cycles. Through tool cooling is highly employed to improve tool life and workpiece integrity when machining Ti-based implants. Advancements in the cryogenic cooling [87] is likely able to make further advancements in these aspects.

Similar to Ti-based alloys, stainless steels also have low thermal conductivity and high affinity to the cutting tool. The heat generation and tool temperature are less in this case but the builtup edge and work-hardening phenomena are more significant in cutting of ductile stainless steel. Similar tool geometry and grade and slightly smaller relief angle (stronger edge strength) as in Tibased alloy machining is used for stainless steels.

Co-based alloys are also difficult to cut materials due to their high wear resistance, mechanical strength and heat resistance. The difficulty in machining Co-based superalloys brings forward two basic problems: (i) short tool lives due to the work hardening and attrition properties of the superalloy and (ii) severe surface damage of machined workpiece due to heat generation and plastic deformations [11]. In industrial applications, the cutting tools for Co-based superalloys are normally the same with the tools employed for Ti superalloys due to the similar cutting conditions.

In Mg-based alloys machining, due to their tendency to react with water and form highly explosive hydrogen gas which makes the process unsafe, the use of cutting fluids is limited. Hence, dry machining is usually preferred over wet machining. Due to the risk of temperature rise, dry machining is conducted with controlled cutting speeds and feed rates as both these factors influence heat generation. Cryogenic machining could be an alternative for machining at high cutting speeds and feed rates [41]. From the literature, it seems that no specific cutting tools are used for machining of Mg-based alloys, topic which could represent the subject for research investigations.

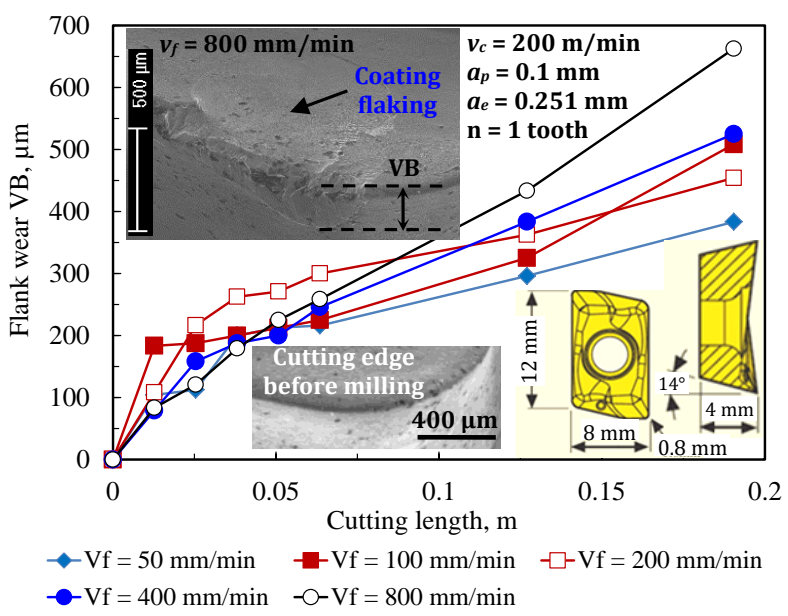

Fig. 38. Tool wear patterns in cutting NiTi alloys [194].

Due to their superelasticity, high ductility, and strong work hardening of NiTi alloys, short tool life and burr formation are critical issues in cutting of SMA alloys [67, 194]. Furthermore, the coupling phenomena between phase transformation and loading (large strain, high strain rate, and high temperatures) are very complex in a cutting process. The (Ti, Al) N/TiN coated carbide inserts with general purpose synthetic cutting fluid are preferable in cutting SMA [194]. Tool wear is mainly characterised by large flank wear and coating flaking as well as some degree of notching and microchipping (Fig. 38). The very high strength (up to $3 \mathrm{GPa}$ ) of the material imposes significant mechanical loading on the tool/work interface, which results in an exceedingly strong adhesion on the flank face. In addition, the high specific heat of nitinol is expected to produce high cutting temperatures which induce tribo-chemical phenomena on tool coatings thus, yielding to large flaking of the coatings. 
In polymer cutting, due to its viscoelastic properties and special cutting mechanism, as stated in Section 3, the high rake angles and sharp tool are need to suppress the crack [5]. With its relative low strength the cutting temperature is generally low and air cooling method could be applied in the polymer cutting process.

\subsection{Parameters and tooling for machining soft and hard tissues}

\subsubsection{Soft tissue cutting tools}

For soft tissue surgery the tools usually employed are scalpel blades, ophthalmologic blades and knives, and scissors [142].

The scalpel blade is the most common cutting tool for dissection of soft tissue, which are generally made of hardened and tempered stainless steel. Studies have been conducted to identify the cutting edge geometry, measure the cutting forces, determine the sharpness, and investigate soft tissue cutting mechanics. A generalized geometric model was developed by Shetty et al. [164] to describe the cutting edge geometry in terms of normal rake angle (Fig. 39a) and inclination angle (Fig. 39b) of continuous scalpel cutting edge. Chanthasopeephan et al. [29] studied the localized soft-tissue deformation immediately preceding crack growth observed during the scalpel blade cutting of soft tissue. Results showed that for a given cutting speed, the soft tissue resistance for deformation decreased as the cutting angle was varied from $45^{\circ}$ to $90^{\circ}$. For a given cutting angle, the resistance for deformation decreased with increase in cutting speed.

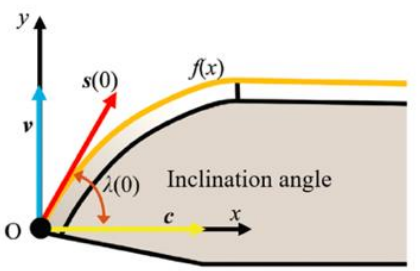

(a)

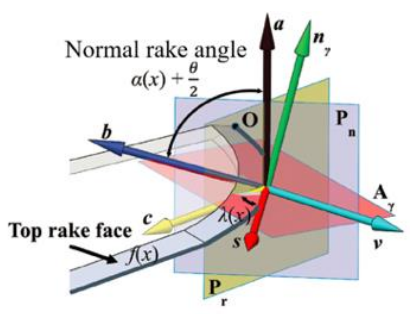

(b)
Fig. 39. Coordinate system and vectors used in geometric model to define the (a) inclination angle and (b) normal rake angles of scalpel blades [164].

Ophthalmologic surgery requires special blades and knifes for soft tissue cutting; the four major types are: keratome, stab, enlarging, crescent, and sideport (also known as MVR) blades.

Scissors are important tools for soft tissue cutting for dissection and to cut tissues in surgical cases. Common surgical scissors for soft tissue cutting include iris scissors, tenotomy scissors, Metzenbaum scissors, Mayo scissors, and Potts-Smith scissors.

\subsubsection{Bone cutting tools}

For orthopaedic, surgery, drilling, tapping, sawing, and milling are the main cutting processes of bone. Carbide and stainless steel cutting tools are commonly used for milling and drilling of hard tissue in surgical and dental operations [165].

\subsubsection{Drilling}

Bone drilling is the most common procedure in orthopedic surgery, used for the fixation of broken bone, joint fusion, prosthetic device installation, and many other procedures. Bone drilling often produces high temperature and results in the thermal osteonecrosis that affects the healing and, thus, could affect the quality-of-life of the patients [140].

Three common bone drills exist, namely: cannulated drill, twist drill, and Kirschner wires (K-wires), as shown in Fig. 40(a) and (b) [139]. Twist drills have standard two-flute geometry and much sharper (e.g. $60^{\circ}$ ) point angle compared to traditional drills for metal cutting. K-wires are smooth stainless steel pins commonly used for fixation of broken bones from finger tips to toes [28].



(a)

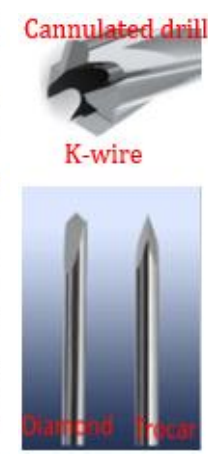

(b)

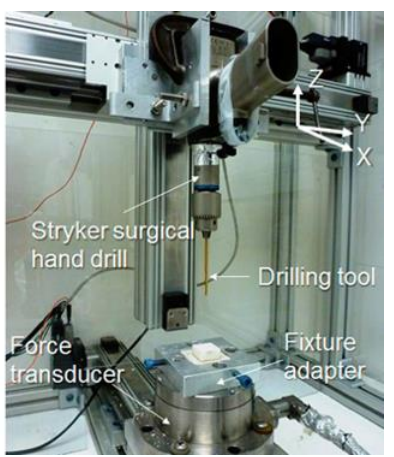

(c)

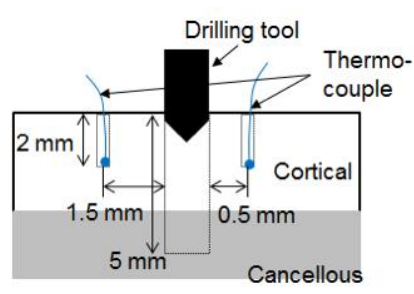

(d) (e)



Fig. 40. A study of bone drilling temperature: (a) three common types drills, (b) closed-up views of cannulated drill tip and K-wires, (c) bone drilling setup, (d) embedded thermocouple and (e) bone drilling test setup [139].

Within the range of cutting conditions employed for orthopaedic surgery, it has also been found that the drill diameter does not have a significant effect on the bone temperature. Standard twist drills yield the lowest temperature rise among all drill types while Kwires and cannulated drills which can have substantial temperature rises to cause instant thermal osteonecrosis [139]. Research has also found that diamond-tipped K-wires generated less heat during insertion but the pull force of the K-wire from the hole it drilled in the bone might be lower [115]. To reduce thermal injury and other high-temperature associated complications, Liu et al. [115] developed micro-milled notches in the K-wire with trocar tip (Fig. 41) and demonstrated to be effective for the reducing the bone temperature in drilling by storing bone debris in notches to reduce clogging and heat generation.
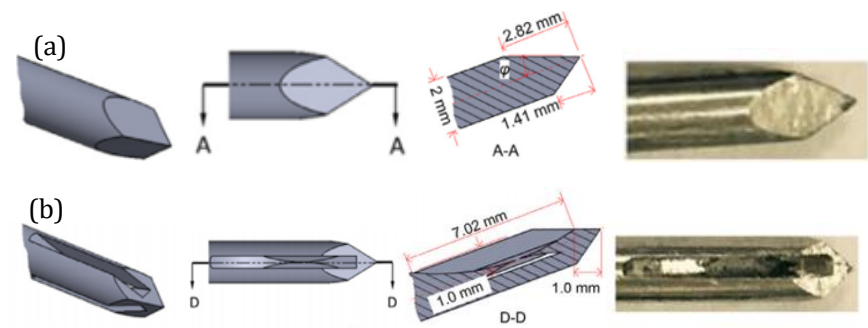

Fig. 41. (a) Regular and (b) notched K-wires for bone drilling [115].

\subsubsection{Milling}

Bone milling is used in orthopaedic surgery for resecting a portion of a bone to expose a surgical site or for reducing a redundant protuberant part of a bone. Bone milling is conducted by small cutters with different shapes: spherical, pear, acorn (Fig. 42). Another multi-point bone milling tool is the acetabular reamer (Fig. 43) used to generate a hemispherical shape in the bone to fit the acetabular metal shell of the hip implant [204]. 


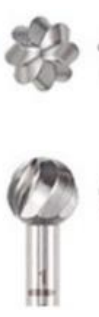

(a)

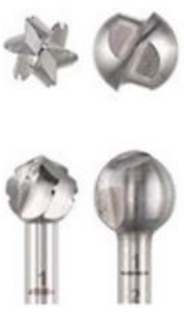

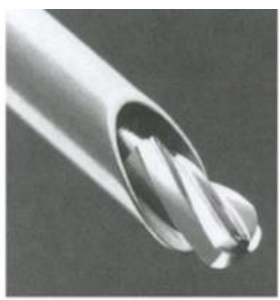

(b)

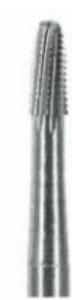

(c)
Fig. 42. Bone milling tools of different shapes: (a) round fluted, (b) pear, (c) cross cut fissure [171].
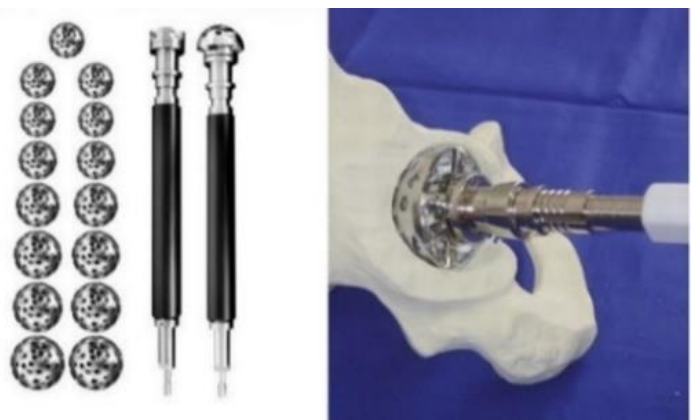

Fig. 43. Acetabular reamer for total hip replacement [204].

To reduce the cutting damage of bone Liao et al. [108] proposed a design of a multi-teeth milling cutter based on the bone cutting mechanism, as shown in Fig. 44, which includes on the back of main cutting edge a succession of micro-cutting edges arranged on an Archimedes spiral that enables the minimization of bone surface damages. By adjusting the feed rate, this tool design allows the fine cutting of bone workpiece with the micro-cutting edges following the "fracture" cutting of main cutting edge, thus to reduce the fracture and thermal damage of bone cut surface.

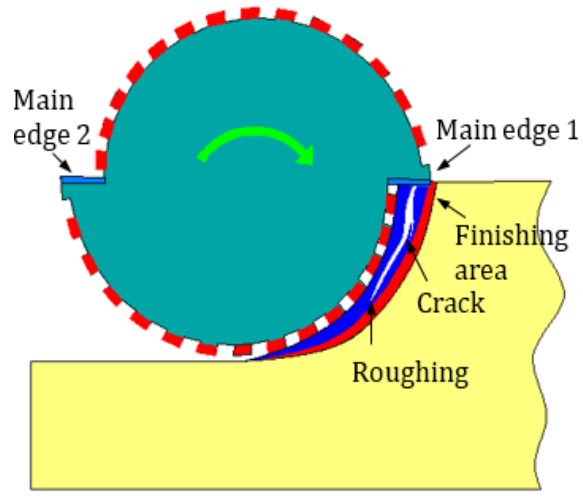

(a)

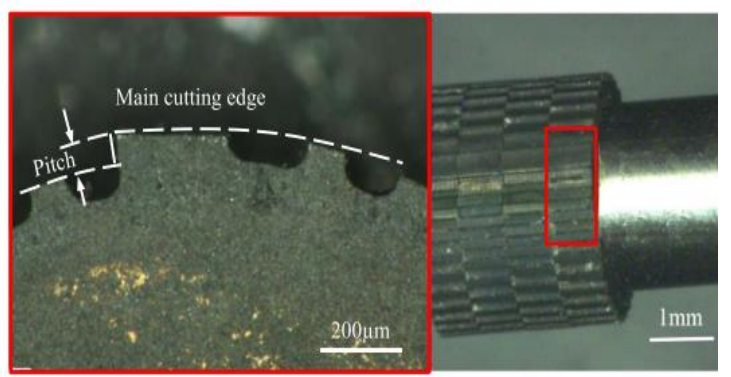

(b)

Fig. 44. Multiple teeth milling cutter designed based on the bone cutting mechanism: (a) cutting mechanism, (b) tool design. [108]

\subsubsection{Sawing}

Sawing is another common bone cutting process to section bones. The Gigli saw (Fig. 45a) has a flexible sharp edge wire with the advantage of bone sawing without a large operating area and the disadvantage of low material removal rate [172]. Fig. 45(b) shows the reciprocating bone saw (also known as jig saw), which is used in unicompartmental knee arthroplasty to cut the tibia for fitting the knee implant [22]. A cup-shaped bone saw with continuous rotary movement is the trephine (Fig. 45d) for perforation and/or taking bone samples [64].



(a)



(b)

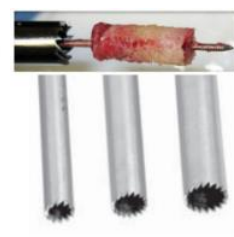

(c)
Fig. 45. Bone sawing tools: (a) Gigli saw [172], (b) reciprocating bone saw (jig saw) [22] and (c) trephine [64].

\subsubsection{Ultrasonic-assisted bone cutting}

Ultrasonic-assisted bone cutting has also been developed to reduce the cutting forces. The different sensitivity of the hard and soft tissues to ultrasound enables selective bone cutting without damaging the surrounding soft tissues, nerves and vessels. Compared to conventional bone machining, ultrasonic-assisted process achieves lower cutting forces and thermal damage with appropriate cutting parameters. Fig. 46 shows examples of ultrasonic assisted osteotomy insert tips for cutting teeth [171].

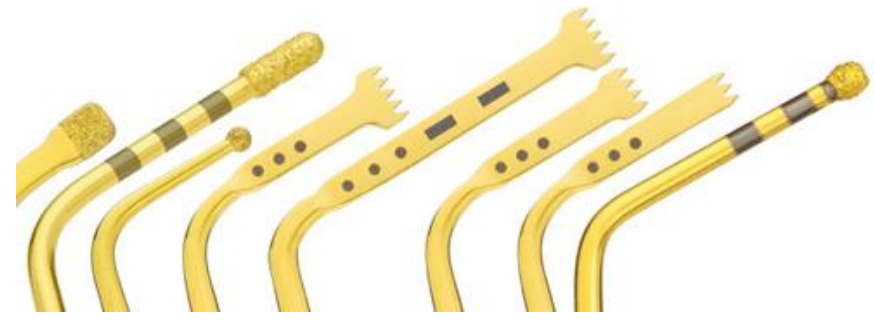

Fig. 46. ultrasonic assisted osteotomy insert tips for cutting teeth [171]

\section{Functional requirements and associated machining challenges of selected biomedical applications}

In this chapter, the functional requirements and related machining challenges associated with the manufacture of representative biomedical components are discussed. We refer to the implication of machining upon surface quality, dimensional accuracy, mechanical performance, wear and corrosion resistance.

\subsection{Surface quality, geometric and dimensional accuracy requirements.}

\subsubsection{Orthopaedic implants}

Orthopaedic devices include hip and knee replacement components, artificial elbow and ankle joints, trauma repair instruments, spinal bone plates and various repair pins, rods and fasteners. Most of joint reconstruction medical procedures are concerned with hip and knee replacement. The key functional requirements associated with these parts are strength, reliability, light weight and biocompatibility thus, requiring the use of high performance biocompatible materials. 
The description and functional requirements of the main parts of knee and hip implant are listed in Table 6. The metal alloy components of these implants must possess excellent surface finishes to minimize wear of any plastic counterparts and allow the joint to function for its projected lifetime of 20 years or more. In a knee replacement, for example, both the femoral component and tibial tray must be very smooth to protect the plastic bearing insert against wear.

Table 6 Material, condition of supply and qualitative functional requirements for a knee component (L: Low, M: Medium, H: High) (Source: SECO tools AB)

\begin{tabular}{lllllll}
\hline Part & Material & Condition of supply & $\begin{array}{l}\text { Strength } \\
\text { /Stiffness }\end{array}$ & $\begin{array}{l}\text { Corrosion } \\
\text { Resistance }\end{array}$ & Biocompatibility & Surface requirements \\
\hline Femoral & CoCr & Casting, forging, bar & M/H & M-H & M-H (90\%) & $\begin{array}{l}\text { Minimal manual polishing, Burr- } \\
\text { free surface } \\
\text { No manual polishing, Burr-free } \\
\text { surface, Ra }<0.2 \text { um on bearing } \\
\text { surface } \\
\text { Bearing insert }\end{array}$ \\
Tibial & UHMWPE & Disc & - & - & - & $\begin{array}{l}\text { Superior finish of bottom flat, } \\
\text { locking details and side wall. } \\
\text { Superior finish of bottom flat, } \\
\text { locking details and side wall. }\end{array}$ \\
\hline
\end{tabular}

The manufacture of orthopaedic metallic components would typically involve a sequence of operations, e.g. forming, machining and finishing processes (Fig. 47) [1]. With regards to the machining processes, grinding operations generally follow the milling/turning process in order to achieve an improved surface finish. However, grinding generates high temperatures and stress in the ground components, which can affect the product's strength and performance. Grinding can be supported or in some cases replaced with the application of advanced cutting tools and highspeed milling strategies. The goal of the milling operations is to achieve a burr-free outside profile and a superior surface finish that offers the exact required surface quality, integrity and dimensional accuracy. If there is a post treatment such as polishing, the time for that task can be minimized because of the defined surface roughness and structure achieved in the milling process. On the tooling side, parallel goals are the long, reliable tool life and maximum productivity.

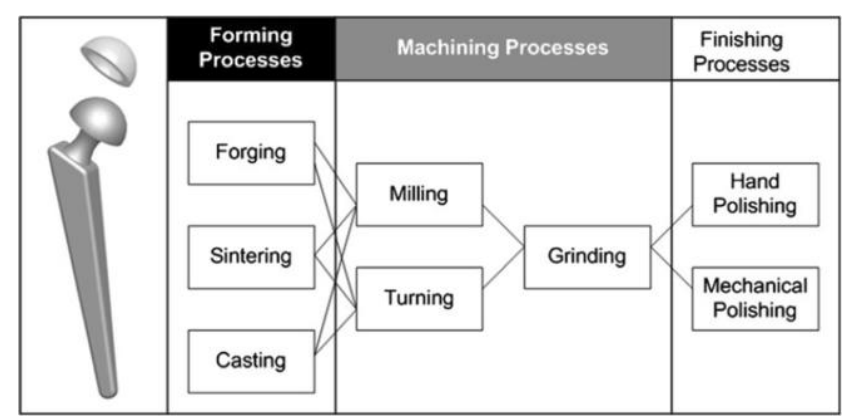

Fig. 47 Manufacturing process steps for the fabrication of metallic components of prostheses [1].

The complex contours of orthopaedic components often necessitate use of specific sequences of specialised tools. The tibial tray, for example, typically can require up to seven separate machining operations. Those operations can include roughing, tray base roughing, tray base finishing, chamfer milling, t-slot undercut machining, wall finishing/chamfering, and undercut deburring. The challenge is to achieve superior surface finishes with minimal manual intervention as well as reliable tool performance with the best combination of productivity, cost and quality. Traditionally, carrying out these sorts of multiple operations dictated the use of separate special tools developed to produce each required contour, dimension and surface finish. Special tools require investment in design and development time and expense, and due to their low production volume may have extended lead times and availability constraints. A new approach involves the development and use of standardised tools for productive use in these applications while retaining flexibility to be used in a variety of similar parts in the orthopaedic industry.
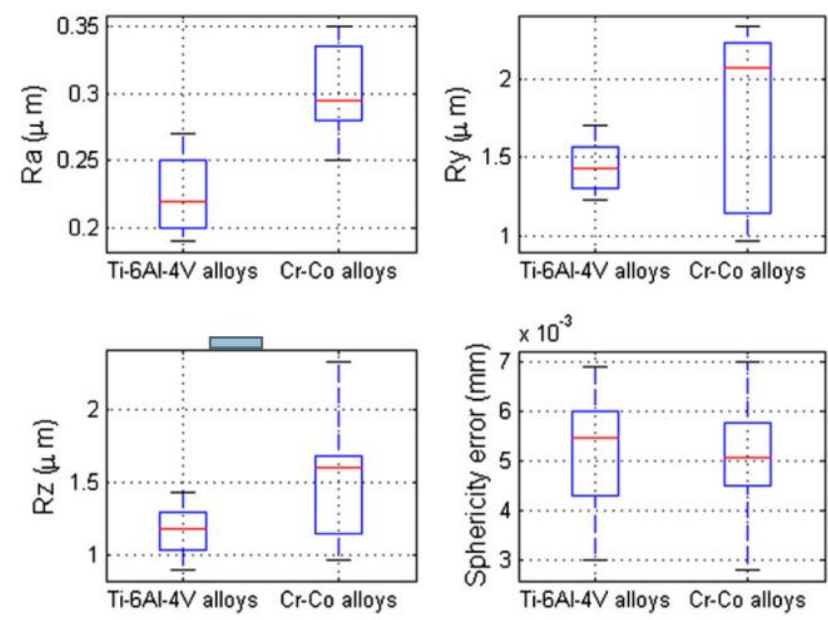

Fig. 48 Boxplots of Ra, Rz, Rg and spherical form deviation $(\varepsilon)$ comparison between $\mathrm{Ti}-6 \mathrm{Al}-4 \mathrm{~V}$ and $\mathrm{Cr}-\mathrm{Co}$ alloys [1]

Abellán-Nebot et al. [1] investigated the influence cutting parameters, machine tool control accuracy and metrology procedures on surface roughness parameters and form errors in contouring operations of Ti64 and CrCo workpieces in the context of spherical prostheses manufacture. Their results indicated that a better surface roughness control could be achieved for Ti-6Al-4V, whereas for $\mathrm{Cr}-\mathrm{Co}$ alloys, a higher variability was observed (Fig. 48). Additionally, sphericity error of the machined specimens obtained from coordinate measuring machine (CMM) was related with the number of measurement points (Fig. 49).

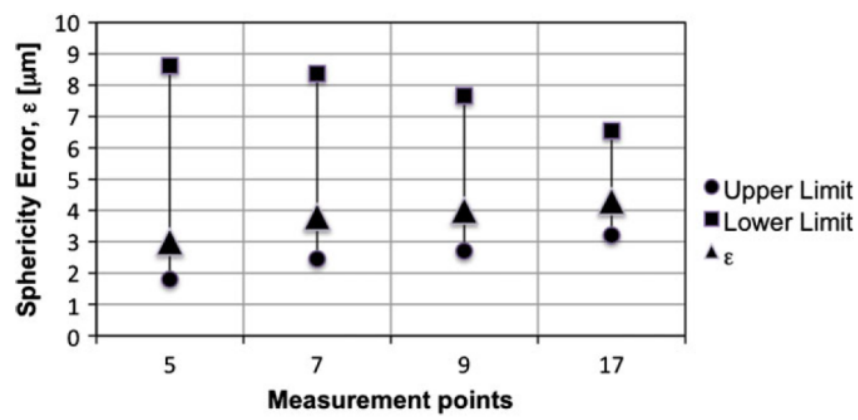

Fig. 49 Influence of the number of measurement points in the estimation of the range with a confidence level of $95 \%$ where the actual value of the sphericity error of the part will lay [1]. 
As suggested by Cubillos et al. [39], dimensional control and surface finish of the femoral head and acetabular liner are critical factors in the manufacturing process due to the risk of increased polyethylene wear, which is the primary cause of aseptic failure of a metal/polymer hip prosthesis. In their investigation, the manufacturing quality (dimensional accuracy and surface finish) of the metal femoral head/UHMWPE liner couples of 5 hip implant manufacturers (A, B, C, D and E) was evaluated using measurement protocols in compliance with international standard requirements (ISO 7206-2:2011 and ISO 21535:2010). The femoral heads of groups A, B and C implants were made of stainless steel while groups D and E were made of Cr-Co-Mo alloy. Their results showed a good dimensional and surface finish control during the manufacturing process of the femoral heads and the diameter, sphericity and roughness of the heads were in accordance with the ISO standard requirements. However, the same control was not apparent for the manufacturing of the acetabular liners. Although all samples had a thickness and sphericity in accordance with the ISO standard, the diameter of the acetabular liners of one manufacturer was not in accordance with the standard (Fig. 50), thus, suggesting the need for better quality control of the manufacturing processes.

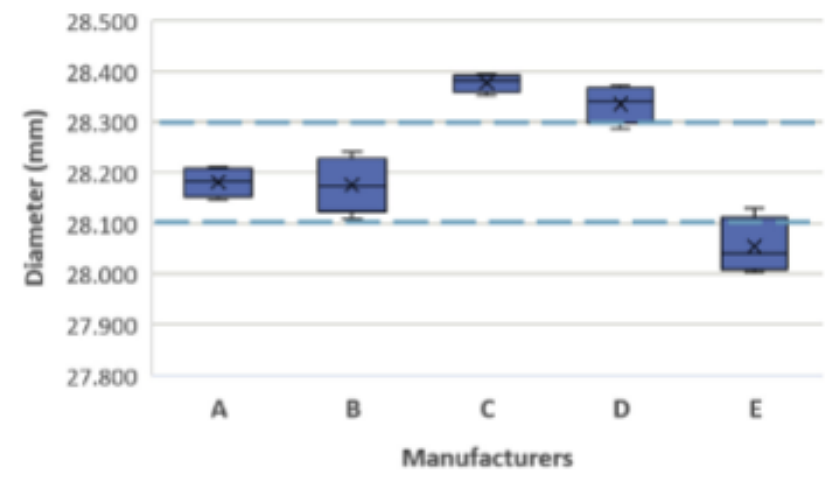

Fig. 50 Diameter of acetabular liner of 5 manufacturers. The dotted lines represent the ISO limits [39].

\subsubsection{Dental components}

Several authors have reported on the progress of computeraided design and computer-aided manufacturing (CAD/CAM) for restorative dentistry applications e.g. to manufacture inlays, onlays, crowns, fixed partial dentures (FPDs), implant abutments, etc. $[18,147,209]$. The advantages of introducing CAD/CAM technology over conventional methods (e.g. lost-wax technique) for crown fabrication and FDPs has been summarized as: (i) application of new materials, (ii) reduced labour, (iii) cost effectiveness and (iv) quality control [128]. An example of CAD/CAM process for the fabrication of fixed dental prostheses (FDPs) is illustrated Fig. 51 [129].

An area of main concern in restorative dentistry is the fit of the fixed dental prostheses or fixed partial dentures with the natural or artificial structures (abutments) that should support them in the patient's mouth [70]. A poor fit can often result in biological complications (e.g. acid from food leaking into the gap causing gum inflammation, tooth decay) and failure of the fixed partial denture component [57]. A large number of investigations have reported on the fit of FDPs to the abutments supporting them, known as "marginal fit" since it provides a good indicator of the durability of the FDP [70]. The method consists in creating a replica of the abutment onto which the FPD is cemented. The external fit can be measured in two dimensions directly using microscopes whereas the measurement of internal fit requires the sectioning and polishing of FPD/abutment replica assembly followed then by measurement with a microscope. An example of this method can be found in the work of Örtorp et al. [136] who investigated the fit of CoCr FDPs produced by four different methods, i.e. conventional lost-wax method (LW), milled wax with lost-wax method (MW), milled CoCr (MC) and direct laser metal sintering (DLMS). Fig. 52 shows the location of the different points in the sectioned framework where the cement film thickness is subsequently measured with a microscope. The mean value and standard deviation (SD) of the cement film thickness measurements for the four production methods is shown in Fig. 53 indicating a best fit for the DLMS group followed by MW, LW and MC group. The largest discrepancy found in the MC group has been attributed by the authors to the wear of milling burs and possible vibration in milling device when machining such a hard material as CoCr [136].

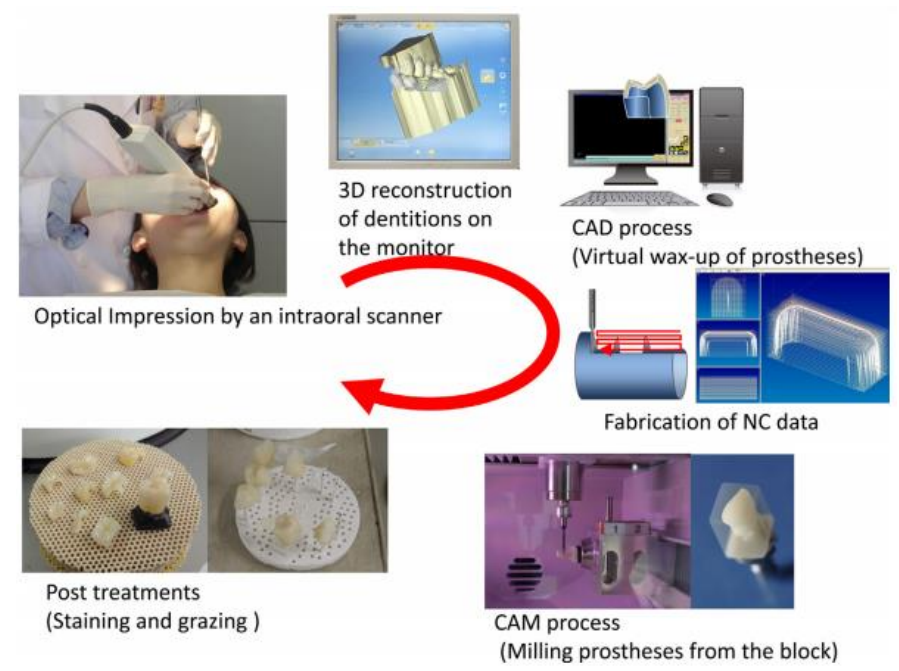

Fig. 51 A process of digital fabrication system of FDPs [129].



Fig. 52 Sectioned framework and location of the measurement points on each abutment [136].

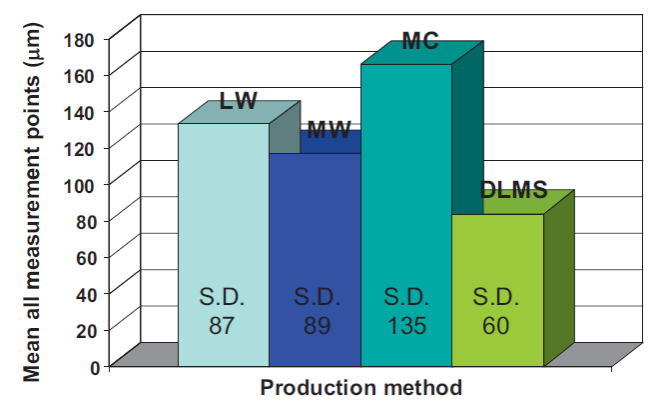

Fig. 53 - Total mean (SD) for all measurement points of cement film thickness for the four production methods. Conventional lost-wax method (LW), Milled wax with lost-wax method (MW), milled Co-Cr (MC), Direct laser metal sintering (DLMS). [136].

Gutiérrez Rubert et al. has demonstrated the possibility to assess three-dimensional geometric variation of fit between Co-Cr FDPs made using three different manufacturing processes: lost wax, CNC 
milling and selective laser sintering [70]. The method is based on a digitalisation procedure using a commercial 3D CAD/CAM software where the original FPD model is compared to the FPDs obtained by the different fabrication methods. Fig. 54 shows examples of FPDs made using each of these processes and Fig. 55 displays views of (a) the profile projections for checking marginal fit of the molar and pre-molar.

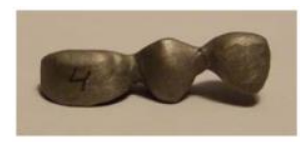

(a) Lost wax

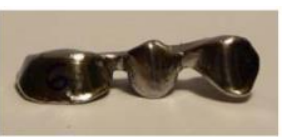

(b) Milling

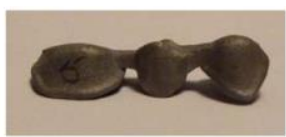

(c) Sintering
Fig. 54 (a) Co-Cr fixed partial denture made using the lost wax technique, (b) milling and (c) selective laser sintering [70].

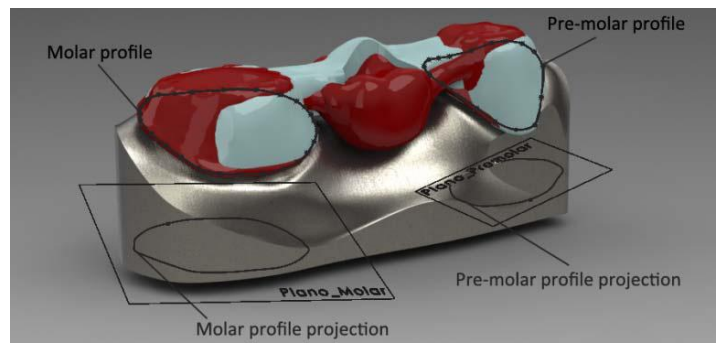

Fig. 55 Views of (a) the profile projections for checking marginal fit of the molar and pre-molar [70].

The geometrical deviations between the original digital model and the digital models of the manufactured FPD samples are reported in Table7, indicating that the samples with the largest discrepancies are the lost-wax FPDs, followed by the sintered FPDs and that the milled FPDs have the closest fit.

Table 7 Size deviations, $\mathrm{mm}^{2}$, between original and digital models of the samples [70].

\begin{tabular}{ccccc}
\hline & \multicolumn{2}{c}{ Molar } & \multicolumn{2}{c}{ Pre-molar } \\
\hline & $\begin{array}{c}\text { Positive } \\
\text { area }\end{array}$ & $\begin{array}{c}\text { Negative } \\
\text { area }\end{array}$ & $\begin{array}{c}\text { Positive } \\
\text { area }\end{array}$ & $\begin{array}{c}\text { Negative } \\
\text { area }\end{array}$ \\
\hline Lost wax_1 & 4.01 & -4.57 & 2.32 & -2.50 \\
Lost wax_2 & 1.18 & -6.71 & 0.52 & -2.74 \\
Milled_1 & 2.10 & -3.94 & 1.07 & -1.30 \\
Milled_2 & 2.70 & -3.89 & 1.38 & -1.78 \\
Sintered_1 & 3.30 & -4.07 & 0.97 & -2.27 \\
Sintered_2 & 1.90 & -4.07 & 1.45 & -1.51 \\
\hline
\end{tabular}

\subsection{Mechanical performance}

A large number of studies have examined the impact of fabrication procedures on the mechanical performance of ceramics (e.g. Alumina, Zirconia based ceramics) for restorative dentistry applications $[4,48,66,75]$. Since the majority of the research focuses on assessing the impact of machining induced damage produced by grinding (i.e. not cutting) [100, 130, 162, $180]$, it is therefore not reported in the present keynote paper.

In the following a couple of examples are presented to illustrate the impact of machining (milling) on the mechanical performance of dental implant restorations.

Cho et al. [38] investigated the fracture strength under vertical and oblique loading of five different abutment-crown combinations (Fig. 56) for single implant-supported restorations, using milled ceramic abutments and all-ceramic crowns. The specimens were loaded at $0^{\circ}$ and $45^{\circ}$ angles (Fig. 57) to the long axis and the load values at the moment of failure were recorded using a universal testing machine. Their results indicated that the fracture strengths under vertical loading were higher than those obtained under oblique loading. The fracture strengths of metalceramic crowns cemented to the titanium abutments were greater than those of all-ceramic crowns cemented on the milled ceramic abutments, regardless of loading direction. Further, no differences in the fracture strengths of the ceramic crowns between the two different abutment types under oblique loading were observed.



Fig 56 Fracture strength measurement at oblique loading [38].
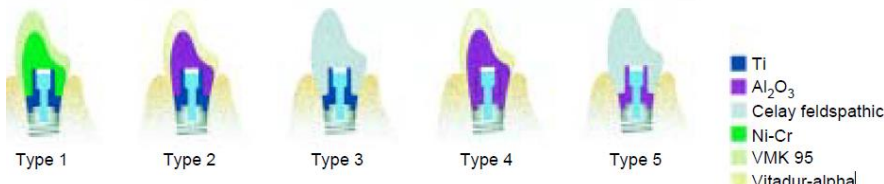

Fig. 57 Design of tested implant restorations (1) metal-ceramic crowns cemented to titanium abutments, (2) In-Ceram crowns cemented to titanium abutments, (3) Celay feldspathic crowns cemented to titanium abutments, (4) In-Ceram crowns cemented to milled ceramic abutments and (5) Celay feldspathic crowns cemented to milled ceramic abutments [38]

Table 8 Fracture Strength (N) of Implant-Supported Restorations (*Standard deviations are in parentheses).

\begin{tabular}{ccc}
\hline Group & Vertical loading & Oblique loading \\
\hline 1 & $1812(312)$ & $333(36)$ \\
2 & $1269(232)$ & $298(35)$ \\
3 & $1628(419)$ & $231(117)$ \\
4 & $858(91)$ & $182(55)$ \\
5 & $786(236)$ & $170(46)$ \\
\hline
\end{tabular}

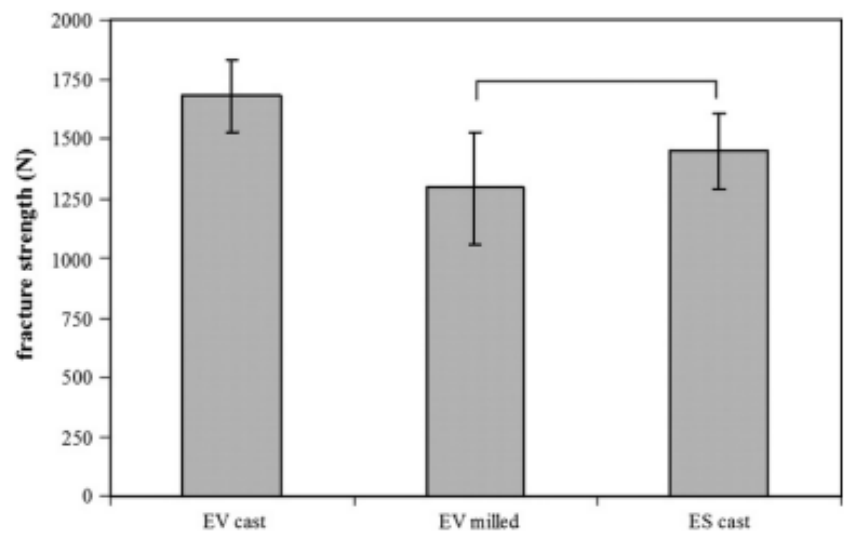

Fig. 58 Mean values and standard deviations of fracture strength. Groups connected with horizontal line did not differ statistically. EV, Esteticor Vision; ES, Esteticor Special [96].

Kellerhoff and Fischer [96] evaluated the fracture strength and thermal shock resistance of metal-ceramic crowns with AuTi frameworks (i.e. Au-1.7Ti-0.1Ir by wt \% - Esteticor Vision) produced either by milling and casting; a high-gold alloy (Esteticor 
Special) was used as a reference. The authors reported that the fracture strength of crowns with milled AuTi frameworks is lower than that obtained with cast AuTi frameworks, but similar to those crowns produced with a reference high-gold alloy (Fig. 58). In the thermal shock resistance test, crowns with milled AuTi frameworks displayed significantly higher thermal shock resistance compared to the other groups (Fig. 59). However, no correlation between fracture strength and thermal shock resistance of metal-ceramic crowns could be established.

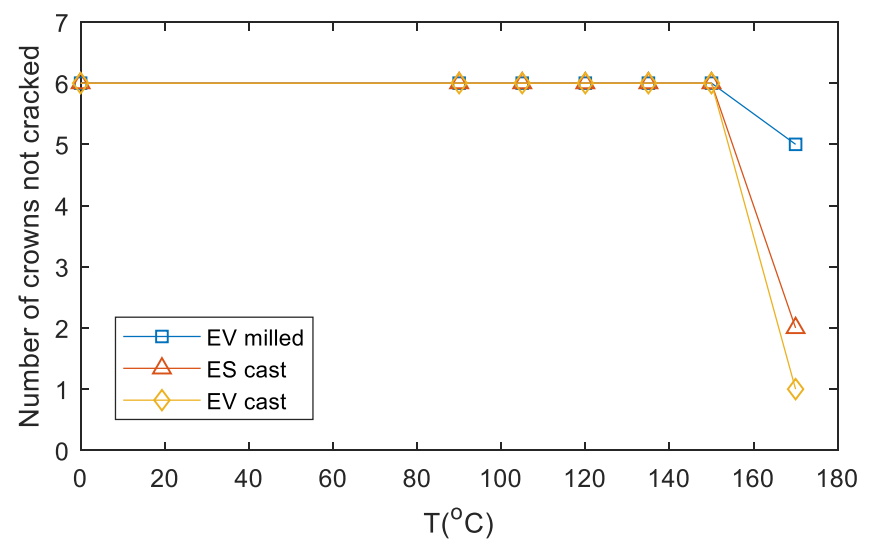

Fig. 59. Thermal shock test survival plot. EV, Esteticor Vision; ES, Esteticor Special [96].

\subsection{Corrosion resistance and tribocorrosion performance.}

Biocompatibility testing consists usually of three main parts, namely the in vitro testing, the in vivo evaluation of local tissue reactions and the in vivo study of systemic effects [51]. In vitro corrosion resistance evaluation is an important part of biocompatibility evaluation of metallic biomaterials [30] and a commonly used method is potentiostatic anodic polarization (PAP) which was first introduced in biomaterials research by Hoar and Mears [Hoa66]. Chen et al. [Che98] investigated the corrosion resistance and ion dissolution of commercially pure titanium with different surface microroughness. Commercial implant (machined) surfaces were produced by milling, while the other four surfaces were prepared by grinding (emery paper), electropolishing and sandblasting to produce different condition of rough surfaces, i.e. macrorough vs microrough surfaces. Comparing with macrorough surface and machining surface, microrough surfaces resulted in better corrosion resistance and a lower titanium ion release rate which were found similar to those of smooth surfaces (Fig. 60).

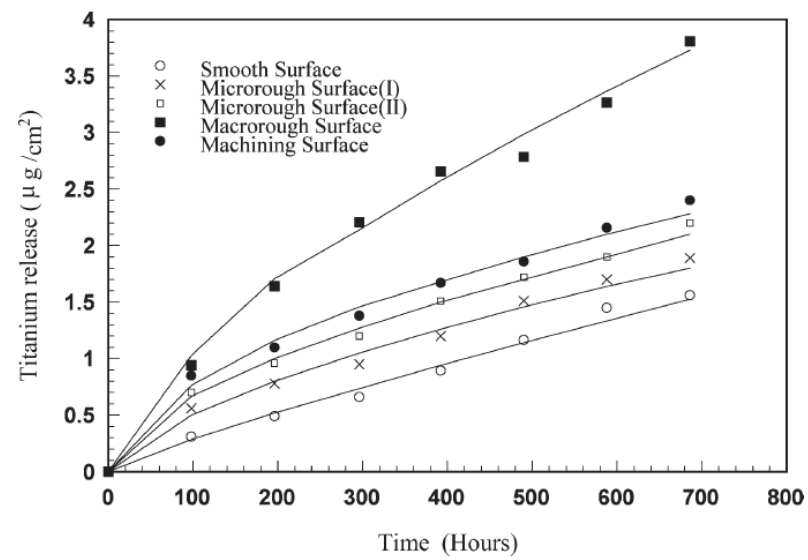

Fig. 60 Titanium ion release amount versus immersion time curves of naturally oxidized titanium samples with different surface roughness [30].
Bruschi and co-workers reported in several investigations on the impact of machining parameters and cooling strategies on the wear behaviour [23, 24] and tribocorrosion performance [16, 17] of wrought and additive manufactured Ti6Al4V alloys for biomedical applications. Wear tests were performed using a cylinder-on-plate configuration in a wet and temperaturecontrolled saline environment (Fig. 61) in order to mimic the reciprocating sliding wear behaviour under human body conditions. Their results indicated that the use of cryogenic cooling during machining significantly affected the Ti6Al4V surface properties improving its wear performances, in terms of lower friction coefficient (Fig. 62) and less release of metal debris due to abrasive wear compared to dry cutting conditions, regardless the alloy as-delivered condition [23].

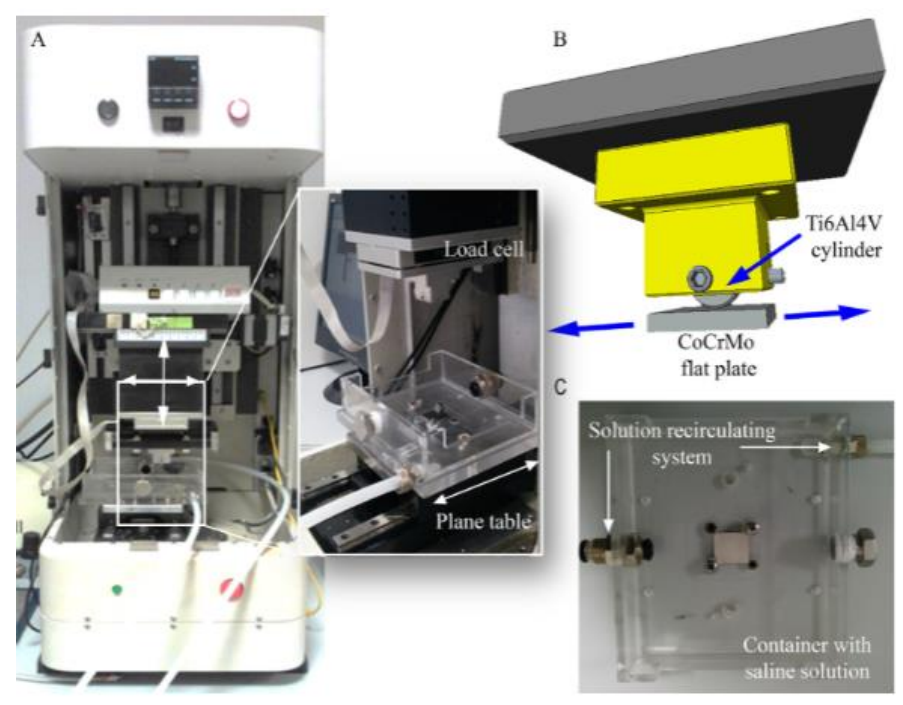

Fig. 61 Reciprocating sliding wear test set-up used in [23]

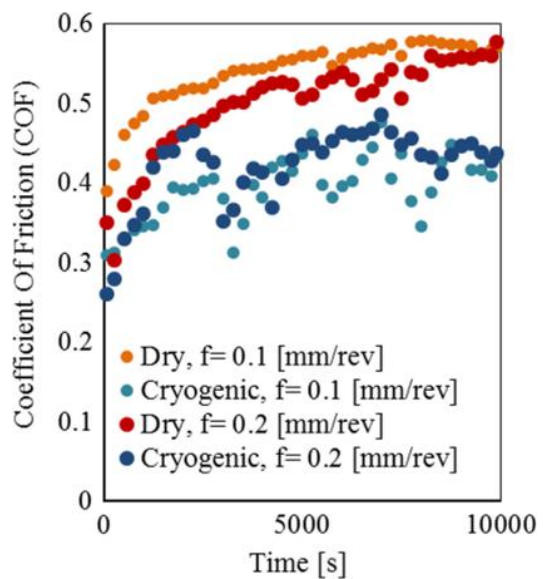

Fig. 62 Influence of feed rate and cooling strategy on friction coefficient in the case of the EBM Ti64 cylinders machined at vc=50m/min. [23]

In a subsequent investigation based on a similar testing approach, Bruschi et al. [23], showed that by coupling machining and heat treatment a synergistic effect can be achieved to improve the wear resistance of Electron Beam Melted (EBM) Ti6Al4V. Further development of the method to conduct wear testing under more realistic contact and sliding conditions between a Ti6Al4V acetabular cup and a CoCr femoral head was reported in [24] highlighting again the beneficial impact of cryogenic machining of Ti6Al4V on wear performance.

Bertolini et al. [16] reported on the effect of the cutting parameters and cooling strategies on the fretting corrosion behaviour of the EBM Ti6Al4V alloy under conditions replicating 
the taper interfaces of a modular hip junction. They indicated that cryogenic machining was the most effective cutting strategy that could enhance the mechanical, chemical, and tribological behaviour of the machined surfaces. Such was also demonstrated by the authors in [17] when investigating the dental tribocorrosion behaviour of wrought and additive manufactured Ti6Al4V specimen produced by cryogenic machining and further subjected to reciprocated sliding against $\mathrm{ZrO}_{2}$ plates in artificial saliva to mimic human mouth condition.

Several investigators have reported on the impact of machining parameters on the surface integrity, mechanical behaviour and corrosion performance of magnesium-calcium biodegradable alloys for biomedical applications [154,192].
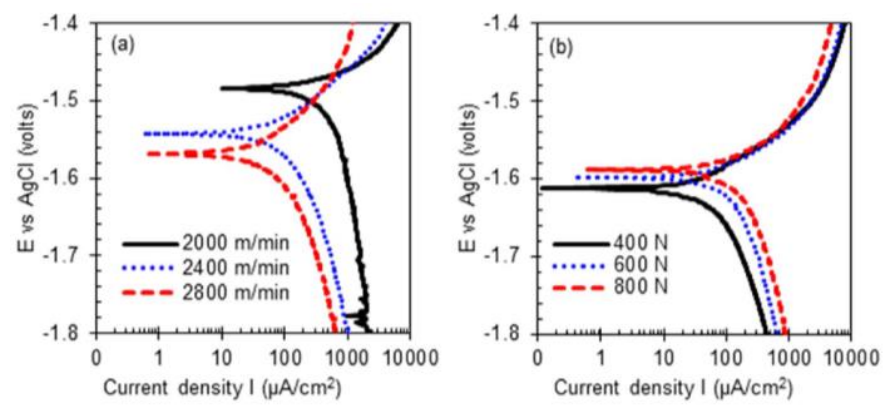

Fig. 63 Potentiodynamic polarization curves: (a) effect of cutting speed; (b) effect of rolling force. [154]

Denkena and Lucas [47] compared the corrosion resistance of machined vs deep rolled magnesium-calcium alloy in saline solution environment. Their results showed that the deep rolling process reduced the corrosion rate by a factor of approx. 100 when compared to turning. This was attributed to the high residual compressive stresses generated in the subsurface along with the ability for the deep rolling process to seals micro cracks and pores in the surface thus preventing the corrosion medium from penetrating and bursting the surface and subsurface. A recent study by Salashoor et al. [154] also confirms that a combination of dry cutting-finish burnishing of magnesium-calcium biodegradable alloy $\mathrm{MgCa} 0.8$ (w\%) can significantly improve surface integrity and corrosion performance (Fig. 63 and 64).
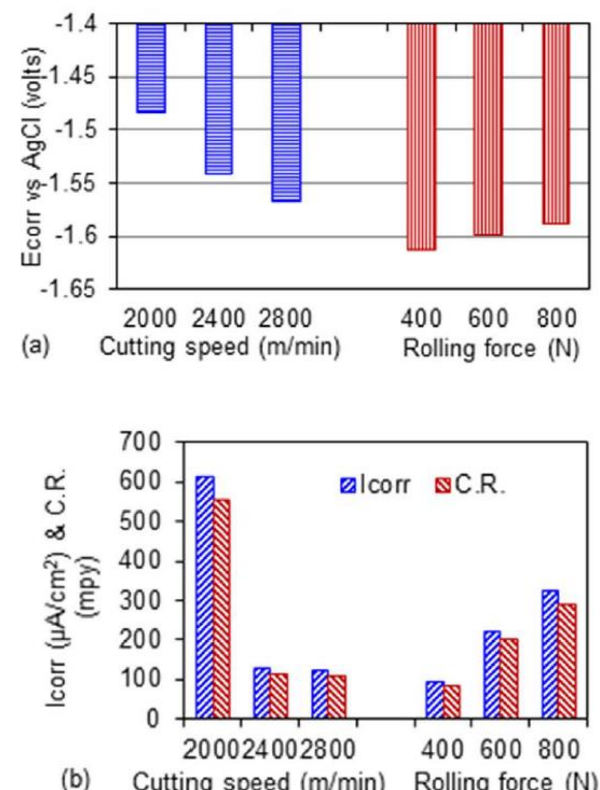

Fig. 64 Effects of cutting speed and rolling force on (a) ECorr and ICorr; (b) corrosion rate

\section{Machine tools, process monitoring, specialist end-effectors}

\section{and cutting tool manipulators}

Although conventional machine tools and cutting process are unusually employed for biocompatible materials machining, there is a set of specialist tooling/end-effectors/manipulators that support the cutting process of these materials to reach the special medical requirements. This chapter reveals the specifics of the hardware for this set of niche applications.

\subsection{Machine tools and process monitoring}

Generally, medical parts have complex shapes as they need to comply with the specifics of individual patients. Tailor-made medical care is an effective way to improve the patient's quality of life (QOL), but this comes with challenges to comply with short delivery times and low manufacturing costs to enable affordability. In this respect, most manufacturers prefer the use of multitask machine tools that cover a wide range of operations, e.g. milling, turning and deburring (Fig. 65) which enables the production of a finished product with one chucking (see implant examples - Fig. 66). For example, although intramedullary rod, that supports the screws and bones (Fig. 66c), are hollow structures of high aspect ratios which include many oblique side holes to insert screws, it is possible to finish them with multitasking machine tools (Fig. 67).

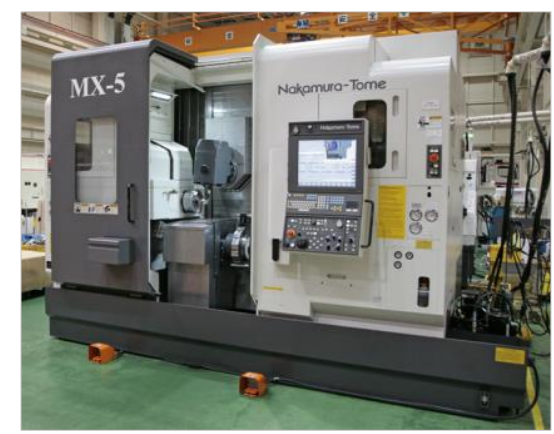

Fig. 65. Multi-tasking machine tools based on turning center (Source: Nakamura-Tome Precision Industry Co., Ltd.)

As some implants have high aspects ratios, e.g. intramedullary rod - Fig. 66(c), techniques to include additional supports to limit machining vibrations are often employed (Fig. 67b).

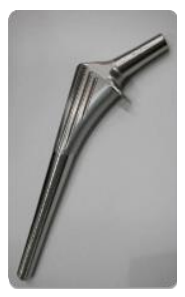

(a) Hip joint

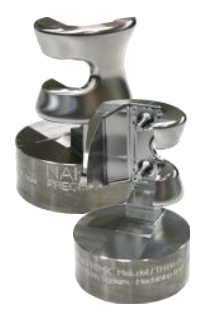

(b) Knee joint

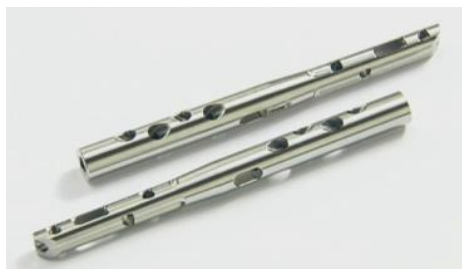

(c) Intramedullary rod
Fig. 66. Examples of components for femoral implants (Source: NakamuraTome Precision Industry Co., Ltd.)

When the target is a medical application, controlling the temperature during the clinic surgery is an important issue and high cutting temperature would lead to tissue damage (necrosis in bone surgery) [55, 105]. Shin et al. used a radiation thermometer to measure the temperature of the workpiece and the cutting chips [166]. Sugita et al. embedded a thermocouple in the workpiece, measured the temperature rise, and estimated the temperature inside the bone [177]. The temperature of the workpiece during bone machining was found to range from room temperature to 
about $80^{\circ} \mathrm{C}$. Hence, further research is needed to ensure that the cutting temperature stay at low value to reduce the thermal damage of tissues.

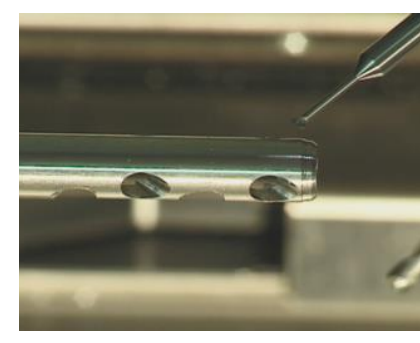

(a) Deburring of inner hole

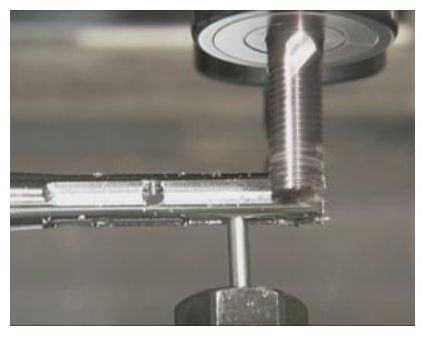

(b) Tension support
Fig. 67. Features of multi-tasking machine tool (Source: Nakamura-Tome Precision Industry Co., Ltd.)

One the other hand, due to the special structure of bone during the orthopedic surgery process it is necessary to know cutting area of the bone in real time, especially when the cutting tool breakthrough the cortical bone, thus to reduce the damages of the surrounding tissues. However, it is difficult to estimate the cutting position/penetration of the bone and currently this is mainly controlled based on the surgeons' experience. There are some researches that proposed the monitoring process based on the cutting force $[103,116]$; however, this can only predict the cutting breakthrough of the cortical bone (Fig. 68a). Liao and Axinte [107] also proposed a novel methodology by detecting the acoustic emission signal generated in the bone structure during the cutting process to estimate the cutting position in the bone (Fig. 68b) and avoid sudden tool exist which could cause the bone damages.

(a)
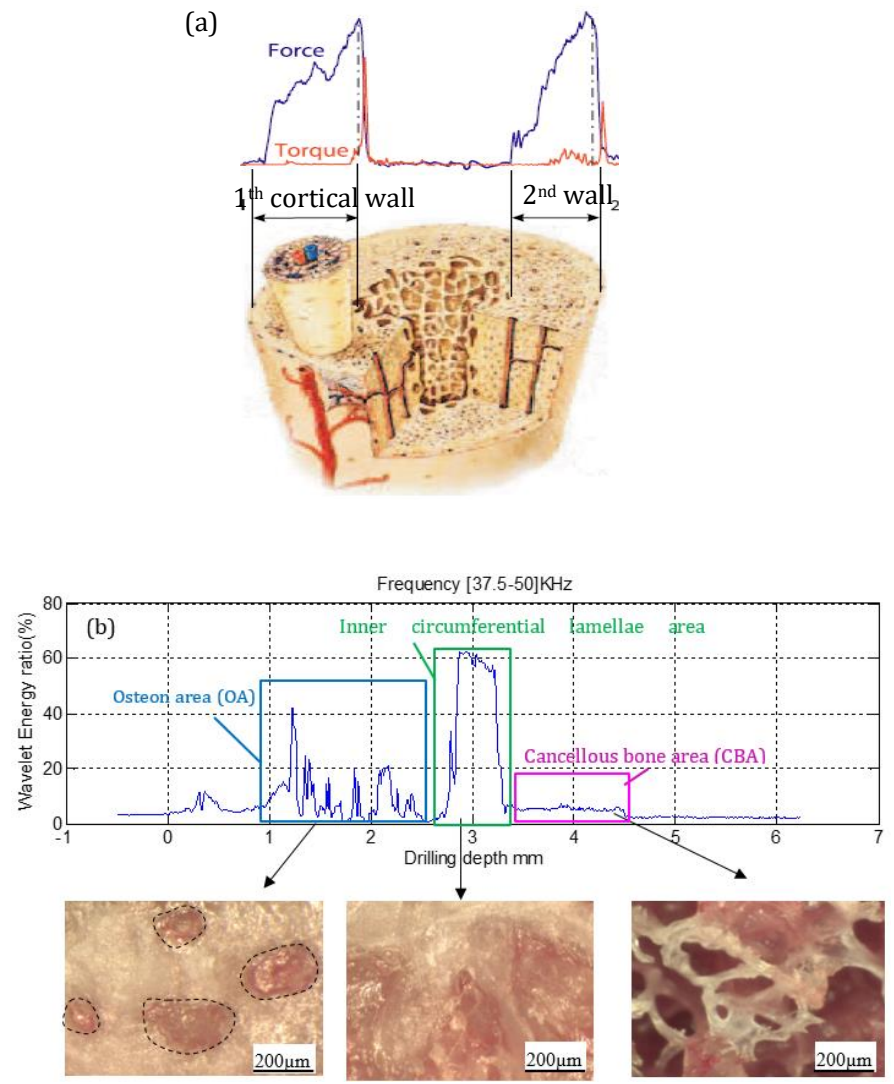

Fig. 68 (a) Cutting force signal and (b) acoustic emission signal for detecting the cutting position of bone $[107,116]$.
6.2. Specialist end effectors and multi axis robotic cutting system surgical assisted system

In recent years, end effectors and manipulators that support the surgery have become widespread all over the world. The target applications are roughly divided into cutting soft tissues such as skin and internal organs and cutting hard tissues such as bones. One of the representative devices is the da Vinci ${ }^{\circledR}$ Surgical System from Intuitive Surgical, Inc. da Vinci® was launched in 1999 (Fig. 69a). Excellent results have been shown using this surgically assisted system at clinical sites $[69,80,123]$. Gradually, application fields have been extended to urology, obstetrics and gynaecology, and the general surgical field.

In orthopaedic surgery, robot-assisted systems are developed to assist in surgical procedures like hip and knee replacement, spine surgery, and reconstruction of ligaments. Robot-assisted surgery also provides surgical navigation for intraoperative measurement and improve accuracy to bone cutting. Robots also enable minimally-invasive surgical approaches through smaller incisions.

ROBODOC [95] was the first system developed for knee and hip replacement. It utilized a CT scan to generate a preoperative cutting tool path to automatically mill the bone cavity for implants. The successor to the Robodoc ${ }^{\circledR}$ System, TSolution One $\AA$ Surgical System from THINK Surgical (Fig. 69b), has been used in bone resection for hip joint replacement surgery $[97,182,133]$.
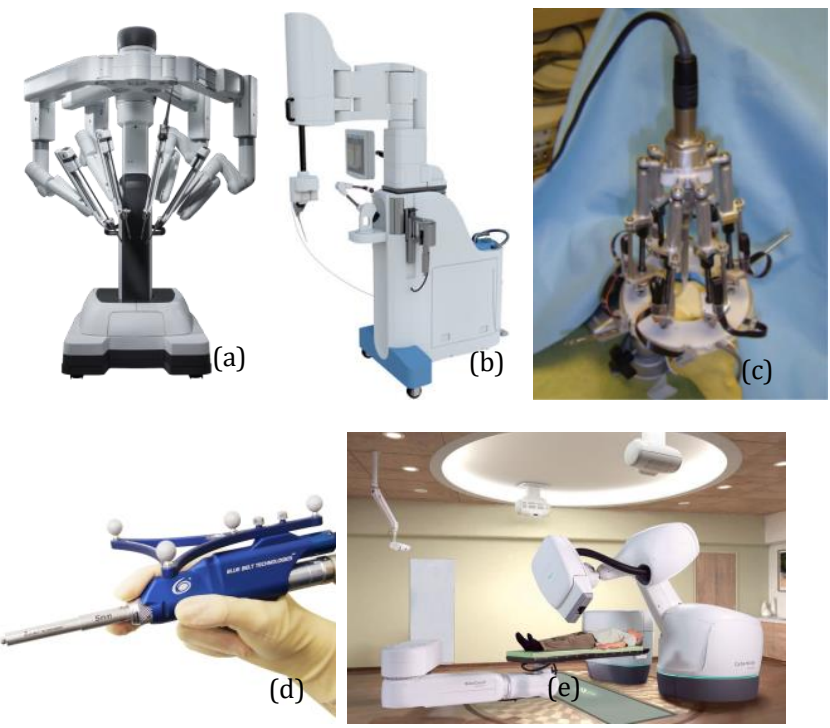

Fig. 69. (a) Vinci® Surgical System (b) TSolution One® Surgical System, (c) Miniature bone-attached robotic system (MBARS), (d) NAVIO (e) CyberKnife system

A similar commercial system, Computer Assisted Surgical Planning and Robotics (CASPAR) was developed by Maquet, which was also based on preoperative path planning [168]. Alternatively, the Acrobot System introduced a semi-active mode, in which computer control was used to keep the milling tool within certain cutting region for creating a cavity to accommodate the implant while the tool was deigned to move only in response to the surgeon's input [86]. These three systems used modified industrial robots with serial manipulators and large workspace.

Also, user-guided intraoperative tool trajectory planning and execution for drilling and milling procedures were possible using multi-planar $\mathrm{x}$-Ray images. Based on this concept, several compact, bone-attached mini surgical robotic systems, coupled with a commercially-available navigation system for trajectory planning, such as MBARS (Fig. 69c) [202], Praxiteles [146], and HyBAR [170], have been developed. These systems seek for the optimal miniaturisation that maintained the structural strength for high 
speed bone removal during milling during minimally invasive joint replacement surgery.

Another surgical system for orthopaedic applications is the Mako® Robotic-Arm Assisted Technology from MAKO Surgical Corp $[143,144]$ which could decrease the tremor of the hands. It is also equipped with a navigation function by a preoperative plan. The NAVIO device from Smith Nephew accurately removes bone identified by the surgeon according to the patient-specific plan (Fig. 7d) [Lonner 14]. NAVIO is a small device and can be easily set up for both partial and total knee replacement procedures.

CyberKnife ${ }^{\circledR}$ was developed as a system to support the treatment of tumours with gamma rays with no invasion (Fig. 69e) [98]. This system uses a robot arm to determine the position and posture to irradiate gamma rays based on a CT image. In order to minimize damage to other organs during positioning, CyberKnife $₫$ automatically follows and corrects the irradiation point if the patient moves during treatment [62].

Current robotic systems seem not to have a function for automation. If possible, the load and fatigue of the surgeon may be alleviated, and the difficulty of the surgery may be decreased.

\section{Conclusions and future challenges}

The ever-evolving demands of medical surgeries require that cutting technology keeps a brisk pace of research and engineering development. However, due to the material particularities and special requirement of implants and tissues involved in surgery, the machining of these material is challenging. This paper presents the state-of-art of the machining process of the representative biocompatible materials including both the artificial materials and living tissues. The particularities of materials properties and biomedical applications lead to special cutting mechanism, surface response, machining facilities and tooling.

Based on the analysis of the recent scientific and engineering advances in the field, the following future challenges, which could materialise in research opportunities, have been identified.

- Challenges driven by the variety and specifics of the workpiece materials

Although some materials could be similar to other fields, the surface requirement in biomedical applications could be very different from the general engineering applications, e.g. aerospace and automotive industries. Many studies have been carried out to investigate surface integrity of machined metallic biomaterials, but there has been limited research on how to machine functional surfaces tailored to specific biomedical applications. For example, a rough surface is detrimental for fatigue life of an aerospace component, but a rough surface would be better for bone ingrowth in orthopaedic implants. More collaborations between manufacturing and biomedical communities are needed for tailoring an engineered surface to meet the specific requirements of biomedical applications.

Additive manufacturing (AM) technologies are getting more attentions in biomedical applications as it enables patientcustomised implants of complex geometries, e.g., porous scaffolds. However, surface integrity and geometric accuracy of as 3D printed parts may not meet directly some functional requirements; hence, follow-up machining is often needed. Since the properties of workpiece material/surface resulting from AM processes are different from those of traditional bulk properties, more research effort is needed to investigate the material removal mechanisms and surface integrity in machining of as printed parts to meet the requirements for biological implants.

- Challenges driven by the interactions between workpiece materials and cutting tools
The future cutting tools for machining Ti-based alloys is aligned with use of the layer physical vapor deposition (PVD) and chemical vapor deposition (CVD) coatings which are able to withstand the high tool temperature and associated chemical reaction and diffusion tool wear. The research in advanced tool geometry, materials, and coating for cutting of CoCr, Mg alloys, and NiTi SMA biocompatible materials is very limited and it seems that no clear scientific and engineering guidance exist on this topic; hence, the opportunity for the machining research community to fill in the gaps. Nevertheless, with the development of new materials for biological implants, new challenges for machining research will arise to comply with the ever-higher regulated surface quality and surface integrity requirements.

For cutting soft tissues, the tool geometry and cutting edge sharpness and wear are key research opportunities. The motion of the cutting edge and its interaction with the soft, easy-to-deform, inhomogeneous and anisotropic tissue are complex and require more in-depth investigation. The vibration of cutting tool may help to reduce to cutting force and tissue deformation, but may generate friction and increase of tissue temperature.

On the other hand, the understanding of cutting of living tissues is still unclear. The current research of both soft and hard tissues focuses on the in vitro study but lack of in vivo study which leads to inability to reveal the real mechanisms occurring during the surgery. In vivo study of the tissue cutting mechanism and their effect of the surgery will be needed. This will further trigger the development of cutting tools that minimise the collateral damages of the living tissues, thus enabling faster patient recovery.

- Challenges driven by functional requirements of the machined surfaces in biomedical materials

While some researches have been carried out in the field to evaluate the functionality (e.g. fatigue performance) of the machined implants, on which conventional testing/analysis procedures can be employed, there is very little information on how different cutting methods of the hard tissues (e.g. bones) affects the recovery of the patient. This would require in vivo test of tissues machining followed by clinical studies, case in which needs compliance with appropriate legislated and ethic procedures.

- Challenges driven by tooling and end-effectors manipulators

While machine tools for machining biological implants are likely to follow the same trends for other applications, in contrast, the automated/robotic surgery to enable multi-axis manipulation of the cutting tools for both soft and hard living tissues is a very hot topic of research. To this end, it is important that the advantages of using such systems outweigh the drawbacks. For example, the disadvantages include fewer types of surgical tools, training time, initial investment, maintenance expenses, delay in operation, setup time. On the other hand, the advantages include outputs superior to surgeons, operability of surgical tools, minimally invasive, early recovery. Additionally, robotic surgery could allow easy collection of key data (tool trajectory, forces) for later use on tool development, cutting process understanding and further for machine learning. Nevertheless, on more conventional approaches, there is a vast domain of opportunities to develop ancillary tooling to assist the surgeons with precise positioning of the cutting tools.

\section{Acknowledgements:}

The authors would like to thank Dr. Ziye Liu from University of Alabama, Dr. Lei Chen from University of Michigan, and Dr. Kizaki Toru from University of Tokyo for their valuable contribution to this paper. 


\section{References}

[1] Abellán-Nebot JV, Siller HR, Vila C, Rodríguez CA (2012) An experimental study of process variables in turning operations of Ti-6Al-4V and $\mathrm{Cr}-\mathrm{Co}$ spherical prostheses. The International Journal of Advanced Manufacturing Technology 63(9-12):887-902

[2] Ahmed W, Jackson MJ, (Eds.) (2016) Surgical tools and medical devices, Berlin: Springer.

[3] Alam K, Mitrofanov AV, Silberschmidt VV (2010) Thermal analysis of orthogonal cutting of cortical bone using finite element simulations. International Journal of Experimental and Computational Biomechanics 1(3):236-251.

[4] Alao AR, Ying L (2016) Assessment of elasticity, plasticity and resistance to machining-induced damage of porous pre-sintered zirconia using nanoindentation techniques. Journal of Materials Science \& Technology 32: 402-410.

[5] Aldwell B, Hanley R, O'Donnell GE (2014) Characterising the machining of biomedical grade polymers. Proceedings of the Institution of Mechanical Engineers Part B: Journal of Engineering Manufacture 228(10):1237-1251.

[6] Aldwell B, O'Mahony J, O'Donnell GE (2015) The effect of workpiece cooling on the machining of biomedical grade polymers. Procedia CIRP 33:305-310.

[7] Altan M, Altan E (2014) Investigation of burr formation and surface roughness in drilling engineering plastics. Journal of the Brazilian Society of Mechanical Sciences and Engineering, 36(2):347-354.

[8] Andri, What Makes Titanium Dental Implants Consumption Market Research Report as an Interesting One. https://tokenexa.com/titanium-dentalimplants-consumption-market-global-research-insight-2018-2023-majorplayersstraumann-danaher-dentsply-and-more/33923/ (Accessed 20 Oct. 2018)

[9] Arrizubieta JI, Lamikiz A, Cortina M, Ukar E, et al (2018) Hardness, grainsize and porosity formation prediction on the Laser Metal Deposition of AISI 304 stainless steel. International Journal of Machine Tools and Manufacture 135 53-64.

[10] Attar H, Ehtemam-Haghighi S, Kent D, Dargusch MS (2018) Recent developments and opportunities in additive manufacturing of titanium-based matrix composites: A review. International Journal of Machine Tools and Manufacture 133: 85-102.

[11] Aykut Ş, Bagci E, Kentli A, Yazıcıoğlu O (2007) Experimental observation of tool wear, cutting forces and chip morphology in face milling of cobalt based superalloy with physical vapour deposition coated and uncoated tool. Materials \& design 28(6):1880-1888.

[12] Azmi AI (2013) Chip formation studies in machining fibre reinforced polymer composites. International Journal of Materials and Product Technology 46(1):32-46.

[13] Ballo AM, Akca EA, Ozen T, Lassila L, et al (2009) Bone tissue responses to glass fiber-reinforced composite implants-a histomorphometric study. Clinical oral implants research 20(6):608-615.

[14] Barry J, Byrne G, Lennon D (2001) Observations on chip formation and acoustic emission in machining Ti-6Al-4V alloy. International Journal of Machine Tools and Manufacture 41(7):1055-1070.

[15] Beaucamp A, Simon P, Charlton P, King C, et al (2017). Brittle-ductile transition in shape adaptive grinding (SAG) of $\mathrm{SiC}$ aspheric optics. International Journal of Machine Tools and Manufacture 115: 29-37.

[16] Bertolini R, Bruschi S, Bordin A, Ghiotti A, et al (2016), Fretting corrosion behavior of additive manufactured and cryogenic-machined Ti6Al4V for biomedical applications, Adv. Eng. Mater 19(6): 1-9.

[17] Bertolini R, Bruschi S, Ghiotti A, Pezzato L, et al (2017) Influence of the machining cooling strategies on the dental tribocorrosion behaviour of wrought and additive manufactured Ti6Al4V, Biotribology 11: 60-68.

[18] Bidra AS, Taylor TD, Agar JR (2013) Computer-aided technology for fabricating complete dentures: Systematic review of historical background, current status, and future perspectives. The Journal of prosthetic dentistry 109(6):361-366.

[19] Black J, Hastings G (Eds.) (2013) Handbook of biomaterial properties. Springer Science \& Business Media.

[20] Bonnet C, Valiorgue F, Rech J, Claudin C, et al (2008) Identification of a friction model-Application to the context of dry cutting of an AISI 316L austenitic stainless steel with a TiN coated carbide tool. International Journal of Machine Tools and Manufacture 48(11):1211-1223.

[21] Boyer, RR (1985) Titanium and titanium alloys. ASM International: ASM Handbook. 9: 458-475.

[22] Brunori A, Bruni P, Greco R, Giuffré R, et al (1995) Celebrating the centennial (1894-1994): Leonardo Gigli and his wire saw. Journal of Neurosurgery 82(6):1086-1090.

[23] Bruschi S, Bertolini R, Bordin A, Medea F, et al. (2016) Influence of the machining parameters and cooling strategies on the wear behaviour of wrought an additive manufactured Ti6Al4V for biomedical applications, Tribology International 102: 133-142.

[24] Bruschi S, Bertolini R, Medeossi F, Ghiotti A, et al (2018) Case study: The application of machining-conditioning to improve the wear resistance of Ti6Al4V surfaces for human hip implants, Wear 394-395: 134-142.

[25] Butler-Smith PW, Axinte DA, Daine M, Kennedy AR, et al (2015) A study of an improved cutting mechanism of composite materials using novel design of diamond micro-core drills. International Journal of Machine Tools and Manufacture 88: 175-183.
[26] Carr JW, Feger C (1993) Ultraprecision machining of polymers. Precision Engineering 15(4):221-237.

[27] CeramTec GmbH, (2010). Increased Fracture Strength and Excellent Wear Properties BIOLOX® delta

[28] Chandrabose, R (2016) K-wiring: Principles and techniques. New York, USA: Thieme Medical Publishers.

[29] Chanthasopeephan T, Desai JP, Lau ACW (2007) Modeling Soft-Tissue Deformation Prior to Cutting for Surgical Simulation: Finite Element Analysis and Study of Cutting Parameters. IEEE Transactions on Biomedical Engineering 54(3):349-359.

[30] Chen G, Wen X, Zhang N (1998) Corrosion resistance and ion dissolution of titanium with different surface microroughness, Bio-Medical Materials and Engineering 8: 61-74.

[31] Chen L, El-Wardany T, Harris W (2004) Modelling the effects of flank wear land and chip formation on residual stresses. CIRP Annals-Manufacturing Technology 53(1):95-98.

[32] Chen Y, Li Y, Kurosu S, Yamanaka K, et al (2014) Effects of sigma phase and carbide on the wear behavior of CoCrMo alloys in Hanks' solution. Wear 310(12):51-62.

[33] Chen Y, Xu Z, Smith C, Sankar J (2014) Recent advances on the development of magnesium alloys for biodegradable implants. Acta Biomaterialia 10(11):4561-4573.

[34] Cheung CF, Ho LT, Charlton P, Kong LB, et al (2010) Analysis of surface generation in the ultraprecision polishing of freeform surfaces. Proceedings of the Institution of Mechanical Engineers Part B: Journal of Engineering Manufacture 224(1):59-73

[35] Chevalier J, Gremillard L, Virkar AV, Clarke DR (2009) The TetragonalMonoclinic Transformation in Zirconia: Lessons Learned and Future Trends. Journal of the American Ceramic Society 92(9):1901-1920.

[36] Childs THC, Arola D (2011) Machining of cortical bone: Simulations of chip formation mechanics using metal machining models. Machining Science and Technology 15(2):206-230.

[37] Chng CB, Lau DP, Choo JQ, Chui CK (2012) A bioabsorbable microclip for laryngeal microsurgery: Design and evaluation. Acta Biomaterialia 8(7):28352844

[38] Cho HW, Dong JK, Jin TH, Oh SC, et al (2002). A study on the fracture strength of implant-supported restorations using milled ceramic abutments and allceramic crowns. International Journal of Prosthodontics 15(1). 15:9-13

[39] Cubillos PO, Dos Santos VO, Pizzolatti ALA, Da Rosa E, et al (2018) Evaluation of surface finish and dimensional control of tribological metal-ultra high molecular weight polyethylene pair of commercially available hip implants. The Journal of Arthroplasty 33(3):939-944.

[40] Dandekar CR, Shin YC (2012) Modeling of machining of composite materials: a review. International Journal of Machine tools and manufacture 57:102-121.

[41] Danish M, Ginta TL, Habib K, Carou D (2017) Thermal analysis during turning of AZ31 magnesium alloy under dry and cryogenic conditions. The International Journal of Advanced Manufacturing Technology 91(5-8):28552868.

[42] Dargusch MS, Sun S, Kim JW, Li T, et al (2018) Effect of tool wear evolution on chip formation during dry machining of Ti-6Al-4V alloy. International Journal of Machine Tools and Manufacture 126: 13-17.

[43] Davim, JP (Ed.) (2013). Machining composites materials. John Wiley \& Sons.

[44] Denkena B, Biermann D (2014) Cutting edge geometries. CIRP Annals 63(2):631-53

[45] Denkena B, Köhler J, Turger A (2011) Modeling the Polishing Process with Resilient Diamond Tools for Manufacturing of Complex Shaped Ceramic Implants, in: Conference of the American Society of Precision Engineering (ASPE), Denver, USA, pp. 1-4.

[46] Denkena B, Köhler J, van der Meer, M (2013) A roughness model for the machining of biomedical ceramics by toric grinding pins. CIRP Journal of Manufacturing Science and Technology 6(1):22-33.

[47] Denkena B, Lucas A (2007) Biocompatible Magnesium Alloys as Absorbable Implant Materials - Adjusted Surface and Subsurface Properties by Machining Processes. CIRP Annals 56(1):113-116.

[48] Denry I (2013) How and when does fabrication damage adversely affect the clinical performance of ceramic restorations. Dental materials 29: 85-96.

[49] Diaz OG, Axinte DA (2017) Towards understanding the cutting and fracture mechanism in ceramic matrix composites. International Journal of Machine Tools and Manufacture 118: 12-25.

[50] Do T, Kwon P, Shin CS (2017) Process development toward full-density stainless steel parts with binder jetting printing. International Journal of Machine Tools and Manufacture 121: 50-60.

[51] Ducheyne P (1983) In vitro corrosion study of porous metal fibre coatings for bone ingrowth. Biomaterials 4:185-191.

[52] Duerig T, Pelton A, Stöckel D (1999) An overview of nitinol medical applications. Materials Science and Engineering: A 273:149-160.

[53] Erbel R, Di Mario C, Bartunek J, Bonnier J (2007) Temporary scaffolding of coronary arteries with bioabsorbable magnesium stents: a prospective, nonrandomised multicentre trial. The Lancet 369(9576):1869-1875.

[54] Ezugwu EO, Bonney J, Da Silva RB, Çakir O (2007) Surface integrity of finished turned Ti-6Al-4V alloy with PCD tools using conventional and high pressure coolant supplies. International Journal of Machine Tools and Manufacture 47(6):884-891.

[55] Feldmann A, Ganser P, Nolte L, Zysset P (2017) Orthogonal cutting of cortical bone: Temperature elevation and fracture toughness. International Journal of Machine Tools and Manufacture 118: 1-11. 
[56] Feng Z, Rho J, Han S, Ziv I (2000) Orientation and loading condition dependence of fracture toughness in cortical bone. Materials Science and Engineering: C 11(1):41-46.

[57] Foster LV (1990) Failed conventional bridge work from general dental practice: clinical aspects and treatment needs of 142 cases. British Dental Journal 168(5):199-201.

[58] Friedrich CR (2000) Near-cryogenic machining of polymethyl methacrylate for micromilling tool development. Materials and Manufacturing Processes 15(5):667-678.

[59] Fu R, Jia Z, Wang F, Jin Y, et al (2018) Drill-exit temperature characteristics in drilling of UD and MD CFRP composites based on infrared thermography. International Journal of Machine Tools and Manufacture 135:24-37.

[60] Gao D, Liao Z, Lv Z, Lu Y (2015) Multi-scale statistical signal processing of cutting force in cutting tool condition monitoring. The International Journal of Advanced Manufacturing Technology 80(9-12):1843-1853.

[61] Ge Z, Ding X (2018) Design of thermal error control system for high-speed motorized spindle based on thermal contraction of CFRP. International Journal of Machine Tools and Manufacture 125: 99-111.

[62] Gerszten PC, Ozhasoglu C, Burton SA, Vogel WJ, et al (2004) CyberKnife Frameless Stereotactic Radiosurgery for Spinal Lesions: Clinical Experience in 125 Cases. Neurosurgery 55(1):89-99.

[63] Giner E, Arango C, Vercher A, Fuenmayor FJ (2014) Numerical modelling of the mechanical behaviour of an osteon with microcracks. Journal of the mechanical behavior of biomedical materials 37:109-124.

[64] Giraud JY, Villemin S, Darmana R, Cahuzac JP, et al (1991) Bone cutting. Clinical Physics and Physiological Measurement 12(1):1-19.

[65] Gordon S, Hillery MT (2003) A review of the cutting of composite materials. Proceedings of the Institution of Mechanical Engineers Part L: Journal of Materials: Design and Applications 217(1):35-45.

[66] Guilardi LF, Pereira GKR, Gündel A, Rippe MP, et al (2017) Surface micromorphology, phase transformation, and mechanical reliability of ground and aged monolithic zirconia ceramic, Journal of the mechanical behavior of biomedical materials 65: 849-856.

[67] Guo Y, Klink A, Fu C, Snyder J (2013) Machinability and surface integrity of Nitinol shape memory alloy. CIRP Annals - Manufacturing Technology 62(1): 83-86.

[68] Guo YB, Salahshoor M (2010) Process mechanics and surface integrity by highspeed dry milling of biodegradable magnesium-calcium implant alloys. CIRP Annals - Manufacturing Technology 59(1):151-154.

[69] Guthart GS, Salisbury JK (2000) The Intuitive telesurgery system: overview and application. IEEE International Conference on Robotics and Automation. Symposia Proceedings, 1: 618-621.

[70] Gutiérrez Rubert SC, Meseguer Calas MD, Bellera Sosa J, Folguera Arbas F (2013) Analysis of variability in the manufacture of Cr-Co fixed partial dentures by geometric comparison. Procedia Engineering 63:481 - 488

[71] Hänzi AC, Metlar A, Schinhammer M, Aguib H, et al (2011) Biodegradable wound-closing devices for gastrointestinal interventions: Degradation performance of the magnesium tip. Materials Science and Engineering: C 31(5):1098-1103.

[72] Hartung PD, Kramer BM, von Turkovich BF (1982) Tool wear in titanium machining. CIRP Annals 31(1):75-80.

[73] Harzallah M, Pottier T, Gilblas R, Landon Y, et al (2018) A coupled in-situ measurement of temperature and kinematic fields in Ti-6Al-4V serrated chip formation at micro-scale. International Journal of Machine Tools and Manufacture 130: 20-35.

[74] Hering B, Helmecke P, Köhler J, Denkena B (2013) The influence of machining on residual stresses and corrosion behavior of MgLa2 osteosynthesis plates, Biomedical Engineering/Biomedizinische Technik 2013; 58 (Suppl. 1), 4058.

[75] Hjerppe J et al (2016) Surface roughness and the flexural and bend strength of zirconia after different surface treatments. The Journal of prosthetic dentistry. 116:577-583.

[76] Hoar TP, Mears DC (1966) Corrosion resistant alloys in chloride solutions: materials for surgical Implants, Proc. Roy. Soc. A294: 486-510.

[77] Houchuan Y, Zhitong C. and ZiTong Z (2015) Influence of cutting speed and tool wear on the surface integrity of the titanium alloy Ti-1023 during milling. The International Journal of Advanced Manufacturing Technology 78(5-8):11131126.

[78] Hu NS, Zhang LC (2004) Some observations in grinding unidirectional carbon fibre-reinforced plastics. Journal of materials processing technology 152(3):333-338.

[79] Hua J, Shivpuri R (2004) Prediction of chip morphology and segmentation during the machining of titanium alloys. Journal of Materials Processing Technology 150(1-2):124-133.

[80] Hubens G, Coveliers H, Balliu L, Ruppert M, et al (2003) A performance study comparing manual and robotically assisted laparoscopic surgery using the da Vinci system. Surgical Endoscopy and Other Interventional Techniques 17(10):1595-1599.

[81] Hughes JI, Sharman A.R.C, Ridgway K (2006) The Effect of Cutting Too Material and Edge Geometry on Tool Life and Workpiece Surface Integrity. Proceedings of the Institution of Mechanical Engineers Part B: Journal of Engineering Manufacture 220(2):93-107.

[82] Hwang TW, Malkin S (1999) Grinding mechanisms and energy balance for ceramics. Journal of manufacturing science and engineering 121(4):623-631.

[83] Immelmann S, Welle E, Reimers W (1997) X-ray residual stress analysis on machined and tempered HPSN-ceramics. Materials Science and Engineering: A 238(2):287-292.
[84] Ismail SO, Dhakal HN, Popov I, Beaugrand J (2016) Comprehensive study on machinability of sustainable and conventional fibre reinforced polymer composites. Engineering Science and Technology, an International Journal 19(4):2043-2052.

[85] Jackson MJ, Robinson GM, Sein H, Ahmed W, et al (2005) Machining cancellous bone prior to prosthetic implantation. Journal of Materials Engineering and Performance 14(3):293.

[86] Jakopec M, Rodriguez Baena F, Harris S J, Gomes P, et al (2003) The hands-on orthopaedic robot "acrobot": early clinical trials of total knee replacement surgery. IEEE Transactions on Robotics and Automation 19(5):902-911.

[87] Jawahir IS, Attia H, Biermann D, Duflou J (2016) Cryogenic manufacturing processes. CIRP Annals 65(2):713-36.

[88] Jia Z, Fu R, Niu B, Qian B, et al (2016) Novel drill structure for damage reduction in drilling CFRP composites. International Journal of Machine Tools and Manufacture, 110, 55-65

[89] Johnson-Walls D, Evans AG, Marshall DB, James MR (1986) Residual Stresses in Machined Ceramic Surfaces. Journal of The American Ceramic Society 69(1):44-47.

[90] Kakinuma Y, Kidani S, Aoyama T (2012) Ultra-precision cryogenic machining of viscoelastic polymers. CIRP Annals-Manufacturing Technology 61(1):79-82.

[91] Karpat Y, Bahtiyar O, Değer B (2012) Mechanistic force modeling for milling of unidirectional carbon fiber reinforced polymer laminates. International Journal of Machine Tools and Manufacture 56:79-93.

[92] Karpat Y, Polat N (2013) Mechanistic force modeling for milling of carbon fiber reinforced polymers with double helix tools. CIRP Annals-Manufacturing Technology 62(1):95-98.

[93] Kaynak Y, Karaca HE, Jawahir IS (2015) Cutting Speed Dependent Microstructure and Transformation Behavior of NiTi Alloy in Dry and Cryogenic Machining. Journal of Materials Engineering and Performance 24(1):452-460.

[94] Kaynak Y, Karaca HE, Noebe RD, Jawahir IS (2013) Tool-wear analysis in cryogenic machining of NiTi shape memory alloys: A comparison of tool-wear performance with dry and MQL machining. Wear 306(1-2):51-63.

[95] Kazanzides P, Mittelstadt BD, Musits BL, Bargar WL, et al (1995) An integrated system for cementless hip replacement. IEEE Engineering in Medicine and Biology Magazine 14(3):307-313.

[96] Kellerhoff RK, Fischer J (2007) In vitro fracture strength and thermal shock resistance of metal-ceramic crowns with cast and machined AuTi frameworks. Prosthet Dent 97: 209-15.

[97] Kianmajd B, Soshi M (2017) A new Methodology of finding Optimal Toolpath and Tooling Strategies for Robotic Assisted Arthroplasty. Journal of Medical Devices 11(c):1-7.

[98] Kilby W, Dooley JR, Kuduvalli G, Sayeh S, et al (2010) The CyberKnife Robotic Radiosurgery System in 2010. Technology in Cancer Research \& Treatment $9(5): 433-452$

[99] Kobayashi A (1967) Machining of plastics. New York: McGraw-Hill.

[100] Kosmač T, Oblak C, Jevnikar P, Funduk N, Marion L (1999) The effect of surface grinding and sandblasting on flexural strength and reliability of Y-TZP zirconia ceramic. Dental Materials 15: 426-433.

[101] Kuo C, Hsu Y, Chung C, Chen CCA (2017) Multiple criteria optimisation in coated abrasive grinding of titanium alloy using minimum quantity lubrication. International Journal of Machine Tools and Manufacture 115: 4759.

[102] Lange FF, James MR, Green DJ (1983) Determination of Residual Surface Stresses Caused by Grinding in Polycrystalline Al203. Journal of The American Ceramic Society 66(2):16-17

[103] Lee WY, Shih CL (2006) Control and breakthrough detection of a three-axis robotic bone drilling system. Mechatronics 16(2):73-84

[104] Liang S, Shih A (2015) Analysis of Machining and Machine Tools, Springer.

[105] Liao Z, Axinte D, Gao D (2019) On modelling of cutting force and temperature in bone milling. Journal of Materials Processing Technology. 266: 627-638.

[106] Liao Z, Axinte DA (2016) On chip formation mechanism in orthogonal cutting of bone. International Journal of Machine Tools and Manufacture 102:41-55.

[107] Liao Z, Axinte DA (2016) On monitoring chip formation, penetration depth and cutting malfunctions in bone micro-drilling via acoustic emission. Journal of Materials Processing Technology 229:82-93.

[108] Liao Z, Axinte DA, Gao D (2017) A novel cutting tool design to avoid surface damage in bone machining. International Journal of Machine Tools and Manufacture 116:52-59.

[109] Liao Z, Axinte D, Mieszala M, M'Saoubi R, et al (2018) On the influence of gamma prime upon machining of advanced nickel based superalloy. CIRP Annals, 67(1): 109-112.

[110] Liisa T. Kuhn, 6 - BIOMATERIALS, (Eds): John D. Enderle, Susan M. Blanchard, Joseph D. Bronzino, Introduction to Biomedical Engineering (Second Edition), Academic Press, 2005: 255-312.

[111] Lin HC, Lin KM, Chen YC (2000) A study on the machining characteristics of TiNi shape memory alloys. Journal of Materials Processing Technology 105(3):327-332

[112] Liu D, Tang Y, Cong WL (2012) A review of mechanical drilling for composite laminates. Composite Structures 94(4):1265-1279.

[113] Liu J, Suslov S, Ren Z, Dong Y, Ye C (2019) Microstructure Evolution in Ti64 Subjected to Laser-assisted Ultrasonic Nanocrystal Surface Modification. International Journal of Machine Tools and Manufacture 136: 19-33

[114] Liu X, Chu PK, Ding C (2004) Surface modification of titanium, titanium alloys, and related materials for biomedical applications. Materials Science and Engineering: R: Reports 47(3-4):49-121. 
[115] Liu Y, Belmont B, Wang Y, Tai B, et al (2017) Notched K-wire for low thermal damage bone drilling. Medical Engineering \& Physics 45:25-33.

[116] Louredo M, Díaz I, Gil JJ (2012) DRIBON: A mechatronic bone drilling tool. Mechatronics 22(8):1060-1066

[117] M'Saoubi R, Axinte D, Soo SL, Nobel C, et al (2015) High performance cutting of advanced aerospace alloys and composite materials. CIRP Annals 64(2): 557580.

[118] M'Saoubi R, Chandrasekaran H (2005) Innovative Methods for the Investigation of Tool-Chip Adhesion and Layer Formation during Machining CIRP Annals - Manufacturing Technology 54(1):59-62.

[119] M'Saoubi R, Outeiro JC, Changeux B, Lebrun JL, et al (1999) Residual stress analysis in orthogonal machining of standard and resulfurized AISI 316L steels. Journal of Materials Processing Technology 96(1-3):225-233.

[120] Maegawa S, Morikawa Y, Hayakawa S, Itoigawa F, et al (2016) Mechanism for changes in cutting forces for down-milling of unidirectional carbon fiber reinforced polymer laminates: modeling and experimentation. International Journal of Machine Tools and Manufacture 100:7-13.

[121] Malak SF, Anderson IA (2008) Orthogonal cutting of cancellous bone with application to the harvesting of bone autograft. Medical engineering \& physics $30(6): 717-724$.

[122] Malkin S, Hwang TW (1996) Grinding Mechanisms for Ceramics. CIRP Ann. Manuf. Technol 45(2):569-580.

[123] Marano A, Choi YY, Hyung WJ, Kim YM, et al (2013) Robotic versus laparoscopic versus open gastrectomy: A meta- analysis. Journal of Gastric Cancer 13(3):136-148.

[124] Masoomi M, Thompson SM, Shamsaei N (2017) Laser powder bed fusion of Ti$6 \mathrm{Al}-4 \mathrm{~V}$ parts: Thermal modeling and mechanical implications. International Journal of Machine Tools and Manufacture 118:73-90.

[125] Mei J, Diaz OG, Axinte DA (2017) An approach on capturing the influence of the stochasticity of fibre distributions for modelling the variability of cutting forces in composite materials. Composites Part B: Engineering 125: 27-38.

[126] Mitsuishi M, Cao J, Bártolo P, Friedrich D, et al (2013) Biomanufacturing. CIRP Annals 62(2): 585-606.

[127] Mitsuishi M, Warisawa S, Sugita N (2004) Determination of the machinin characteristics of a biomaterial using a machine tool designed for total knee arthroplasty. Annals CIRP 53(1):107-12.

[128] Miyazaki T, Hotta Y, Kunii J, Kuriyama S, et al (2009) A review of dental CAD/CAM: current status and future perspectives from 20 years of experience. Dental materials journal 28(1):44-56.

[129] Miyazaki T, Nakamura T, Matsumura H, Ban S, et al (2013) Current status of zirconia restoration. Journal of Prosthodontic Research 57(4):236-261.

[130] Mohammadi-Bassir M, Babasafari M, Rezvani MB, Jamshidian M (2017) Effect of coarse grinding, overglazing, and 2 polishing systems on the flexural strength, surface roughness, and phase transformation of yttrium-stabilized tetragonal zirconia. The Journal of prosthetic dentistry 118(5): 658-665.

[131] Mohd Jani J, Leary M, Subic A, Gibson MA (2014) A review of shape memory alloy research, applications and opportunities. Materials \& Design (1980 2015) 56:1078-1113

[132] Moore JZ, Malukhin K, Shih AJ, Ehmann KF (2011) Hollow Needle Tissue Insertion Force Model. CIRP Annals 60(1):157-160.

[133] Moustris GP, Hiridis SC, Deliparaschos KM, Konstantinidis KM (2011) Evolution of autonomous and semi-autonomous robotic surgical systems: a review of the literature. The International Journal of Medical Robotics and Computer Assisted Surgery 7(4):375-392.

[134] Nasr Mohamed NA, Ng E.-, Elbestawi MA (2007) Modelling the effects of tooledge radius on residual stresses when orthogonal cutting AISI $316 \mathrm{~L}$. International Journal of Machine Tools and Manufacture 47(2):401-411.

[135] Novitskaya E, Chen PY, Lee S, Castro-Ceseña A, et al (2011) Anisotropy in the compressive mechanical properties of bovine cortical bone and the mineral and protein constituents. Acta Biomaterialia, 7(8):3170-3177.

[136] Örtorp A, Jönsson D, Mouhsen A, Steyern PV (2011) The fit of cobalt-chromium three-unit fixed dental prostheses fabricated with four different techniques: A comparative in vitro study. Dental Materials 27(4): 356-363.

[137] Outeiro J, Pina J, M'saoubi R, Pusavec F, et al (2008) Analysis of residual stresses induced by dry turning of difficult-to-machine materials. CIRP AnnalsManufacturing Technology 57(1):77-80.

[138] Outeiro JC, Umbrello D, M'Saoubi R (2006) Experimental and numerical modelling of the residual stresses induced in orthogonal cutting of AISI 316L steel. International Journal of Machine Tools and Manufacture 46(14):1786 1794.

[139] Palmisano AC, Tai BL, Belmont B, Irwin TA, et al (2015) Comparison of Cortica Bone Drilling Induced Heat Production Among Common Drilling Tools. Journal of Orthopaedic Trauma 29(5):e188-e193.

[140] Pandey RK, Panda SS (2013) Drilling of bone: A comprehensive review. Journal of Clinical Orthopaedics and Trauma 4(1):15-30.

[141] Park JB, Lakes RS (2007) Biomaterials: An Introduction, Springer, New York, USA.

[142] Parker, M., 1915, Detachable-blade knife, 1287411A.

[143] Pearle AD, Kendoff D, Stueber V, Musahl V, et al (2009) Perioperative management of unicompartmental knee arthroplasty using the MAKO robotic arm system (MAKOplasty). American Journal of Orthopedics 38(2):16-19.

[144] Pearle AD, O'Loughlin PF, Kendoff DO (2010) Robot-assisted unicompartmental knee arthroplasty. The Journal of arthroplasty 25(2): 230-237.

[145] Pereira RB, Brandão LC, de Paiva AP, Ferreira JR, et al (2017) A review of helical milling process. International Journal of Machine Tools and Manufacture 120: 27-48
[146] Plaskos C, Cinquin P, Lavallée S, Hodgson AJ (2005) Praxiteles: a miniature bone-mounted robot for minimal access total knee arthroplasty. The International Journal of Medical Robotics and Computer Assisted Surgery $1(4): 67-79$

[147] Priest, G (2005) Virtual-designed and computer-milled implant abutments. Journal of Oral and Maxillofacial Surgery 63(9):22-32.

[148] Rad HR, Idris MH, Kadir MR, Farahany S (2012) Microstructure analysis and corrosion behavior of biodegradable $\mathrm{Mg}$-Ca implant alloys. Materials \& Design 33:88-97.

[149] Rahaman MN, Yao A, Bal BS, Garino JP, et al (2007) Ceramics for prosthetic hip and knee joint replacement. Journal of the American Ceramic Society 90(7):1965-1988.

[150] Ramakrishna S, Mayer J, Wintermantel E, Leong KW (2001) Biomedical applications of polymer-composite materials: a review. Composites science and technology 61(9):1189-1224.

[151] Rossi F, Thomas B, Carole M (2106) Thermal finite-difference modeling of machining operations in polymers. Procedia CIRP 46:234-237.

[152] Salahshoor M, Guo YB (2011) Cutting mechanics in high speed dry machining of biomedical magnesium-calcium alloy using internal state variable plasticity model. International Journal of Machine Tools and Manufacture 51(7-8):579590.

[153] Salahshoor M, Guo YB (2012) Biodegradable orthopedic magnesium-calcium (MgCa) alloys, processing, and corrosion performance. Materials 5(1):135155.

[154] Salahshoor M, Li C, Liu ZY, Fang XY, et al (2018) Surface integrity and corrosion performance of biomedical magnesium-calcium alloy processed by hybrid dry cutting-finish burnishing, Journal of the Mechanical Behavior of Biomedical Materials 78: 246-253

[155] Samuel R, Chandrasekar S, Farris TN, Licht RH (1989) Effect of Residual Stresses on the Fracture of Ground Ceramics. Journal of the American Ceramic Society 72(10):1960-1966.

[156] Santiuste C, Rodríguez-Millán M, Giner E, Miguélez H (2014) The influence of anisotropy in numerical modeling of orthogonal cutting of cortical bone. Composite Structures 116:423-431.

[157] Saxena KK, Qian J, Reynaerts D (2018) A review on process capabilities of electrochemical micromachining and its hybrid variants. International Journal of Machine Tools and Manufacture 127:28-56.

[158] Schwartzentruber J, Spelt JK, Papini M (2017) Prediction of surface roughness in abrasive waterjet trimming of fiber reinforced polymer composites. International Journal of Machine Tools and Manufacture 122:1-17.

[159] Schwartzentruber J, Spelt JK, Papini M (2018) Modelling of delamination due to hydraulic shock when piercing anisotropic carbon-fiber laminates using an abrasive waterjet. International Journal of Machine Tools and Manufacture 132: 81-95.

[160] SECO, Innovative Tooling Solutions. https://usercontent.azureedge.net/Content/UserContent/Documents/02096 6.pdf (Accessed 26 Oct. 2018)

[161] Sezek S, Aksakal B, Karaca F (2012) Influence of drill parameters on bone temperature and necrosis: a FEM modelling and in vitro experiments. Computational Materials Science 60:13-18.

[162] Shahrbaf S et al. (2014) Fracture strength of machined ceramic crowns as a function of tooth preparation design and the elastic modulus of the cement. Dental materials 30: 234-241.

[163] Shang Z, Liao Z, Sarasua JA, Billingham J, Axinte D (2019) On modelling of laser assisted machining: Forward and inverse problems for heat placement control. International Journal of Machine Tools and Manufacture, 138: 36-50.

[164] Shetty PP, Hatton RW, Barnett AC, Homich AJ, et al (2017) Modeling the cutting edge geometry of scalpel blades. Proceedings of the Institution of Mechanical Engineers Part B: Journal of Engineering Manufacture 231(1):65-72.

[165] Shih AJ (2008) Biomedical Manufacturing: A New Frontier of Manufacturing Research. Journal of Manufacturing Science and Engineering 130(2):021009.

[166] Shipley H, McDonnell D, Culleton M, Lupoi R (2018). Optimisation of process parameters to address fundamental challenges during selective laser melting of Ti-6Al-4V: A review. International Journal of Machine Tools and Manufacture 128: 1-20

[167] Shyha I, Soo SL, Aspinwall D, Bradley S (2010) Effect of laminate configuration and feed rate on cutting performance when drilling holes in carbon fibre reinforced plastic composites. Journal of materials processing technology 210(8): 1023-1034.

[168] Sidpara AM, Jain VK (2012) Nanofinishing of freeform surfaces of prosthetic knee joint implant. Proceedings of the Institution of Mechanical Engineers Part B: Journal of Engineering Manufacture 226(11):1833-1846.

[169] Siebert W, Mai S, Kober R, Heeckt PF (2002) Technique and first clinical results of robot-assisted total knee replacement. The Knee 9(3):173-180.

[170] Song S, Mor A, Jaramaz B (2009) HyBAR: hybrid bone-attached robot for joint arthroplasty. The International Journal of Medical Robotics and Computer Assisted Surgery 5(2):223-231.

[171] Stryker, 2018, CORE Cutting Accessories. http://www.stryker.com/latm/products/Instruments/GeneralMultiSpecialty Instruments/PowerTools/MicroPower/CORE/Burs/index.html. (Accessed 26 Feb 2018)

[172] Stryker, 2018, Stryker 6.0 mm Egg Bur. http://www.wemed1.com/stryker-60mm-egg-bur (Accessed 26 Feb 2018)

[173] Sugita N, Ishii K, Furusho T, Harada K, et al (2015) Cutting temperature distribution measurement by micro sensor array integrated on rake face of cutting tool. CIRP Annals 64(1):77-80. 
[174] Sugita N, Ishii K, Sui J, Terashima M (2014) Multi-grooved cutting tool to reduce cutting force and temperature during bone machining. CIRP AnnalsManufacturing Technology 63(1):101-104.

[175] Sugita N, Mitsuishi M (2009) Specifications for machining the bovine cortical bone in relation to its microstructure. Journal of biomechanics 42(16):28262829.

[176] Sugita N, Osa T, Aoki R, Mitsuishi M (2009) A New Cutting Method for Bone Based on its Crack Propagation Characteristics. CIRP Annals - Manufacturing Technology 58(1):113-118

[177] Sugita N, Osa T, Mitsuishi M (2009) Analysis and Estimation of CuttingTemperature Distribution during End Milling in Relation to Orthopedic Surgery. Medical Engineering \& Physics 31(1):101-107.

[178] Sun J, Guo YB (2009) A comprehensive experimental study on surface integrity by end milling Ti-6Al-4V. Journal of Materials Processing Technology 209(8):4036-4042.

[179] Sun S, Brandt M, Dargusch MS (2009) Characteristics of cutting forces and chip formation in machining of titanium alloys. International Journal of Machine Tools and Manufacture 49(7-8):561-568.

[180] Sundh A, Sjögren G (2008) A study of the bending resistance of implantsupported reinforced alumina and machined zirconia abutments and copies. Dental materials 24: 611-617.

[181] Talha M, Behera CK, Sinha OP (2013) A review on nickel-free nitrogen containing austenitic stainless steels for biomedical applications. Materials Science and Engineering: C 33(7):3563-3575.

[182] Taylor RH, Joskowicz L, Williamson B, Kalvin G, et al (1999) Computerintegrated revision total hip replacement surgery: concept and preliminary results. Medical image analysis 3(3):301-19.

[183] Thilmany J (2018) Everyday Prosthetic Fingers. https://www.asme.org/engineering topics/articles/bioengineering/everyday-prosthetic-fingers (Accessed 20 Oct. 2018)

[184] Tsukamoto R, Chen S, Asano T, Ogino M, et al (2006) Improved wear performance with crosslinked UHMWPE and zirconia implants in knee simulation. Acta orthopaedica. 77(3):505-511.

[185] Turger A, Kohler J, Denkena B, Correa TA, et al (2013) Manufacturing conditioned roughness and wear of biomedical oxide ceramics for all-ceramic knee implants. Biomedical engineering online 12(1):84.

[186] Ueda K, Nakaie K, Namba S, Yoneda T, et al (2013) Mass Loss and Ion Elution of Biomedical Co-Cr-Mo Alloys during Pin-on-Disk Wear Tests. Materials Transactions 54(8):1281-1287.

[187] Umbrello D, M'Saoubi R, Outeiro JC (2007) The influence of Johnson-Cook material constants on finite element simulation of machining of AISI 316L steel. International Journal of Machine Tools and Manufacture 47(3-4):462470 .

[188] URL: $\quad$ https://4.imimg.com/data4/UX/UM/MY-7359787/ss-surgicalinstruments-500x500.jpg (Accessed 20 Oct. 2018)

[189] Van Rietbergen B, Majumdar S, Pistoia W, Newitt DC, et al (1998) Assessment of cancellous bone mechanical properties from micro-FE models based on micro-CT, pQCT and MR images. Technology and Health Care 6(5, 6):413-420.

[190] Veiga C, Davim JP, Loureiro AJR (2013) Review on machinability of titanium alloys: the process perspective. Rev. Adv. Mater. Sci, 34(2):148-164.

[191] Waizy H, Seitz J, Reifenrath J, Weizbauer A, et al (2013) Biodegradable magnesium implants for orthopedic applications. Journal of Materials Science 48(1):39-50.

[192] Waizy H, Weizbauer A, Maibaum M, Witte F, et al (2012) Biomechanical characterisation of a degradable magnesium-based (MgCa0.8) screw, Journal of Materials Science: Materials in Medicine 23: 649-655

[193] Wang H, Chang L, Mai YW, Ye L, et al (2018) An experimental study of orthogonal cutting mechanisms for epoxies with two different crosslink densities. International Journal of Machine Tools and Manufacture 124: 117125 .

[194] Weinert K, Petzoldt V (2004) Machining of NiTi based shape memory alloys. Materials Science and Engineering: A 378(1-2):180-184.

[195] Weinert K, Petzoldt V (2008) Machining NiTi micro-parts by micro-milling. Materials Science and Engineering: A 481:672-5.

[196] Weinert K, Petzoldt V, Kötter D (2004) Turning and Drilling of NiTi Shape Memory Alloys. CIRP Annals - Manufacturing Technology 53(1):65-68.

[197] Wennerberg A, Albrektsson T (2009) Effects of titanium surface topography on bone integration: a systematic review. Clinical oral implants research 20:172-184.

[198] Williams DF, in: Brunette DM, Tengvall P, Textor M, Thomsen P, (Eds.) (2001) Titanium in Medicine, Springer, Berlin, 13-24.

[199] Williams DF, McNamara A, Turner RM (1987) Potential of polyetheretherketone (PEEK) and carbon-fibre-reinforced PEEK in medical applications. Journal of materials science letters 6(2): 188-190.

[200] Windhagen H, Radtke K, Weizbauer A, Diekmann J, et al (2013) Biodegradable magnesium-based screw clinically equivalent to titanium screw in hallux valgus surgery: short term results of the first prospective, randomized, controlled clinical pilot study. BioMedical Engineering OnLine 12(1):62

[201] Witte F (2010) The history of biodegradable magnesium implants: A review. Acta Biomaterialia 6(5):1680-1692.

[202] Wolf A, Jaramaz B, Lisien B, DiGioia AM (2005) MBARS: mini bone-attached robotic system for joint arthroplasty. The International Journal of Medical Robotics and Computer Assisted Surgery 1(2):101-121.

[203] Wu SK, Lin HC, Chen CC (1999) A study on the machinability of a Ti49.6Ni50.4 shape memory alloy. Materials Letters 40(1):27-32.
[204] Wuhu Ruijin Medical Instrument \& Device Co., L., 2018, Acetabular Reamer orthopedic Drill Shaft Shells/Orthopedic Acetabular Reamer for knee joint surgeries. https://www.alibaba.com/product-detail/Acetabular-Reamerorthopedic-Drill-Shaft-Shells 1971472988.html. (Accessed 25 Feb 2018).

[205] Xu W, Zhang L (2016) Mechanics of fibre deformation and fracture in vibration-assisted cutting of unidirectional fibre-reinforced polymer composites. International Journal of Machine Tools and Manufacture 103:4052.

[206] Xu W, Zhang LC (2014) On the mechanics and material removal mechanisms of vibration-assisted cutting of unidirectional fibre-reinforced polymer composites. International Journal of Machine Tools and Manufacture 80:1-10.

[207] Yamaguchi H, Graziano AA (2014) Surface finishing of cobalt chromium alloy femoral knee components. CIRP Annals - Manufacturing Technology 63(1):309-312.

[208] Yang M, Li C, Zhang Y, Jia D, Zhang X, et al (2017) Maximum undeformed equivalent chip thickness for ductile-brittle transition of zirconia ceramics under different lubrication conditions. International Journal of Machine Tools and Manufacture, 122, 55-65.

[209] Yin L, Song XF, Song YL, Huang T, et al (2006) An overview of in vitro abrasive finishing \& CAD/CAM of bioceramics in restorative dentistry. International Journal of Machine Tools \& Manufacture 46(9):1013-1026

[210] Yue X, Yang X, Tian J, He Z, et al (2018) Thermal, mechanical and chemical material removal mechanism of carbon fiber reinforced polymers in electrical discharge machining. International Journal of Machine Tools and Manufacture 133: 4-17.

[211] Zeng S, Blunt L (2014) Experimental investigation and analytical modelling of the effects of process parameters on material removal rate for bonnet polishing of cobalt chrome alloy. Precision Engineering 38(2):348-355.

[212] Zhang B, Zheng XL, Tokura H, Yoshikawa M (2003) Grinding induced damage in ceramics. Journal of materials processing technology 132(1-3):353-364.

[213] Zhang W, Wang X, Hu Y, Wang S (2018) Predictive modelling of microstructure changes, micro-hardness and residual stress in machining of 304 austenitic stainless steel. International Journal of Machine Tools and Manufacture 130: 36-48.

[214] Zhao Z, To S (2018) An investigation of resolved shear stress on activation of slip systems during ultraprecision rotary cutting of local anisotropic Ti-6Al-4V alloy: Models and experiments. International Journal of Machine Tools and Manufacture 134: 69-78. 